TE WHARE WĀNANGA O TE ŪPOKO O TE IKA A MĀUI

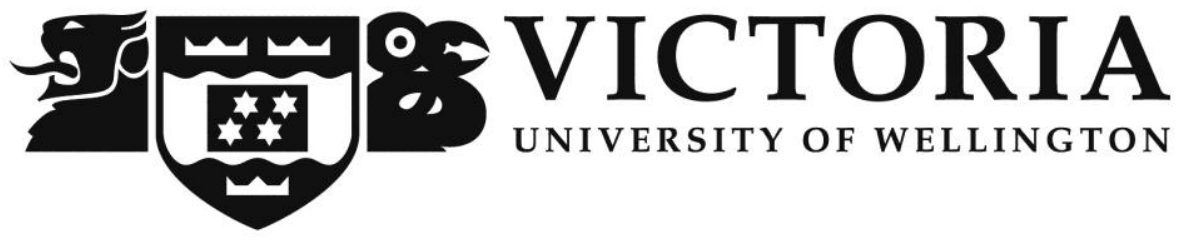

The Influence of Non-Governmental Organisations (NGOs) on Primary Education Policy in Laos

By

\title{
Oulath Saengouthay
}

A thesis submitted to Victoria University of Wellington in partial fulfilment of the requirements for the degree of Masters in Development Studies

School of Geography, Environment and Earth Sciences Victoria University of Wellington 


\begin{abstract}
Laos is a poor and aid-dependent country in South-East Asia. Its primary education development has depended heavily on external assistance, which has caused some scholars to argue that education policy is shaped by this influence. While major donors have played a significant role in driving Lao primary education development, NGOs are increasingly engaging in the process since Laos has adopted global commitments, particularly the Education for All goals of the Millennium Development Goals. While the Government of Laos values NGOs' contributions as equally to those of major donors, it commonly views NGOs as 'service providers' and major donors as 'policy counterparts'. The government is wary of NGOs' mission and this has also shaped NGOs' space in the policy arena.
\end{abstract}

This thesis has examined the extent to which NGOs have influenced Lao primary education policy since the adoption of the Vientiane Declaration on Aid Effectiveness in 2006. This research draws on a social constructivist epistemology, and data collection employed qualitative methods including semi-structured interviews, analysis of relevant policy documents, and participant observation. The interviews involved 24 participants representing government agencies, NGOs, donor organisations and education specialists. The main focus of interviews was to explore the degree of NGOs' influence on primary education policy, the mechanisms and strategies that NGOs use to exercise their influence, and how such mechanisms and strategies have impacted on their role at policy level.

The findings indicate that NGOs have limited influence on Lao primary education policy. Although they have some influence through participating in policy dialogues, they have minimal influence on the outcomes of policy development. The fact that NGOs have limited influence on policy outcomes is attributed partly to their limited financial capacity and partly the limits of their specialised expertise to support and convince the government for policy change. The deciding factor, nevertheless, is the government's reluctance to integrate NGOs' advice and recommendations into Lao primary education policy due to its wariness of NGOs' influence, particularly on politically sensitive issues. 


\section{Acknowledgements}

This thesis is a product of cooperation from a number of people without whom it would not have been possible. It is not possible to mention all the names here. First of all, I would like to express my heartfelt gratitude to my supervisor Dr Polly Stupples for her exceptional guidance and support throughout the process of this thesis. Her encouragement and leadership inspired me to work attentively toward the completion of this thesis.

I would also like to thank Professor John Overton, my interim supervisor and Director of Development Studies Programme at Victoria University of Wellington (VUW), who provided me with guidance at the beginning of this research prior to Dr Stupples's tenure. His excellent advice made my fieldwork possible.

Big thanks also go to Anna Rogers and Dr Rachel Tallon and the rest of the team at VUW for helping me refine my ideas.

My gratitude also goes to my generous sponsor, the New Zealand Aid Programme, for funding my study in New Zealand as well as my research in Laos. Both my study and this thesis would not have been possible without that support.

I am profoundly grateful to my research participants from the Lao government agencies, NGOs, donor organisations, and education specialists, for sharing with me their experiences, knowledge and insights. Without their active participation, this thesis would not have been completed.

I am much obliged to my family, friends and colleagues both in New Zealand and Laos for their continued support during my study in New Zealand and my fieldwork in Laos. Special thanks go to my parents whose faith in me has never changed. I also owe my brother thanks for shouldering all family responsibilities during the time I was away for my study in New Zealand. 


\section{Table of Contents}

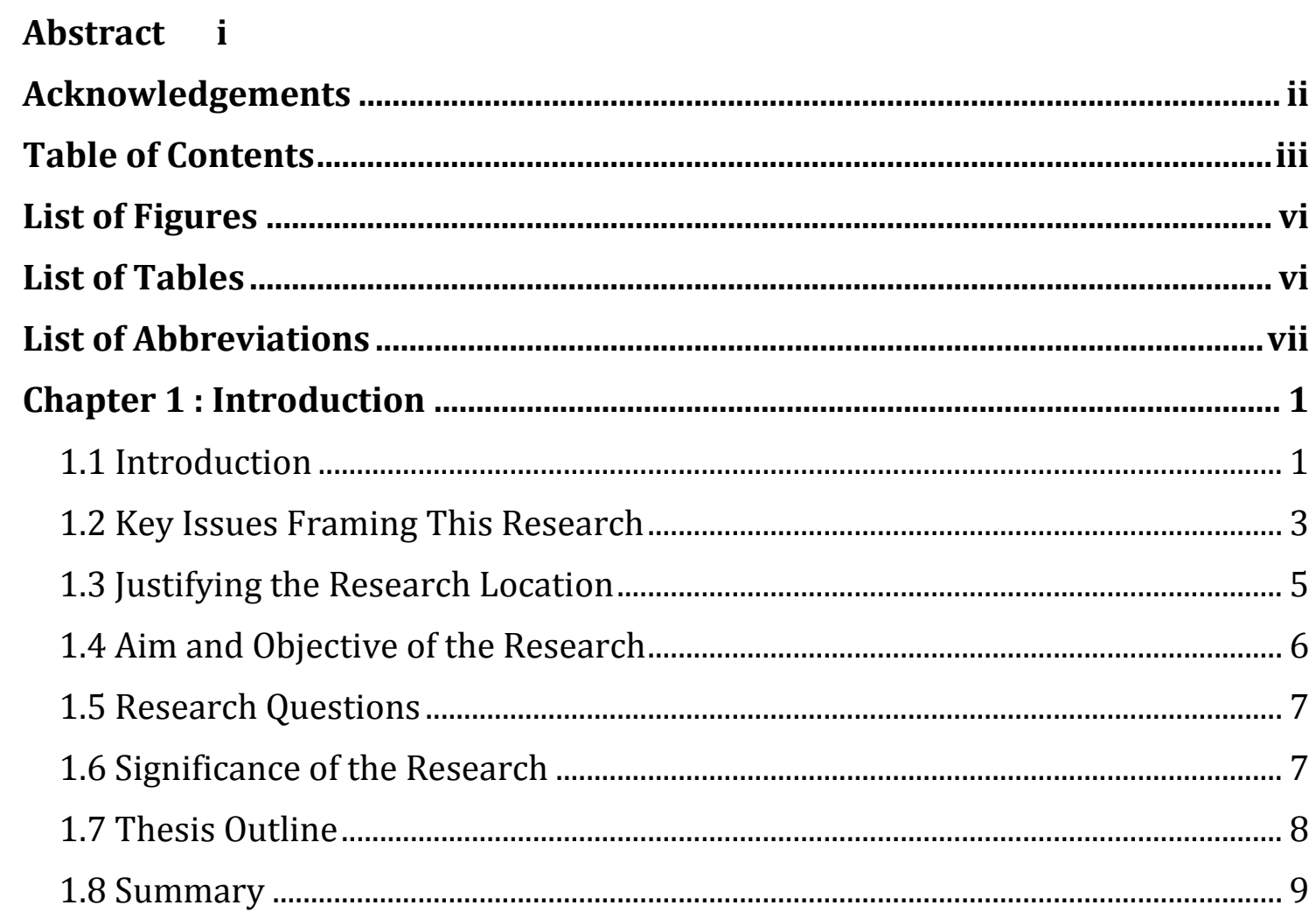

Chapter 2 : Literature Review ............................................................................... 10

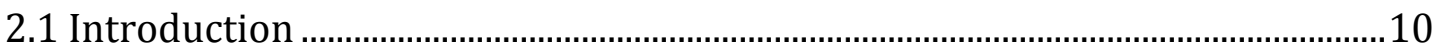

2.2 Understanding the Meaning, Evolution and Multifaceted Roles of NGOs .......10

2.2.1 Definition of NGOs .....................................................................................

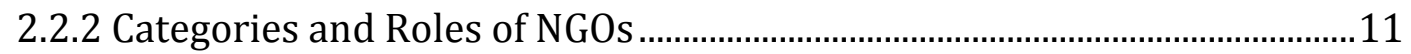

2.2.3 NGOs' Relationships with other Development Partners ...............................13

2.2.4 NGOs' Influence on Government Policy ……........................................................ 15

2.2.5 External Influence on Lao Education Policy ...................................................16

2.3 Key Policy Documents Reflecting NGOs' Role at Policy Level..............................17

2.3.1 Paris Declaration on Aid Effectiveness............................................................17

2.3.2 Vientiane Declaration on Aid Effectiveness......................................................... 18

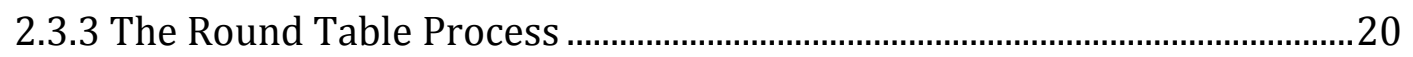

2.3.4 Dakar Framework for Action ...........................................................................2 21

2.3.5 Education Strategic Vision 2000- 2020 _......................................................... 21

2.3.6 Education for All National Plan for Action 2003 - 2015 ...............................22

2.3.7 National Education System Reform Strategy 2006 - 2015 ..........................24

2.3.8 Education Sector Development Framework 2009-2015 .............................25 


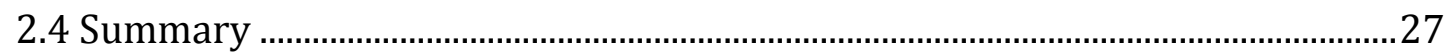

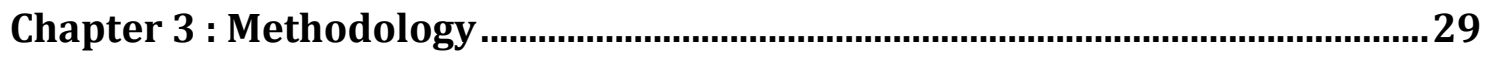

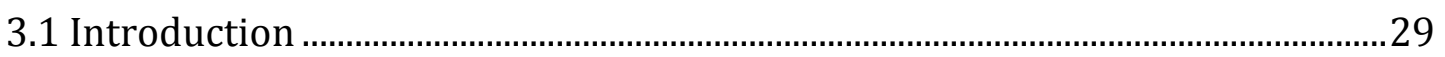

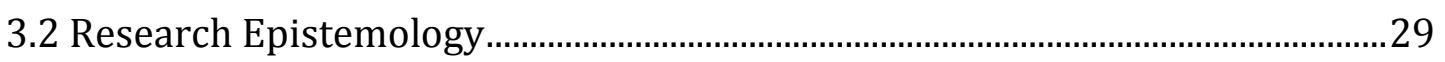

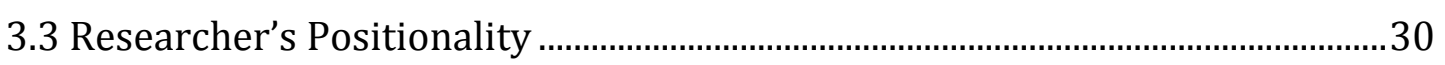

3.4 The Research Design Process .................................................................................. 31

3.5 Sampling and Research Participant Selection........................................................... 31

3.6 Research Methods.........................................................................................................3

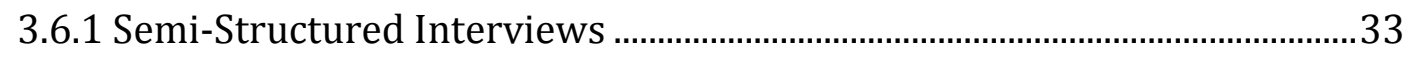

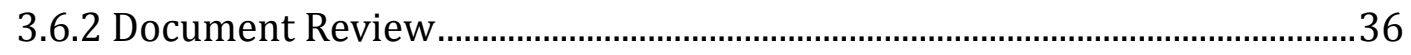

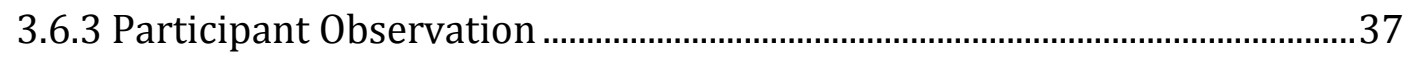

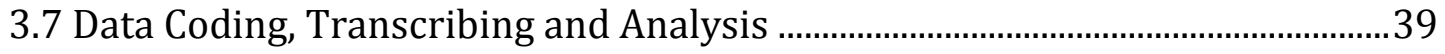

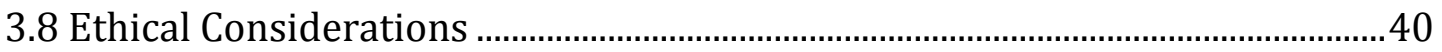

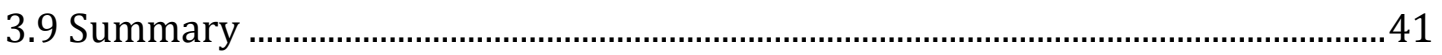

Chapter 4 : The Social, Economic, Political and Educational Context of Laos 43

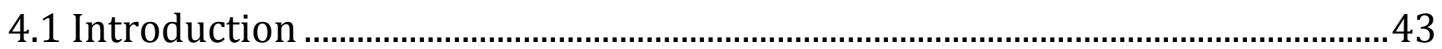

4.2 Broad Features of Laos' Social, Economic and Political Context .........................43

4.2.1 Geographical and Demographical Features ....................................................43

4.2.2 Political Context ....................................................................................................46

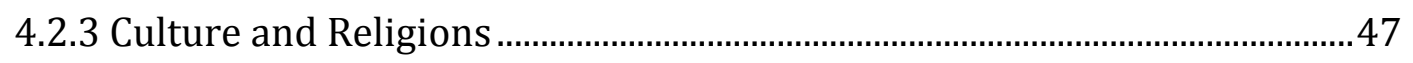

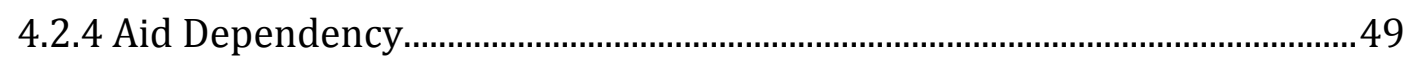

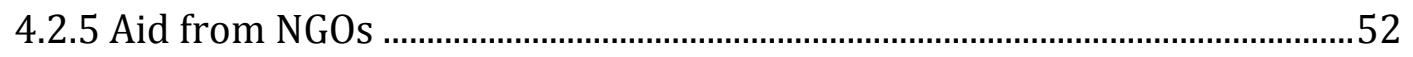

4.3. The Context of Lao Education ........................................................................... 54

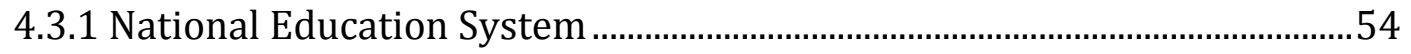

4.3.2 Education Management and Administration .................................................55

4.3.3 Current Situation of Lao Education .....................................................................

4.3.4 Primary Education in Focus ………............................................................... 59

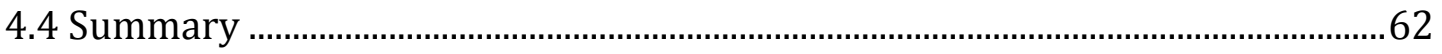

\section{Chapter 5 : The Role of NGOs in Laos and their Influence on Primary}

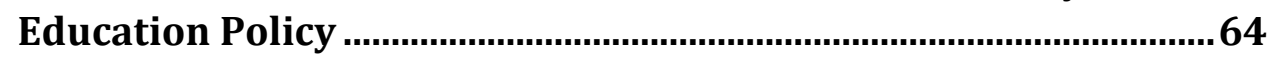

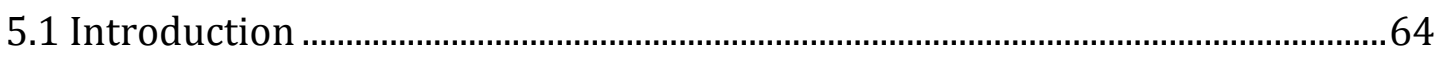

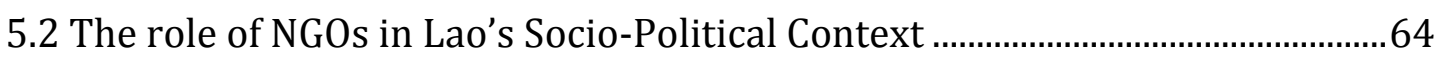

5.3. Differences between NGOs and Major Donors at the Policy Level....................71

5.4 The Influence of NGOs on Lao Primary Education Policy......................................76 
5.4.1 The Introduction of a Multilingual Curriculum. .76

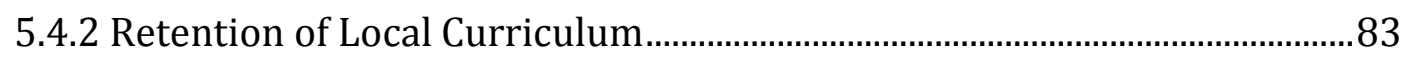

5.4.3 Enforcement of Free Primary Education........................................................85

5.5 Politics of Participation and Rhetoric of Recognition? ..........................................87

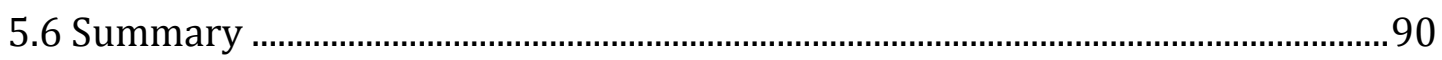

Chapter 6 : NGOs' Mechanisms and Strategies for influencing Primary

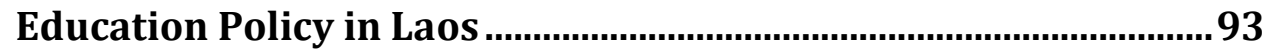

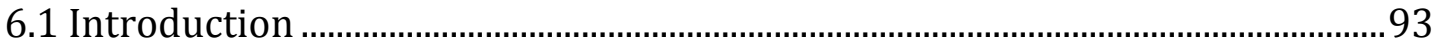

6.2 Education Sector Working Group and NGOs' Policy Influence............................93

6.3 Informal Education Donor Working Group and NGOs' Policy Influence .........97

6.4 Capacity Development for Policy Makers as an Influencing Strategy ..............99

6.5 Specialist Deployment as an Influencing Strategy ................................................ 105

6.6 Other External Influences on Lao Primary Education Policy............................ 110

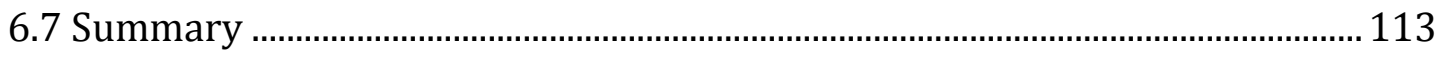

Chapter 7 : Discussion and Conclusion ................................................................ 115

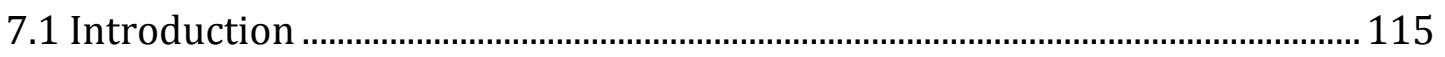

7.2 Addressing the Research Questions …………................................................. 115

7.2.1 NGOs' Roles in Laos: Service Providers vs. Policy Advocates................... 116

7.2.2 NGOs-GoL Relationships after the Adoption of Vientiane Declaration 122

7.2.3 The Mechanisms and Strategies that NGOs use to Influence Lao Primary

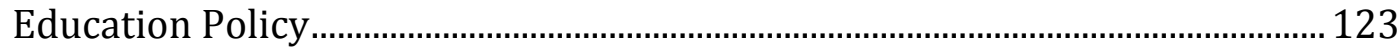

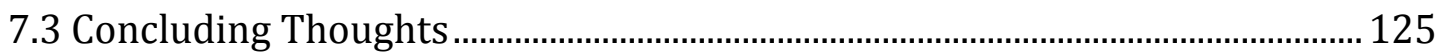

7.3.1 Government Takes Lead with More Inclusive Decision-Making Process

7.3.2 Appreciation of Socio-Political Context....................................................... 128

7.3.3 People as the Centre of Development........................................................ 129

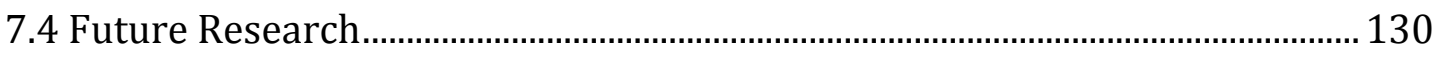

References 132

Appendix I: Ethics Approval ....................................................................... 143

Appendix II: Supervisor's Support Letter ............................................................ 145

Appendix III: Participant Information Sheet..................................................... 148

Appendix IV: Research Consent Form ～.......................................................151

Appendix V: Interview Questions ........................................................................ 155

Appendix VI: Request Letter for Interview Appointment (for Government Offices) ........................................................................................ 161 


\section{List of Figures}

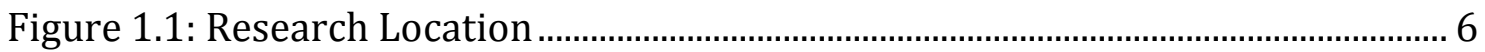

Figure 3.1: Overview of Research Methodology ............................................................. 38

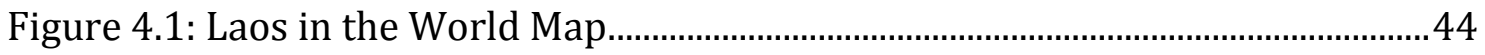

Figure 4.2: ODA and NGOs Disbursement to the Education Sector in Laos in the

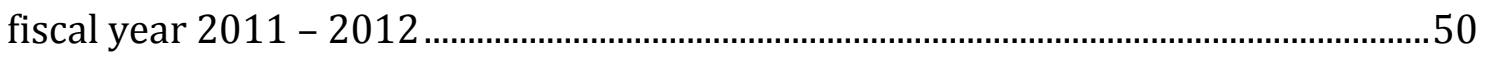

Figure 4.3: Average Education Investment Share by Sub-Sector (2011 - 2015).....62

Figure 6.1: Education Sector Working Group Structure ...............................................96

\section{List of Tables}

Table 2.1: List of the Countries and Organisations that Signed the Vientiane

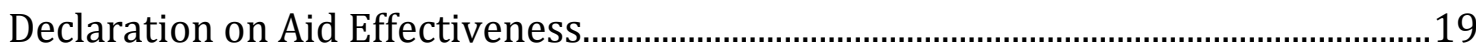

Table 2.2: Relationship between EFANPA and EFA Goals and MDGs...........................23

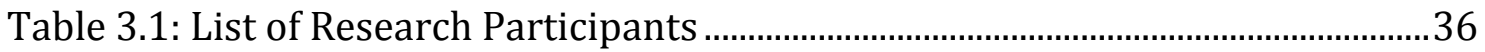

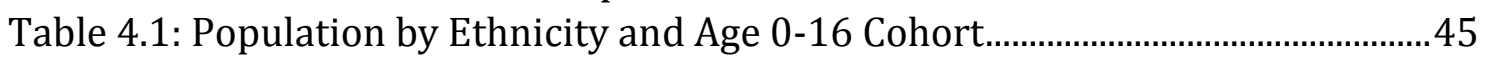

Table 4.2: Development Partners' Support to Lao Education Development ..............51 


\section{List of Abbreviations}

\begin{tabular}{|c|c|}
\hline $\mathrm{ADB}$ & Asian Development Bank \\
\hline AEC & ASEAN Economic Community \\
\hline AEPF9 & 9th Asia-Europe People Forum \\
\hline ASEAN & Association of South-East Asian Nations \\
\hline AusAID & Australian Agency for International Development \\
\hline BEQUAL & Basic Education Quality and Access in Laos Programme \\
\hline DESB & District Education and Sports Bureau \\
\hline DFA & Dakar Framework for Action \\
\hline DFAT & Australian Department of Foreign Affairs and Trade \\
\hline DPs & Development Partners \\
\hline EFA & Education for All \\
\hline EFANPA & Education for All National Plan of Action \\
\hline ESDF & Education Sector Development Framework \\
\hline ESDP & Education Sector Development Plan \\
\hline ESWG & Education Sector Working Group \\
\hline ESWG FG & Education Sector Working Group Focal Group \\
\hline EU & Union European \\
\hline GNI & Gross National Income \\
\hline GoL & Government of Laos \\
\hline IEDWG & Informal Education Donor Working Group \\
\hline JICA & Japanese International Cooperation Agency \\
\hline LDC & Least Developed Country \\
\hline LPRP & Lao People‘s Revolutionary Party \\
\hline MDGs & Millennium Development Goals \\
\hline MoES & Ministry of Education and Sports \\
\hline MoFA & Ministry of Foreign Affairs \\
\hline $\mathrm{MoU}$ & Memorandum of Understanding \\
\hline NA & National Assembly \\
\hline NESRS & National Education System Reform Strategy \\
\hline NGOs & Non-Governmental Organisations \\
\hline NGPES & National Growth and Poverty Eradication Strategy \\
\hline
\end{tabular}




\begin{tabular}{|c|c|}
\hline NPAs & Non-Profit Associations \\
\hline NSEDP & National Socio-Economic Development Plan \\
\hline ODA & Official Development Assistance \\
\hline OECD & Organisation for Economic Co-operation and Development \\
\hline PD & Paris Declaration on Aid Effectiveness \\
\hline PESS & Provincial Education and Sports Services \\
\hline RTIMs & Round Table Implementation Meetings \\
\hline RTP & Round Table Process \\
\hline SDGs & Sustainable Development Goals \\
\hline SIDA & Swiss International Development Agency \\
\hline SoQ & School of Quality \\
\hline SWAp & Sector-wide Approach \\
\hline SWGs & Sector Working Groups \\
\hline UBE & Universal Basic Education \\
\hline UN & United Nations \\
\hline UNDAF & United Nations Development Assistance Framework \\
\hline UNDP & United Nations Development Programme \\
\hline UNESCO & $\begin{array}{l}\text { United Nations Educational, Scientific and Cultural } \\
\text { Organization }\end{array}$ \\
\hline UNICEF & United Nations Children's Fund \\
\hline VD & Vientiane Declaration on Aid Effectiveness \\
\hline VUW & Victoria University of Wellington \\
\hline WB & World Bank \\
\hline
\end{tabular}




\section{Chapter 1: Introduction}

\subsection{Introduction}

Non-government organisations (NGOs) have contributed considerably to development in least developed and developing countries. Their works range from humanitarian assistance to long-term development interventions, which often support underprivileged groups living in remote areas (Banks \& Hulme, 2012). NGOs have proliferated since the 1980s in both numbers and coverage, and have increasingly exerted both direct and indirect influence on individuals, states and donors (Green, 2008). Nevertheless, this is not always the case and the extent of their influence seems to vary, depending on context, environment and the political situation of a particular country. Under many circumstances, NGOs' roles can be less advocacy-based and more like that of service providers (McCormick, 2012). In many cases NGOs operate under close supervision of the government which can make them act more as appendages of the state than independent organisations (Roberts, 2004). In Laos, for example, where this study is based, NGOs' operations are closely supervised by the government, which has ultimate control over NGOs' operations (ibid.).

Like other poor countries, Laos relies almost entirely on external funding for its primary education: foreign aid accounts for more than three-quarters of all investment and over one-third of total public expenditure ${ }^{1}$ in this sector (Kim \& Jeong, 2013; Phommalangsy, 2013). Given the heavy dependence on external support, the national education policy is influenced through aid conditionality by foreign aid agencies, whose global priorities differ from those constructed nationally (Phommalangsy, 2013). Through financial and technical supports, major

\footnotetext{
${ }^{1}$ In Laos, foreign aid is provided through two channels: major donors (both bilateral and multilateral) usually channel their funding to the government through Sector-wide Approaches (SWAp), and NGOs normally provide direct funding to projects that they implement in partnership with communities and government authorities.
} 
donors such as the World Bank (WB), Asian Development Bank (ADB), Australian Department of Foreign Affairs and Trade (DFAT) - formerly known as Australian Agency for International Development (AusAID) - and the European Union (EU) have convinced national policy makers to align Lao education policy with global agendas, such as the Millennium Development Goals (MDGs) and Education for All (EFA) goals ${ }^{2}$.

The adoption of MDG2 on Universal Primary Education and particularly the EFA goals by the Government of Laos (GoL) has also opened the door for NGOs to support the government's effort over the last decade (McCormick, 2012). There are about 160 international NGOs operating in Laos (INGO Network, 2015). Many of them have education as one of their programme components. This will be elaborated further in chapter 5 . It should also be noted that there are only international NGOs in Laos, and no local NGOs are present at the moment. Therefore, the term 'NGOs' in this paper, when referring to the Lao context, always means international NGOs. Additionally, there are about 46 local Non-Profit Associations (NPAs) operating in different development interventions across the country. Their roles are similar to NGOs and they are likely to become local NGOs in the future. They are not the focus of this study and will not be discussed in detail. Although Development Partners (DPs) theoretically includes donors, NGOs and NPAs, the profile of NPAs (especially at policy level) are often less recognised due to their limited resources.

\footnotetext{
2 In the year 2000, more than 160 governments adopted EFA goals during the World Education Forum convened in Dakar, Senegal, establishing the new millennium development goal of providing every girl and boy with primary school education by 2015 (Burnett, 2008; Peters, 2007). The EFA includes six goals as follows:

1. To expand early childhood care and education, especially for the most vulnerable and disadvantaged children;

2. To ensure that all children have access to and complete free and compulsory primary education of good quality;

3. To ensure equitable access of all young people to appropriate learning and life skills programs;

4. To achieve a $50 \%$ improvement in levels of adult literacy by 2015 , especially for women, and equitable access to basic and continuing education for all adults;

5. To eliminate gender disparities in primary and secondary education by 2005 and achieve gender equality in education by 2015 ; and

6. To improve all aspects of the quality of education so that recognized and measurable learning outcomes are achieved by all, especially in literacy, numeracy, and essential life skills (ibid.).
} 


\subsection{Key Issues Framing This Research}

The enforcement of the Vientiane Declaration on Aid Effectiveness (VD) in Laos since 2006 has shifted the way aid programmes are implemented in the country. VD was contextualised from the Paris Declaration on Aid Effectiveness (PD), with the aim of harmonising foreign assistance and aligning DPs' interventions with national priorities (GoL, 2006). Consequently, GoL is legitimised in the international community and committed to taking lead and ownership of all development projects in the country, while on the other hand, the influence of DPs is expected to reduce gradually.

While GoL is committed to improving education development in Laos through attracting assistance from DPs, understanding and implementing the roles of each party remains a challenge. The relationship between GoL and DPs, particularly NGOs remains fragile, undermining genuine discussions between the two parties (ADB, 2011; Kunze, 2012). Although some mechanisms, predominantly, the Education Sector Working Group (ESWG), have been established for multistakeholder consultations, there has been no mechanism to ensure that all voices are heard and inputs are integrated into policy. Furthermore, inadequate understanding of Laos' social and political context often results in the failure of NGOs to advocate for policy change in a constructive way.

Suspicion and tensions between the government and NGOs has often led to mistrust, undermining the former's willingness to incorporate the latter's inputs into policy development despite the fact that the latter are engaged in the consultation process. In other words, whether or not GoL perceives NGOs as true policy counterparts remains an open question. On the other hand, being unable to act as governments' policy counterparts, some NGOs develop their own strategies to sidestep state procedures and implement their own policies in communities (Frank et al., 2007). This usually leads to resentment between the government and NGOs, resulting in a lack of a 'holistic' development approach, and programme failures (ibid.). Consequently, communities lose education benefits when projects close down due to the non-alignment of NGO policy with government policy and lack of government approval. Therefore, mechanisms need to be identified to create more collaborative 
working relationships among development actors and it is crucial to appreciate the roles of different stakeholders in policy formulation and practice (UNDP, 2013). In practical terms, the most effective framework that ensures NGOs' constructive participation in the process and outcomes of Lao primary education policy development - while maintaining a healthy relationship with GoL - needs to be identified for the sake of local communities, taking into account the real social and political contexts of Laos.

My passion for a holistic approach to development stems from my experience working with different UN agencies and NGOs, mostly in senior positions, that has enabled me to observe several issues pertaining to how different roles play out and how different actors exercise influence over decision-making process. I found that roles were often not adequately defined, which frequently led to confusion, tensions and failure of projects. My experience engaging in project design and implementation also bore witness to the power politics enacted among stakeholders which shaped their interactions and relationships and led to different project outcomes. Different players exercised their power in different ways by using their own tactics and authority to frame their own agenda (Pettit, 2012).

My interest in the influence of NGOs on education policy in Laos is grounded in current debate surrounding partnerships between the GoL and NGOs, and the latter's influence on education policy (McCormick, 2012; Roberts, 2004). I was particularly inspired by the work of Phouvanh Phommalangsy (2013), who wrote about 'the influence of foreign aid on education policy in Laos'. He argues that donors have massive influence on Lao education policy due to their substantial financial assistance to GoL (Phommalangsy, 2013). He concluded, when discussing the role of donors, that:

"Donors have played significant roles in assisting the government through convincing national policy makers that Lao education policy should be aligned with global agendas, such as the Millennium Development Goals and Education for All." (Phommalangsy, 2013, p.1) 
I wondered how NGOs whom I believed GoL perceived as smaller international donors, influenced government policy given their lesser financial strength and different working approaches and agenda. Informed by the results of recent research indicating unequal power relations between donors and GoL (Phommalangsy, 2013), I was also intrigued to explore power relations between the government and NGOs, and compare these with relationships between government and donors. Therefore, while Phommalangsy (2013) focused on the influence of big donors on Lao education policy from 1990-2000, my research focuses on NGOs' influence on Lao primary education policy from 2006-2015. I believe that the adoption of VD in 2006 has significantly affected relationships between GoL and NGOs and other DPs in general. Moreover, while not aiming to scrutinise preconditions for funding required by DPs as Phommalangsy's (2013) study did, my research seeks to examine the strategies and mechanisms that NGOs, in particular, use to influence Lao primary education policy within the Lao context.

\subsection{Justifying the Research Location}

This research was conducted in Vientiane, the capital of Laos, where government ministries and country offices of NGOs and donor agencies are located (see figure 1.1). I have chosen Laos as my research location, because I considered that the outcomes of this study would be beneficial for my home country where I have lived all my life. In addition to my contextual familiarity, I have built strong relationships with relevant NGOs, with government personnel and donor agencies. I have worked in the education sector for a number of years and witnessed some changes in the Lao education system with the strong engagement of DPs. As Robertson et al. (2007) and Steer \& Wathne (2010) argue, the policy changes advocated by international organisations often fail to appreciate historical, cultural and political contexts of recipient countries, which in turn can result in mismatches with locally constructed priorities. 


\section{Figure 1.1: Research Location}

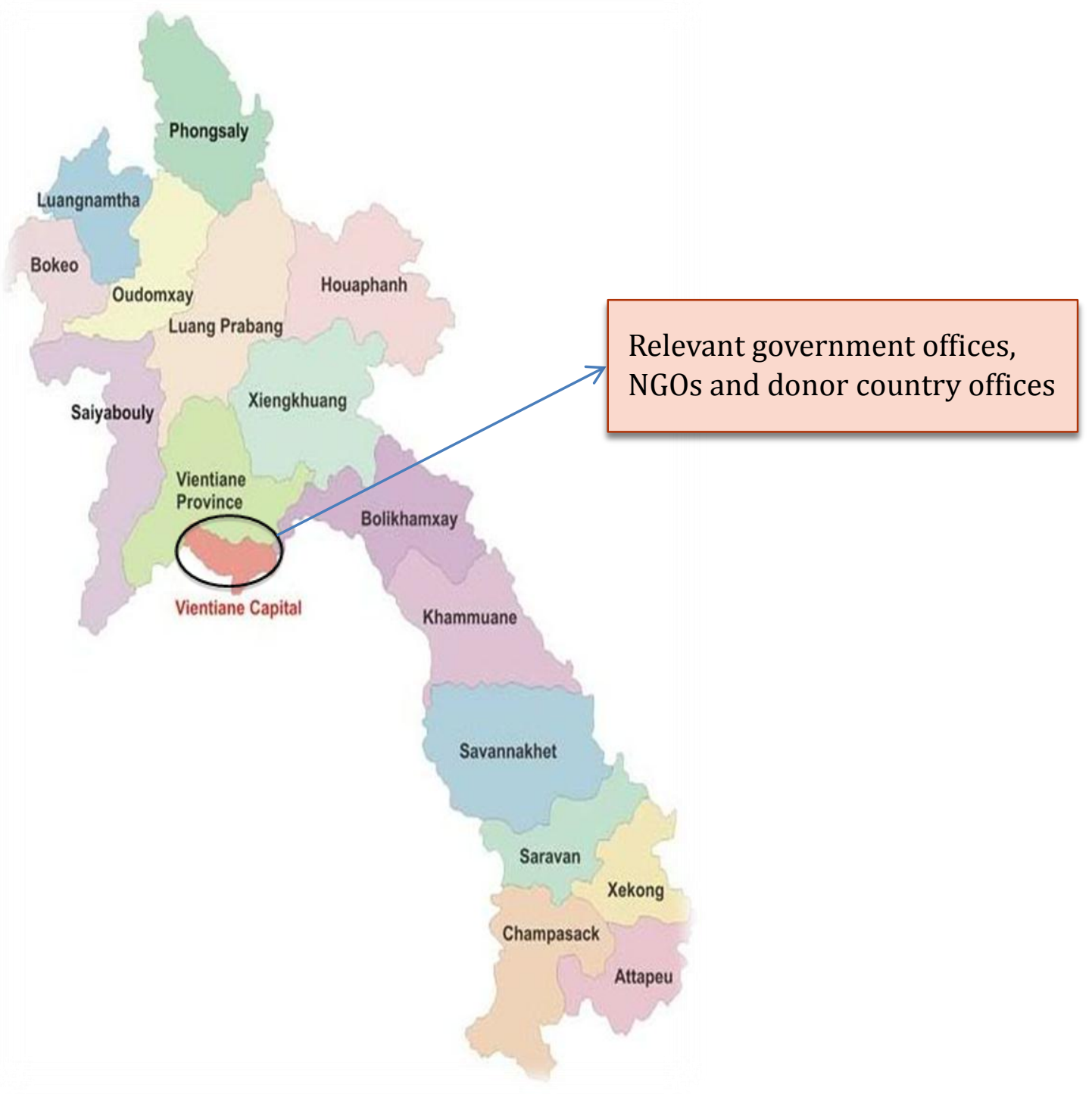

\subsection{Aim and Objective of the Research}

The main objective of this study is to examine the extent to which NGOs influence primary education policy in Laos. In doing so, it aims to investigate how NGOs' role is perceived by GoL and major donors given that NGOs are active actors in development in Laos, and in the education sector in particular. The way in which NGOs navigate their role within the socio-political context of Laos through building relationships and partnerships with the government and donors is likely to affect their profile and level of participation, and thus will also be explored. More recently, the enforcement of VD since 2006 has unequivocally shifted relationships between GoL and NGOs (GoL, 2006), and this shift has great potential to shape NGOs' role at 
policy level. Therefore, changes in relationships between GoL and NGOs since the adoption of VD will be scrutinised to clarify the role of NGOs in the contemporary context. Taking Batley's (2011) perspective on board that NGOs can identify and deploy strategies and mechanisms to try to exert policy influence in different contexts, my research seeks to elaborate the strategies and mechanisms that NGOs use to influence Lao primary education policy. These are then assessed in relation to the current socio-political context of Laos and how they may contribute to constructive and holistic development of Lao primary education.

\subsection{Research Questions}

In order to respond to the aforementioned aim and objective of the research, this study seeks to answer the following questions:

1. How do the Government of Laos and major donors perceive the role of NGOs at policy level?

2. How has the relationship between the Government of Laos and NGOs changed since the adoption of Vientiane Declaration on Aid Effectiveness in 2006 in relation to primary education policy?

3. What mechanisms and strategies have NGOs used to influence Lao primary education policy?

\subsection{Significance of the Research}

This research provides greater understanding of the extent to which NGOs have influenced the process and outcomes of Lao primary education policy. Although there have been some similar studies on the influence of external assistance on Lao education policy (Phommalangsy, 2013; McCormick, 2012; Fox, 2004; Roberts, 2004; Adam et al., 2001), none of them examined the influence of NGOs on Lao primary education policy. This study has extensively scrutinised NGOs' influence on Lao primary education policy as well as how they exercise such influence. It also provides insight into power relations between NGOs and GoL in relation to the process and outcomes of primary education policy development through different strategies and mechanisms, particularly through the officially accepted platform ESWG. This study on NGOs in Laos is also significant in the way that it was 
extensively grounded in real research fieldwork rather than case studies by which most NGO research is heavily undertaken (Bebbington, 2004).

It is hoped that this research may also be used to inform GoL, NGOs and donors regarding the roles of NGOs in the Laos context in order to support better partnerships and more holistic policy development. As the education sector is the largest recipient of NGO aid in Laos and is recognised as the first development priority by GoL (Kim \& Jeong, 2013; Phommalangsy, 2013), it is hoped that research findings will also benefit other sectors where similar policy partnerships exist. This research also aims to enlighten donors and governments to appreciate the roles of NGOs in policy interventions more generally in the region.

\subsection{Thesis Outline}

This thesis comprises seven chapters in total. Chapter One provides an introduction to the research question, discusses the status of NGOs operating in the Lao socio-political context, and describes a recent shift in policy influence. The chapter describes research objectives and questions.

Chapter Two provides a literature review covering arguments about the roles of NGOs in development in general, and particularly in Laos. The chapter also discusses key debates around NGOs' influence at policy level in relation to the education sector. Relationships between NGOs, governments and donors in the circle of aid coordination are also presented in this chapter.

Chapter Three outlines the methodology of this study as drawing on a social constructivist epistemology and using a variety of qualitative methods, including semi-structured interviews, document review and participant observation. It describes how the research has been designed, how data has been analysed and discusses my own positionality as well as ethical considerations.

Chapter Four presents some contextual background with an overview of Lao's social, economic and political characteristics, particularly those that influence the 
discussions and outcomes of this research. It then discuss Lao primary education development in light of national and international agendas.

Chapters Five and Six present research findings and analysis. Chapter Five focuses on the roles of NGOs in relation to primary education policy consultation and formulation, and Chapter Six explores the potential mechanisms and strategies employed by NGOs for policy influence.

Finally, Chapter Seven discusses the research results with an emphasis on linking key findings with literature, relevant studies, arguments and debate surrounding research issues. The chapter ends with some concluding thoughts and recommendations for future research.

\subsection{Summary}

This chapter has outlined the background of the research and presented an overview of the impact of foreign aid on Lao primary education policy. The chapter has also briefly described issues that framed my research interest, especially issues around existing relationships between the government and NGOs in Laos in terms of primary education policy, and my experience as a development practitioner, especially in the education sector. The research objective and questions were also defined in this chapter. 


\section{Chapter 2: Literature Review}

\subsection{Introduction}

This chapter outlines the conceptual background regarding the roles of NGOs in development, particularly in relation to primary education policy in Laos. There are two main sections in this chapter. The first section discusses the definition and evolution of NGOs with an emphasis on debates surrounding NGOs' influence on development policies. The second section reviews some key policy documents that shape NGOs' roles in Laos, including the Paris Declaration on Aid Effectiveness (PD), and the Vientiane Declaration on Aid Effectiveness (VD). The two documents are significant, and the latter is a milestone in the changing role of NGOs in Laos that shows the extent of their influence at policy level. The Round Table Process (RTP), which is the key mechanism to support the implementation of VD, is also discussed in this section. As this research focuses on education in Laos, key education documents such as the Dakar Framework for Action (DFA), the Lao Education Strategic Vision up to 2020, the Lao Education for All National Plan of Action (EFANPA) 2003 -2015, the National Education System Reform Strategy (NESRS) 2006 - 2015, the Education Sector Development Framework (ESDF) 2009 - 2015, and the Education Sector Development Plan (ESDP) 2011 - 2015 are also reviewed in this chapter.

\subsection{Understanding the Meaning, Evolution and Multifaceted Roles of NGOs}

This section discusses how NGOs have evolved in the development landscape, as well as their multi-dimensional roles. It also critiques recent studies in light of actors specific to Lao education policy.

\subsubsection{Definition of NGOs}

The term NGOs was coined in 1946 in the UN Charter and has been widely recognised, particularly over the last twenty years (Boli \& Thomas, 1997). Definitions of NGOs vary depending on several characteristics such as size, objectives, organisational structure, and resources (Kim, 2011), as well as the 
geopolitical contexts in which they operate. The World Bank defines NGOs as "private organizations that pursue activities to relieve suffering, promote the interests of the poor, protect the environment, provide basic social services, or undertake community development" (Gibbs et al., 1999,p. ix). Clarke (1998, p.36) defines NGOs as "private, non-profit, professional organizations, with a distinctive legal character, concerned with public welfare goals". Willetts (2001), however, maintains that there is no generally accepted definition of NGOs and that different countries define NGOs differently depending on their social and political perceptions.

Despite the lack of a unanimous definition of NGOs, there are some widely accepted characteristics of NGOs that underpin their existence in the development context. First and foremost, NGOs must not act as, or be affiliated with, political parties or governmental agencies. Furthermore, they should not aim to gain any political power through their operation (Kim, 2011). Secondly, they should not generate profit for the sake of their organisation - conversely, they are expected to work for the benefit of (often poor) people (Kim, 2011; Desai, 2002). Thirdly, NGOs should be based on benevolent purpose and thus all criminal and terrorist groups are excluded from the definition of NGOs despite the fact that they do not belong to any government agencies or political parties (Kim, 2011). It is interesting, however, that several religious charity organisations are regarded as NGOs.

\subsubsection{Categories and Roles of NGOs}

NGOs can be categorised into different types based on their level of organisation, geographical location and main purpose. Korten (1987) divides NGOs into three categories namely, relief NGOs, development NGOs and advocacy NGOs (see Korten, 1987). Relief NGOs have been operating since the end of the Second World War (Chum, 2010). Their key roles include famine relief, natural and man-made disaster response and recovery, and other humanitarian assistance (Martinussen \& Pedersen, 2003). Their work includes food distribution, and providing shelter, clean water, medicine and other basic needs to refugees and affected groups of people (Ahmed \& Potter, 2006). 
The second category are development NGOs, a group that has gained momentum since the 1970s (Korten, 1987). The main purpose of these NGOs is to operate longterm development projects that support poverty alleviation and socio-economic development. They generally assist government in fulfilling needs at the grassroots level that cannot be covered by the governments due to their limited resources (Willis, 2011). NGOs in this category may also concentrate more on community engagement and local empowerment to sustain development over time (Martinussen \& Pedersen, 2003). Some scholars argue that they work more effectively than governments and large donors in helping local communities manage their local resources, which is important for sustainability (Willis, 2011). A good example of this category of NGOs is Save the Children, which is one of the largest international NGOs, and has implemented development projects in more than 120 countries with the aim of improving socio-economic conditions (Kim, 2011).

The last category is advocacy NGOs whose main purpose is to advocate and influence changes in government policies in areas such as human rights and environmental issues (Kim, 2011). This generation of NGOs has played an increasing role in advocating and lobbying government policies since the 1980s (Korten, 1987). In parallel with policy advocacy, they also educate people to be aware of their rights to social and political engagement. As their strategic focus often centres on democratisation and human rights advocacy, their mandate has also shifted from a needs-based to a rights-based approach (Hulme \& Edward, 1997). Through this approach, NGOs have proved to be an important force in driving democratisation, participatory decision making, and human rights protection across the globe (Krut, 1997; Tvedt, 2002; Hyden, 1997).

Many strong NGOs act as a counterweight to authoritarian or tyrannical regimes in advocating for policy change (Mcllwaine, 1998; Ife, 2002). Amnesty International, which advocates for human rights, is a good example of NGOs in this category. Advocacy NGOs seems to be growing in the development landscape, and drawing increasing attention from donors, especially from Western countries (Kim, 2011). 
However, Christina (2001) cautions that the fact NGOs have striven to move towards the policy arena and towards becoming governments' policy counterparts may have diminished their traditional role as catalysts who actually make changes for the poor and marginalised. Moreover, NGOs' operating frameworks are often influenced by donors who exercise their political agenda through funding NGOs to act on their behalf (Mercer, 2002; Howell \& Pearce, 2002; Pearce, 2000). Donors' preference for NGOs to play an advocacy role is partly due to the fact that donors are more eager to maintain good relationships with governments than taking possible risks through advocating for controversial policies (Lundmark \& Malmberg, 2008).

Similarly, while donors have harnessed NGOs as agents of change, socio-political contexts of recipient governments are frequently overlooked by funding organisations. NGOs' lack of understanding of the socio-political contexts of the countries they operate in has resulted in counterproductive interventions and also in unhealthy relationships between NGOs and governments (Christina, 2001). The fact that advocacy NGOs in particular are perceived as governments' opponents and lack adequate backup from major donors (Lundmark \& Malmberg, 2008) has made NGOs in this category more vulnerable than relief and development NGOs to governments' strict scrutiny and supervision (ADB, 2011; Chum, 2010; Delnoye, 2010; Korten, 1987).

Specific to Laos, although most NGOs are in the first and second categories and their role is legally confined to that of a 'provider' of humanitarian aid and development assistance (Roberts, 2004; PMO, 2010), there seems to be a marked move toward policy advocacy. More and more NGOs, particularly educational NGOs, are employing a dual mandate - development and policy advocacy. The shift in NGOs' role in Laos has altered the way that the government and other DPs perceive and interact with NGOs. This will be discussed in more detail in Chapter 5.

\subsubsection{NGOs' Relationships with other Development Partners}

Apart from partnering with governments, international NGOs have increasingly collaborated with other DPs including donor organisations, UN agencies, local NGOs 
and other non-profit organisations. Due to their strengths at grassroots level and efficiency in delivering impacts with local people, NGOs have become implementing agents and sub-contractors of donor and UN agencies (Duffield, 1997). Some major donors, like the World Bank have partnered their projects with NGOs around the world as they acknowledge that NGOs are able to reach poor communities, identify local needs and build capacity for outreach population at low cost (Gibbs et al., 1999). Some NGOs have raised their status to that of UN agencies' in some development interventions. For example, Save the Children has worked as an equal partner with UNICEF in education and other development programmes (Save the Children \& UNICEF, 2012).

NGOs are also well-known for their capacity to provide research-based evidence that they can utilise to attract funding from donors (Zeiser, 1998). Donors generally acknowledge that NGOs have better experiences than them and governments in working successfully with communities, and therefore several donors have increasingly channelled their financial assistance through NGOs (Strand, 2005). Arguably, donor countries are increasingly trusting NGOs more than the recipient governments in terms of fund utilisation, particularly in countries led by incapable or corrupt governments (ibid.). Donors also seem to be more interested in NGO consortium and alliances, where several NGOs share their resources in project implementation. Some donors set a consortium working approach as a precondition for funding application. An example is the upcoming Basic Education Quality and Access in Laos (BEQUAL) programme with a budget of more than 85 million AUD over a 10 year period. The Australian Department of Foreign Affairs and Trade (DFAT) required Child Fund, Plan International, Save the Children and World Vision to work as a consortium for their funding application (DFAT, 2014). Subsequently, this NGO consortium has become a managing contractor for BEQUAL. The fact that DFAT has partnered with an NGO consortium in BEQUAL not only indicates that NGOs are viewed as a competent agent to deliver the programme outcomes, but it also suggests that DFAT is not really confident in the capacity of Government of Laos (GoL) to implement this huge programme with the required accountability and transparency. 
Through invoking international norms, NGOs also work in alliance with DPs to hold governments accountable for human rights, gender and environmental issues (Strand, 2005). Having said that, NGOs and donors are not always on the same page and their working approaches and priorities can be different. Despite the fact that they have a long history of partnership, their advocacy strategies can be very different depending on the political agenda of their respective organisations (Howell \& Pearce, 2002). Furthermore, while NGOs cooperate with some donors, they also monitor donor development projects and may act against the implementation of such projects (Kim, 2011). A notable example is the Narmada dam construction project in India which was funded by the World Bank to be implemented by the Indian government. The project was eventually abandoned in response to the protest of allied NGOs and local communities because of its repercussions on the environment and people's livelihoods (ibid.). Therefore, in certain circumstances, NGOs can act as a counterbalance to both government and donors, and are not always allied with donors as some literature suggests.

\subsubsection{NGOs' Influence on Government Policy}

The fact that governments often perceive NGOs as contributors who fulfil needs at community level rather than acting as policy counterparts often makes NGOs conform to, rather than challenge, government policies (Banks \& Hulme, 2012; Coston, 1998; Kingsbury et al., 2008; Korten, 1987; Willis, 2011). NGOs are more likely to be influenced by governments, because they operate under state rules and regulations (Kim, 2011). They are unable to play their role with complete autonomy despite their nominal identity as independent or non-governmental organisations (Creak, 2014). Conversely, some governments rigorously regulate and monitor NGOs' operation for fear of political insecurity and terrorism (Howell et al., 2008). With such political concerns, governments are prompted to closely supervise NGOs' missions and vigorously scrutinise activity details and funding management of NGOs, which in turn, undermines the responsive and independent operation of NGOs (Bennett, 2000). Moreover, NGOs are alleged to have been too donor-driven, and thus their policy influence relies almost entirely on donors who have better access to dialogues with high level government officials. Therefore, NGOs' missions 
are often more commonly directed by donors' priorities rather than community needs (Mercer, 2002; World Bank, 2009).

Whether governments influence NGOs' operation or NGOs influence government policies depends on the socio-political contexts of the countries in which NGOs are operating (Kim, 2011). In countries with a liberal political system NGOs tend to have stronger influence on government policy; while in countries with a centralised political structure, NGOs are more likely to be influenced by governments (ibid.). For example, in Laos where the political structure is a centralised democracy, NGOs' operations are supervised by the Ministry of Foreign Affairs who guides and closely monitors NGOs' project activities (Roberts, 2004). On the other hand, in countries with more liberal socio-political structures and NGOs are connected with certain political parties, in Thailand for instance, NGOs have great influence on the government's policy (Simpkins, 2003).

Although governments can enforce legal autonomy and bureaucratic hierarchy over NGOs, the latter can still wield influence over decision making processes, most apparently in the setting of agenda (Zeiser, 1998). NGOs can deploy a range of strategies to determine their room for manoeuvre and influence over development policy (Batley, 2011). Under certain circumstances where there is resistance from the state, NGOs can implement changes directly by sidestepping formal procedures and acting under the authority of a global alliance and adequate support from international community and powerful donors (Frank et al., 2007). The fact that NGOs possess evidence-based information that governments and donors might lack also makes them influential at the policy level (Zeiser, 1998). NGOs can use countervailing evidence as a source of strength to advocate for policy change in the global arena (ibid.).

\subsubsection{External Influence on Lao Education Policy}

Major donors such as the World Bank, AusAID (now DFAT) and the UNESCO have a huge influence on the Lao education policy, which has been exercised through aid conditionalities (Phommalangsy, 2013). With their financial power, those influential donors have convinced GoL to align the Lao education system with 
regional and global requirements, especially the Western standards, which in turn significantly affects national ownership on policy development (Munier, 2011; Phommalangsy, 2013). Several NGOs in Laos such as Save the Children, Child Fund, World Vision and Plan International have cooperated with major donors and established different working groups and co-led technical clusters with those major donors to increase their influence on Lao education policy (McCormick, 2012). The extent to which NGOs can actually influence Lao education policy through these mechanisms and strategies are discussed in Chapter 6.

\subsection{Key Policy Documents Reflecting NGOs' Role at Policy Level}

This section reviews key policy documents that shape NGOs' role in Laos, particularly in relation to education policy. Figure 2.2 (below) summarises the recent changes in education policy that these documents reflect.

\subsubsection{Paris Declaration on Aid Effectiveness}

The Paris Declaration on Aid Effectiveness (PD), which was ratified by both the OECD and aid-recipient governments in 2005, aims at strengthening aid effectiveness through ownership of the recipient governments, donor alignment and harmonisation with the priorities of recipient government, enhancing mutual accountability, and results-oriented management (OECD, 2005). The adoption of PD has attempted to shift power from donors to recipient country governments through strengthening ownership and leadership of the aid-receiving governments to ensure that development agenda are "guided by development strategies and priorities established by partner countries" (OECD, 2005, p.2). However, the PD has also been accused of still being a donor-driven paradigm that enables donors' influence over development policies in a more indirect way (Wallace et al., 2007; Makuwira, 2006).

Despite such accusations, PD has also established a platform to assist poor countries to achieve MDGs and move out of Least Developed Country (LDC) status through measurable action plans. The collective effort and commitments to increased aid effectiveness under PD has unprecedentedly called for partner governments to demonstrate effective leadership over their development policies and aid 
coordination (World Bank, 2007). Undeniably, this change in aid architecture has affected the role (particularly at policy level) of NGOs and other civil society organisations, who were not signatories of PD but endorsed the declaration with grave concerns about capacities of partner governments to lead development projects with transparency and accountability (Lavergne \& Wood, 2006).

\subsubsection{Vientiane Declaration on Aid Effectiveness}

In an effort to increase aid effectiveness through strengthened country leadership, the Government of Laos (GoL) and donor agencies translated the PD into the Vientiane Declaration on Aid Effectiveness (VD). This Declaration was signed by GoL and representatives of the 24 partner countries, donor and UN agencies in 2006 (see Table 2.1) with no legally binding obligation between signatories (GoL, 2006). It is recognised as a critical tool through which the government and donors strengthen aid effectiveness in order to achieve the MDGs by 2015 and lift Laos out of the LDC list by 2020 (ibid.). The principles of VD are similar to those of PD, but the emphasis is placed on the leadership role of the government and the harmonisation of development assistance with state priorities (Phommalangsy, 2013; Silaphet, 2008). 
Table 2.1: List of the Countries and Organisations that Signed the Vientiane Declaration on Aid Effectiveness

\begin{tabular}{|l|l|}
\hline No. & Countries/Organisations \\
\hline 1 & Australia \\
\hline 2 & Austria \\
\hline 3 & Belgium \\
\hline 4 & China \\
\hline 5 & Cuba \\
\hline 6 & Finland \\
\hline 7 & France \\
\hline 8 & Germany \\
\hline 9 & Indonesia \\
\hline 10 & Japan \\
\hline 11 & Luxembourg \\
\hline 12 & New Zealand \\
\hline 13 & The Philippines \\
\hline 14 & Poland \\
\hline 15 & The Republic of Korea \\
\hline 16 & Singapore \\
\hline 17 & Sweden \\
\hline 18 & Switzerland \\
\hline 19 & Thailand \\
\hline 20 & The United States of America \\
\hline 21 & The European Commission \\
\hline 22 & Asian Development Bank \\
\hline 23 & World Bank \\
\hline 24 & The United Nations \\
\hline
\end{tabular}

Source: The Vientiane Declaration on Aid Effectiveness, (GoL, 2006)

In order to ensure strategic alignment between the state and DPs and avoid intervention duplication, regular multi-stakeholder dialogues and consultations are led and coordinated through mechanisms designed by GoL:

"the Government exercises an effective leadership role in coordinating aid at the macro and sectoral levels though a substantive and ongoing process of dialogue with relevant stakeholders including the Partners in development; through such mechanisms as the Round Table Meetings and the Sector Working Groups" (GoL, 2006, p.2).

Despite the fact that the VD has no legally binding commitments, it is regarded as a foundational document that all DPs (including NGOs who are not signatories of this 
declaration) have to abide by. VD is normally cited and reflected in MoUs that DPs sign with the government to legitimise state ownership and leadership over all development programmes. The adoption of VD across the entire development spectrum is very significant for development stakeholders in Laos. Whereas country leadership has been increasingly strengthened, NGOs seems to face a daunting challenge of influencing government policy that prompts them to adapt their mechanisms.

\subsubsection{The Round Table Process}

The Round Table Process (RTP) has operated since 1983 with support from the United Nations Development Programme (UNDP) and the Government of Luxembourg in recent years (GoL, 2014). It is a national aid coordination mechanism that provides a unique platform for policy dialogues between GoL and DPs with regards to the country's development agenda and aid effectiveness under the United Nations Development Assistance Framework (UNDAF), and more recently the VD (GoL, 2014; Silaphet, 2008). The RTP comprises of High Level Round Table Meetings (RTMs) held every three years, Round Table Implementation Meetings (RTIMs) organised annually, provincial consultation conducted prior to both RTMs/RTIMs, and Sector Working Groups (SWGs) (GoL, 2014). With an effort to engage focused participation of DPs, GoL proclaimed the establishment of SWGs during the RTIM in 2005 (ibid.). The Education Sector Working Group was also formally established in 2007 as a consequence of RTIM and the enforcement of VD. This will be discussed in Chapter 6.

Traditionally, RTP was considered a platform between GoL and major donors with an aim to strengthen aid coordination and effectiveness through mutual understanding and consensus between the two parties with respect to development policies and strategies including MDGs and the National Growth and Poverty Eradication Strategy (NGPES) (GoL, 2014; Silaphet, 2008). However, in recent years, local authorities, NGOs, civil society and the private sector have increasingly engaged in the consultation process. This is despite the fact that decision making on policy development that feeds into the National Socio-Economic Development Plans (NSEDP) is overwhelmingly at the discretion of national government with a certain 
level of major donors' influence. NGOs, in particular, have increasingly utilised their participation in the RTP to advocate for changes in government policies. For example, in the 2014 RTIM, NGOs participated in policy consultation and advocacy for concrete assurance of civil society's full participation in the national development agenda, especially their engagement in the formulation of the upcoming 8th NSEDP (INGO Network, 2015).

\subsubsection{Dakar Framework for Action}

The World Education Forum held in 2000 in Dakar, Senegal adopted the Dakar Framework for Action (DFA), Education for All (EFA): Meeting Our Collective Commitments (UNESCO, 2000). The framework reiterates state responsibility for the achievement of EFA goals through cross-cutting partnerships and cooperation with global and regional organisations and institutions (ibid.). In doing so, governments were required to develop and incorporate their EFA action plans into wider poverty reduction and development frameworks through more transparent and democratic processes with the engagement of all concerned stakeholders including NGOs and civil society (ibid.). Guided by DFA, governments have been repeatedly advised to "ensure the engagement and participation of civil society in the formulation, implementation and monitoring of strategies for educational development" (UNESCO, 2000, p.8).

GoL participated in the World Education Forum and signed the DFA in 2000 when they also ratified the MDGs (Phommalangsy, 2013). It was also the year that the Education Law of 2000 in Laos was promulgated to enforce free and compulsory primary education (ibid.). More sector planning documents developed in Laos, including the Education Strategic Vision 2020 (MoES, 2000) and EFANAP 2003 2015 (UNESCO, 2005), are associated with DFA.

\subsubsection{Education Strategic Vision 2000- 2020}

After adopting the EFA goals in 2000, GoL developed its education strategic paper in the same year. The vision outlines a long-term framework and a strategic direction for Lao education development for 2000 - 2020. It also serves as a basis framework for on-going discussions and cooperation between MoES and DPs 
(MoES, 2000). The government disseminated this document to DPs so that they could develop a strategy in which their interventions could be applied in a systematic and coordinated manner in line with the Ministry's identified priorities. This paper clearly pronounced GoL's strong commitment to welcoming inputs from DPs: "we wish to favour a streamlined negotiation with bilateral and bilateral as well as non-governmental partners" (MoES, 2000).

This strategic vision recognises the significance of EFA goals and prioritises education as the core of human resource development for the country's long-term socio-economic development. Accordingly, the government together with DPs projected a gradual increase in education investment, with an emphasis on the most educationally disadvantaged areas. The document also lays out policy goals and targets for Lao education development, many of which were later translated into the EFA National Plan of Action.

\subsubsection{Education for All National Plan for Action 2003 - 2015}

The adoption of the MDGs and especially the EFA goals has influenced education policy in aid-receiving countries (McCormick, 2012). The fact that GoL ratified the EFA commitment in 2000 framed the way they developed their education policy; and education development initiatives are inextricably linked with national development discourse. Like many poor countries, education in Laos is "considered a major intervention for poverty alleviation" (MoES, 2000, p. iii). Key education documents such as EFA assessments (MoES, 2000), the EFA National Plan of Action (EFANPA) (MoES, 2004), and the EFA mid-decade assessment (MoES, 2008a) are reflected in NSEDP (GoL, 2011), and are localised from global initiatives such as global EFA goals and MDGs (see Table 2.2). 
Table 2.2: Relationship between EFANPA and EFA Goals and MDGs

\begin{tabular}{|c|c|c|}
\hline $\begin{array}{l}\text { EFA National Plan of } \\
\text { Action }\end{array}$ & EFA Goals & $\begin{array}{l}\text { Millennium } \\
\text { Development } \\
\text { Goals }\end{array}$ \\
\hline $\begin{array}{l}\text { 1. Access and Participation } \\
\text { in Early Childhood Care and } \\
\text { Development (ECCD) }\end{array}$ & $\begin{array}{l}\text { Goal 1: ECCD } \\
\text { Goal 5: Gender }\end{array}$ & $\begin{array}{l}\text { 3. Gender equality and } \\
\text { empowerment of women }\end{array}$ \\
\hline $\begin{array}{l}\text { 2. Access and Participation } \\
\text { in Formal Primary } \\
\text { Education }\end{array}$ & $\begin{array}{l}\text { Goal 2: Universal } \\
\text { Basic Education } \\
\text { (UBE) } \\
\text { Goal 5: Gender }\end{array}$ & $\begin{array}{l}\text { 2.Universal primary } \\
\text { education } \\
\text { 3. Gender equality and } \\
\text { empowerment of women }\end{array}$ \\
\hline $\begin{array}{l}\text { 3. Access and Participation } \\
\text { in Lower Secondary } \\
\text { Education }\end{array}$ & $\begin{array}{l}\text { Goal 2: UBE } \\
\text { Goal 5: Gender }\end{array}$ & $\begin{array}{l}\text { 3. Gender equality and } \\
\text { empowerment of women }\end{array}$ \\
\hline 4. Youth and Adult Literacy & $\begin{array}{l}\text { Goal 4: Literacy } \\
\text { Goal 5: Gender }\end{array}$ & $\begin{array}{l}\text { 3. Gender equality and } \\
\text { empowerment of women }\end{array}$ \\
\hline $\begin{array}{l}\text { 5. Skills Development } \\
\text { Program for } \\
\text { Disadvantaged Groups }\end{array}$ & $\begin{array}{l}\text { Goal 3: Life skills and } \\
\text { lifelong } \\
\text { learning, } \\
\text { Goal 5: Gender }\end{array}$ & $\begin{array}{l}\text { 3. Gender equality and } \\
\text { empowerment of women } \\
\text { 6. HIV/AIDS }\end{array}$ \\
\hline $\begin{array}{l}\text { 6. Improve the Quality and } \\
\text { Relevance of Formal } \\
\text { Primary and Lower } \\
\text { Secondary Education }\end{array}$ & $\begin{array}{l}\text { Goal 2: UBE } \\
\text { Goal 5: Gender }\end{array}$ & $\begin{array}{l}\text { 3. Gender equality and } \\
\text { empowerment of women }\end{array}$ \\
\hline $\begin{array}{l}\text { 7. Education Management } \\
\text { and Administration }\end{array}$ & $\begin{array}{l}\text { No specific EFA Goal: } \\
\text { some } \\
\text { policy indicators are } \\
\text { included }\end{array}$ & No specific MDG Goal \\
\hline
\end{tabular}

Source: EFA Mid-Decade Assessment, (MoES, 2008)

Laos finalised its EFANPA for the year 2003-2015 in December 2004. The main purpose of EFANPA is to accomplish three major tasks, including equitable access to education, improved quality and relevance of education, and strengthened education management (MoES, 2004). More strategically, EFANPA aims to ensure that Laos is able to live up to the EFA goals and the Universal Primary Education MDG. In so doing, four priority segments are identified for concentration including early childhood care and development, primary education, lower secondary education; and non-formal education and skills train (MoES, 2004). With limited financial and technical resources, EFANPA has opened the door to assistance from DPs including NGOs who presumably also frame Lao education policy according to international trends and standards (Phommalangsy, 2013). The EFANPA itself 
indicates that the "government has collaborated with the donor community to develop the strategy" (MoES, 2004, p.39).

As primary education (which consists of five years schooling) is compulsory under the Lao EFA goals, the government and donors and NGOs alike steer their interventions towards graduating all school age children from primary school. To meet these targets, Laos has seen two large-scale education programmes in recent years. The EFA Fast Track Initiative programme was funded by AusAID/DFAT and the World Bank (UNESCO, 2015) and ended in 2014, and the upcoming BEQUAL, with a budget of more than 85 million AUD is also funded by DFAT (DFAT, 2014). These two programmes aim at assisting GoL to realise its EFA goals in response to the EFANPA 2003-2015 and ESDP 2011- 2015, although BEQUAL looks beyond 2015 when it will specifically focus on learning quality improvement (ibid.).

\subsubsection{National Education System Reform Strategy 2006 - 2015}

The National Education System Reform Strategy (NESRS) 2006 - 2015 was an outcome of EFANPA. The NESRS was developed in 2008 by senior education policy makers under close guidance of the newly elected MoES Minister at that time, without any support from DPs (Phommalangsy, 2013). The overall goal of the reform was to improve the quality and standards of education to meet the MDG education targets and thereby contribute to national socio-economic development (MoES, 2008a). As with the EFANPA, this reformed strategy also emphasises education development as the cornerstone of all human development strategies (ibid.).

It is, nevertheless, noteworthy that while NESRS aims at moving Lao education toward international standards, it basically promotes the socialist ideological agenda of GoL. For example, the reform direction states firmly that "education reform must be in line with socialism while developing capable human resource" (MoES, 2008c, p.23). It is also regarded as an ambitious strategy without viable action plans. Phommalangsy (2013, pp.24-25) described it as "a strategy framework that could not be implemented because it contained a 'wish list' without priorities". Nonetheless, NESRS served as a fundamental guide for the development of the 
Education Sector Development Framework, which has become one of the most important documents used for Lao education development among government agencies and DPs.

\subsubsection{Education Sector Development Framework 2009-2015}

The Education Sector Development Framework (ESDF) in Laos was developed in November 2008. It is one of the most comprehensive sector plans serving as a masterplan for education development in Laos (MoES, 2009). It is also closely aligned with EFANPA 2003-2015 and NESRS 2006 - 2015 as well as the government's other broader commitments to education reform towards MDG and EFA achievement (MoES, 2008a; MoES, 2009). ESDF reflects a collective effort among government agencies and DPs to more effective investment in the education sector in Laos. It also responds to joint commitments between GoL and DPs under broader frameworks as the plan outlines below:

"A move towards a balanced and effective approach to education sector development is in line with the Government's policy and Development Partners' strategy on Aid Effectiveness captured in the Paris Declaration and elaborated in the Vientiane Declaration in 2006, in which the formulation of a Sector Development Framework is a key priority" (MoES, 2009, p.3)

Obviously, the ESDF reflects a shared long-term vision and commitment to education sector development by GoL and DPs through aligning development interventions with national priorities in accordance with the Vientiane Declaration. The government has also used ESDF for sector-wide planning and a requirement for external assistance, while DPs have also used ESDF as an entry point for policy influence. It has been claimed that as ESDF development was heavily influenced by DPs, especially major donors with substantial financial power, ESDF continues to serve as a tool for external influence on Lao education policy (Phommalangsy, 2013). However, the role of NGOs in ESDF development as well as their influence on Lao education policy through ESDF, were not widely discussed in existing literature. 


\subsubsection{Education Sector Development Plan 2011 -2015}

The Education Sector Development Plan (ESDP) 2011 - 2015 was developed in 2011. It outlined a concrete action plan with specific priorities for each year (MoES, 2011a). The development of ESDP was claimed to be carried out under an extensive consultative process among MoES, donors, NGOs and other relevant stakeholders through ESWG in line with the Vientiane Declaration. The plan promotes harmonisation of DPs interventions, gender equity and pro-poor policy development within the overarching achievement of the MDGs, and is also in line with key policy frameworks such as the National Growth and Poverty Eradication Strategy (NGPES), National Socio-Economic Development Plan (NSEDP) and the National Education System Reform Strategy (ibid.).

With an effort to harmonise development interventions, the EDSP has introduced a Sector-wide Approach (SWAp) as a transition strategy toward a pooled funding or joint financing arrangement, on which more discussions are needed by ESWG (MoES, 2011a). Under this new funding mechanism, a coordinated approach to interventions among government agencies, donors and NGOs is considered pivotal to successful implementation of ESDP. The introduction of ESDP in the education sector marks another significant shift in the role of NGOs in the education sector in Laos. It might mean that NGOs cannot really operate independently but have to go through all necessary consultation processes with the government and other DPs. How this effects their level of influence remains an open question. 
Figure 2.1: Chronology of Lao Education Policy Development
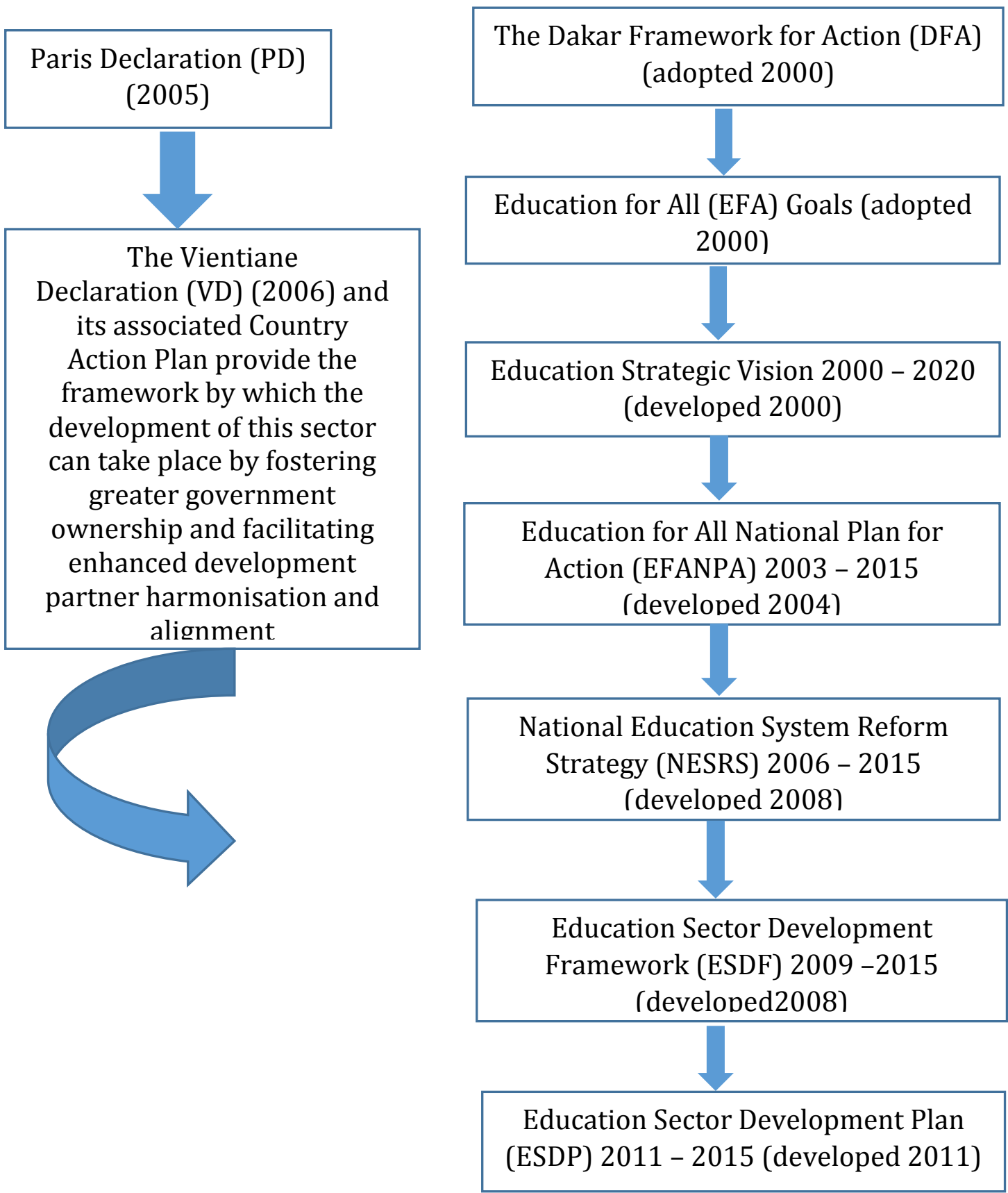

\subsection{Summary}

In this chapter, I have discussed two relevant bodies of literature. I have explored the background and evolution of NGOs in the development industry and drawn attention to the diversity of NGOs. I also described the major categories of NGOs namely relief, development, and advocacy NGOs. While NGOs in Laos are more likely 
to fall in the first and second categories, more and more NGOs are trying to move into advocacy to engage more in policy change. This chapter also focused on the debate surrounding NGOs' influence. While much literature asserts that NGOs do not influence government policies and have a role as 'service providers' rather than 'policy counterparts' of governments, some literature counters that NGOs do have a certain degree of influence at policy level, and that they deploy mechanisms and strategies to exert that influence. The chapter also discussed NGOs' lack of political autonomy in some contexts (including that of Laos), which puts them under state control.

In relation to the consideration of NGOs' influence on government policy in Laos, particularly on primary education policy, some key documents related to aid coordination and education such namely PD, VD, RTP, DFA, EFANPA, NESRS, ESDF and ESDP were also discussed in this chapter. These documents demonstrated that global commitments, especially the EFA goals, have encouraged GoL to open the door for international cooperation and assistance through which external influence has been exerted on Lao education development. 


\section{Chapter 3: Methodology}

\subsection{Introduction}

This chapter focuses on the research methodology that has shaped how the research was designed and the nature of the outcomes produced. The chapter begins describing my epistemological approach as social constructivist. Next, it discusses my positionality as an academic researcher. It then discusses my choice of qualitative methods for data collection, including semi-structured interviews, documentary review and participant observation. The chapter further elaborates how research participants were selected, interviews arranged, and how data was analysed. Finally, the chapter concludes with ethical considerations.

\subsection{Research Epistemology}

Epistemology explores the meaning of knowledge and how we acquire knowledge through philosophical analysis of the specificity of knowledge and its connection with veracity, belief and justification (Hofer, 2001). Epistemologies may be historical, empiricist, rationalist or constructivist, and each approach perceives knowledge in a different way (ibid.). In this research, I considered myself a social constructivist, who sees our understanding of the world to be socially constructed by humans - we actively construct the meaning of world through our interpretation of personal experiences and perceptions (Bäcktorp, 2007; Dowling, 2005). At the same time, we also learn and create meaning of phenomena from the different viewpoints of social actors (ibid.). I use the term 'we' to refer to 'researchers' in general, including myself and the term 'social actors' refers to 'research participants' in this context. Taking my social constructivism approach on board, I sought to establish the meaning of phenomena based on the view of my research participants as well as on my own analysis of the literature and my own professional experience (Creswell, 2009). 


\subsection{Researcher's Positionality}

Positionality shapes how people perceive ethical practices in relation to their research (Hopkins, 2007). Researchers can be positioned as outsiders or insiders, and this will affect how research participants interact, which in turn produces different research processes and outcomes (Sultana, 2007, Kindon et al., 2007; Pain, 2009). Therefore, researchers need to be aware of and constantly reflect on their positionality when undertaking fieldwork (Kindon, 2012).

In this research, I was both an insider and outsider. As a former colleague to most participants, undertaking research in my home country, I was considered an insider. This helped me gain quicker access to interviews, particularly with key government officials who highly valued existing relationships (Couture et al., 2012). In addition, as the former head of an education programme in an NGO, I was familiar with most participants in NGOs and donor agencies. This made interviews more accessible, although some appointments took longer than expected and some NGOs were unable to participate in the research.

I am aware that as an insider in this research, there are risks of bias but I have tried to position myself neutrally to minimise possible biases (Urban \& Quinlan, 2014). It is undeniable that the assumption I carried at the back of my head that NGOs had some degree of influence on government policy might have influenced the way I framed my discussions with participants. This might have partially resulted in biases in interpretation. Moreover, my previous job as an NGO staff member might have hindered my critical examination of NGOs. In the same vein, my positionality as an NGO employee who presumably appreciates the good work of NGOs might have influenced the way I perceived the roles of government and donors.

However, as an academic researcher from an education institution, I was also viewed differently from how I had been viewed in my prior professional role. Although most participants demonstrated their willingness to support my research, they were very careful in providing their opinions, particularly when their voice was recorded. Some of them refused to have their voice recorded for safety concerns and many of them made it clear from the beginning that the views provided were from 
their own personal perspectives, not those of their organisation. The fact that I was viewed as an outside academic researcher allowed me to conduct interviews independently (Couture et al., 2012). This mitigated conflicts of interest, and also produced more accurate research results. I made it clear before the interviews started that I was an academic researcher representing VUW, so participants were aware that the research would be independent from work relationships when it came to interviews. In doing so, it also allowed me to be more critical of NGOs. In order to mitigate bias that might result from my personal relationship with some participants in particular organisations, I also requested to interview another participant that I did not have a prior relationship with to seek a range of perspectives on the issues. However, I acknowledged that balancing my positionality as an outsider and insider at the same time was very difficult in this research and required constant reflexivity and caution as Sultana (2007) suggests.

\subsection{The Research Design Process}

Research questions shape how research is designed. In this study, as the research questions are about perceptions and attitudes of participants on the extent and ways in which NGOs influence education policy in Laos, qualitative inquiry became the main methodological approach. Due to the time constraints of interviews, document review was undertaken before and after the interviews to support data gathering from interviews. There was also some change in target participants after consulting with some people who had conducted research on similar topics. More NGOs and donor agencies were included while the Ministry of Foreign Affairs (MoFA) was left out due to the fact that the research focus was on education policy to which the MoFA was not really relevant. Including more NGOs in the research added a great value and enhanced perspectives on different angles from different dimensions of NGO, particularly the size of NGOs.

\subsection{Sampling and Research Participant Selection}

Sampling is the process of narrowing down target participants through defining representative sub-populations of the research (Lunsford \& Lunsford, 1995). Among other techniques, snowballing is widely used, because it is an effective technique to reduce sample bias, maintain confidentiality and enhance validity of 
research findings (Cohen \& Arieli, 2011; Penrod et al., 2003). Snowballing is "a technique for finding subjects where one subject gives the researcher the name of another, who in turn provides the name of a third, and so on" (Vogt, 2005, p.300). Snowball technique also enables researchers to comprehend a particular issue in more detail through a wider social network (Soulineyadeth, 2014).

In this research, I employed the snowball technique by making it clear in my request to participant organisations whom I wanted to interview for my research. This was very useful as I gained access to participants who were directly involved in primary education policy dialogues and development processes in Laos. Although I did not select participants myself, but rather relied on recommendations from participants' organisations, most assigned interviewees were most relevant to this study. Participant organisations assigned people to particpate based primarily on their knowledge, experience and engagement in policy matters.

In an effort to target the data to my research focus, I only selected the MoES as the representative of the government to participate in my research. I decided to include more NGOs than I initially intended, to expand the diversity of viewpoints. More donor organisations were also selected as interviews moved on, in order to understand their perceptions on NGOs' influence on primary education policy in a broader sense. In order to deepen understanding on how NGOs and donors exert their influence over government policy, some education specialists outside government and DPs were selected to explore broader views on the NGOs' influence and the possible mechanisms and strategies that NGOs use to influence Lao primary education policy.

Participant organisations were purposively chosen based on their relevance to the research topic, i.e. NGOs, donor agencies, government departments and education specialists that work on primary education and engage in policy development. I approached participants differently (as appropriate to the protocols of different organisations). Most appointments with participants from NGOs and donor agencies, as well as education specialists, were made through phone calls and emails while all appointments with government participants were made through 
document submission to their administrative office. Most participants, except two NGO staff, were contacted after the Lao New Year which was a week after I had arrived in Vientiane. Follow-up emails were sent and phone calls were made one day prior to interviews to confirm the date and time of the interview.

\subsection{Research Methods}

Qualitative methods were used in this study to seek different views of varying groups of participants in relation to the research questions. Methods used include a desk-based analysis of literature, semi-structured interviews and participant observation (see Figure 3.1). Qualitative methods are effective to explore and understand phenomena by seeking different views from relevant research target groups (Johnson \& Christensen, 2008). The methods create direct and spontaneous ways of sharing information, expertise and experience between researchers and participants (Mikkelsen, 2005). Qualitative research, ideally, allows participants to freely express their opinions, thoughts and experiences in a deep and detailed manner (Creswell, 2009; Creswell, 2013). Therefore, qualitative research normally involves researchers meeting face to face with participants to conduct interactive interviews in a casual setting (Johnson \& Christensen, 2000; Creswell, 2009). Through qualitative interviews, researchers gradually create the meaning of a certain phenomenon (Denzin \& Lincoln, 2011). Researchers can also interpret the meaning of such phenomenon by drawing on personal reflection and existing literature (Creswell, 2013; Johnson \& Christensen, 2008). Using a combined approach of document review, semi-structured interviews and participant observation, enables researchers to generalise, explain and draw conclusions on issues that vary from their expectations (Fitzgerald, 2006).

\subsubsection{Semi-Structured Interviews}

Among other types of interviews, the most common method in qualitative research is the semi-structured interview (Creswell, 2013; Longhurst, 2003). Semistructured interviews allow an interactive exchange of information between interviewers and interviewees in a flexible way, creating a free-flowing conversation, allowing interviews to go into more detail about specific issues for which information is not necessarily available in the literature (Davidson \& Tolich, 
2003). Through responding to open-ended questions, interviewees can communicate their thoughts, opinions and experiences, while the interviewer can ask additional questions to seek further opinions and clarify their understanding of certain points, particularly in regard to unexpected issues (DiCicco-Bloom \& Crabtree, 2006). Researchers can also adjust their interview questions to suit a particular context, and the positionality, knowledge and experience of participants, in order to gain relevant and in-depth information (Bryman, 2008).

In this study, all interviews were semi-structured and participants raised many interesting and relevant points that were not covered by my prepared interview questions. Through this research method, I gained several new ideas and was constantly led to new questions that I had to revise and develop for the next interviews.

Semi-structured interviews are especially preferable in cross-cultural research in which cultural awareness plays a pivotal role. As reflected by Kindon (2012, p.1), "differences between researchers and research participants are an inevitable part of the fieldwork". These differences require researchers to be reflexive about their positionality, which may lead to power imbalances, institutional discrimination and dominance over research process and outcomes when undertaking research with people from different backgrounds, race, gender and ethnicities (Kindon, 2012; Sultana, 2007). Although I conducted this research in my home country, participants included people from different backgrounds and diverse organisational cultures that influenced the way they participated in the research and the style they used to provide information

I interviewed 24 people in this study (see Table 3.1). They are categorised into four clusters: NGO representatives, donor and UN agencies, government officials, and education specialists. Nine NGO representatives took part in the research, and they are quoted as "Informant NG01-9". Six government officials from relevant Ministry departments were also interviewed and are quoted as "Informant G0V1-6". Five representatives from donor and UN agencies also participated in the research and are quoted as "Informant DU1-5". Finally, four education specialists who had been 
extensively involved in education development in Laos were also interviewed and are quoted as "Informant ES1-4".

Interview questions were developed in both English and Lao (see appendix V) and were sent together with other relevant documents (which were also available in both Lao and English) to participant orgnisations prior to the interviews. All government participants demanded to have interview questions prior to the interview in order to make sure that they assigned the right officials who could then be prepared to provide proper information for the research. This was not the case for other clusters of participant except a donor participant who expressed her wish to see interview questions before hand in order to be prepared for responses.

As interviewing Lao government officials involves politics and power hierarchies (Pollard, 2009), close attention was paid to the translation of some English terms into Lao. I developed a separate set of interview questions for these participants that were more neutral and diplomatic. For example the term 'influence' which sounded confronting was replaced with the term 'intervention' which sounds more neutral when translated into Lao language. In an effort to avoid being confronting in the language used while also maintaining the meaning of the messages I tried to deliver, I had to play around with the language and redirect my questions and ask follow-up questions to verify information.

Ten interviews with NGOs and donor participants were conducted in English while another fourteen interviews were undertaken in Lao. All interviews were conducted face to face at the participants' offices in Vientiane. Most interviews were recorded while a few were not because of participants' security concerns. I usually listened to the voice recordings in the evening of the interview to compare with my note-taking and clarify some points. The average length of an interview was around 50 minutes. 
Table 3.1: List of Research Participants

\begin{tabular}{|l|l|l|l|l|}
\hline No. & $\begin{array}{c}\text { Organisation } \\
\text { Cluster }\end{array}$ & \multicolumn{1}{|c|}{ Code } & $\begin{array}{c}\text { Local or } \\
\text { Expatriate }\end{array}$ & $\begin{array}{c}\text { Years involved in } \\
\text { Lao primary } \\
\text { education policy }\end{array}$ \\
\hline 1 & NGO & Informant NGO1 & Local & 3 years \\
\hline 2 & NGO & Informant NGO2 & Expatriate & 5 years \\
\hline 3 & NGO & Informant NGO3 & Expatriate & 6 years \\
\hline 4 & NGO & Informant NGO4 & Local & 5 years \\
\hline 5 & NGO & Informant NGO5 & Local & 4 years \\
\hline 6 & NGO & Informant NGO6 & Local & 23 years \\
\hline 7 & NGO & Informant NGO7 & Local & 9 years \\
\hline 8 & NGO & Informant NGO8 & Local & 7 years \\
\hline 9 & NGO & Informant NGO9 & Expatriate & 3 years \\
\hline 10 & Government & Informant GOV1 & Local & 10 years \\
\hline 11 & Government & Informant GOV2 & Local & 15 years \\
\hline 12 & Government & Informant GOV3 & Local & 4 years \\
\hline 13 & Government & Informant GOV4 & Local & 4 years \\
\hline 14 & Government & Informant GOV5 & Local & 15 years \\
\hline 15 & Government & Informant GOV6 & Local & 3 years \\
\hline 16 & Donor & Informant DU1 & Local & 5 years \\
\hline 17 & Donor & Informant DU2 & Local & 4 years \\
\hline 18 & Donor & Informant DU3 & Local & 6 years \\
\hline 19 & Donor & Informant DU4 & Expatriate & 1 year \\
\hline 20 & Donor & Informant DU5 & Local & 5 years \\
\hline 21 & $\begin{array}{l}\text { Education } \\
\text { Specialist }\end{array}$ & Informant ES1 & Expatriate & 6 years \\
\hline 22 & $\begin{array}{l}\text { Education } \\
\text { Specialist }\end{array}$ & Informant ES2 & Expatriate & 21 years \\
\hline 23 & $\begin{array}{l}\text { Education } \\
\text { Specialist }\end{array}$ & Informant ES3 & Local & More than 15 years \\
\hline 24 & $\begin{array}{l}\text { Education } \\
\text { Specialist }\end{array}$ & Informant ES4 & Expatriate & 13 years \\
\hline & & & & \\
\hline
\end{tabular}

\subsubsection{Document Review}

A desk-based review was partly done in Wellington before fieldwork. This included a review of the education sector documents discussed in Section 2.3. Further literature was reviewed after I arrived in Vientiane and had an in-depth discussion with Phouvanh Phommalangsy who had recently conducted research in a similar 
field. In reviewing the literature, I tried to identify possible gaps and mismatches between policy documents, the country strategies of NGOs and other donor agencies. This process was very helpful in assisting me to develop more relevant research questions.

More updated documents were also collected from participants, particularly those from NGOs and donor agencies. These documents included the organisational structure and Terms of Reference for the Education Sector Working Group (ESWG) and Focal Groups, an amended education law draft, the ESDP mid-term review report, and the results of the Round-Table meeting 2014.

\subsubsection{Participant Observation}

Participant observation was another technique used in this research to enhance validity of information gained from interviews and document review. It also deepened particular views from different angles through engaging cognitive and emotional information and the reactions of participants (Dingwall, 1997; Tedlock, 2005). I employed participant observation technique while attending an Informal Education Donor Working Group (IEDWG) meeting conducted on 17 June, 2015 by NGOs and donors working in the education sector in Laos. The results and analysis of this IEDWG meeting observation are quoted as "IEDWG 2015" in this thesis. Although I was a member of IEDWG when I worked for Save the Children, I was considered an outsider (as a researcher) and thus had not been authorised to attend an IEDWG meeting held at the end of May. I was told that IEDWG meeting were supposed to be confidential meetings among NGOs and donor agency. Therefore, for [outside] researchers to be able to attend this meeting, all members would need to agree and this might take some time. I was, nevertheless, approved to attend another IEDWG meeting organised the following month as it was less confidential than the one held in May.

The IEDWG meeting gave me deeper understanding on the relationships between NGOs and donors. The focus of this meeting was an update to the amended education law 2015 and draft ESDP 2016-2020. Through observing it I was better able to understand the mechanisms that DPs used to agree on particular issues 
before proposing them to the government for consideration. I observed how NGO representatives interacted with donor representatives and evaluated the level of influence of each party. Observing this meeting allowed me to gain more understanding of the impact and effectiveness of ESWG and IEDWG that I was then able to compare with information obtained from interviews.

Figure 3.1: Overview of Research Methodology

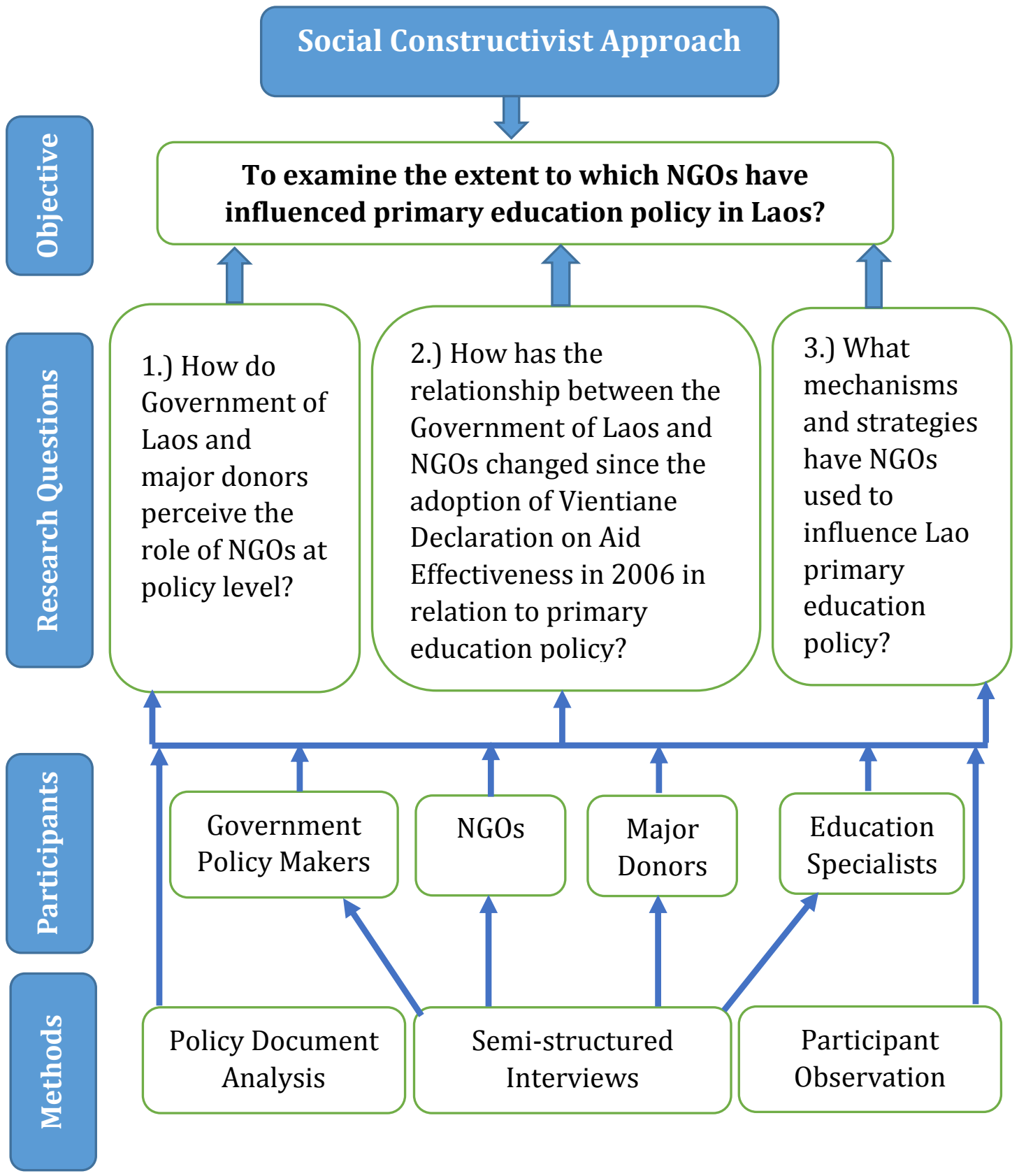




\subsection{Data Coding, Transcribing and Analysis}

Data coding is a means to classify and categorise information according to themes and sub-themes (Auerbach \& Silverstein, 2003; Corbin \& Strauss, 2008). My data collected from interviews was quite diverse and scattered as conversations were in free-flowing style and some participants brought up some issues that were not really related to the questions. The interview questions also varied based on different target groups, which in turn obtained a variety of information. Therefore, coding helped me organise and generate the meaning of textual data in a more systematic way (Basit, 2003; Boyatzis, 1998; Bryan, 2008; Fereday \& MuirCochrane, 2006).

I tried to code the data after each interview to avoid confusing or mixing data from different interviews. I primarily employed axial and selective coding methods but also open coding as new ideas emerged (Bryan, 2008). I had prepared themes and sub-themes of my research concerns in advance, and coded unexpected concepts in an open category before integrating them into existing sub-themes or creating a new theme or sub-themes as necessary.

I arranged the key concepts by themes in relation to my research sub-questions. Supporting ideas were organised as subthemes. Central themes were:

- Relationships between NGOs and GoL in general

- Relationships between NGOs and major donors

- Change in relationships between NGOs and GoL since the adoption of the Vientiane Declaration in 2006

- Role of NGOs in Laos in relation to primary education policy

- Policy gaps in Lao primary education

- Opportunities and challenges of NGOs' influence at policy level

- Key primary education policy areas that NGOs have influenced for change

- Strategies and Mechanisms used/to be used by NGOs for policy influence

- Significance of ESWG and IEDWG

- Other factors contributing to change in Lao primary education policy 
These themes framed the way supporting ideas were incorporated and analysed. I frequently revisited my notes, recordings and my coding system to ensure that what I coded was as detailed and accurate as possible. In addition I adjusted the way I took notes, summarised and coded the interview results as fieldwork progressed, particularly to accommodate most relevant and emerging information. The interviews conducted in Lao language were translated into English before being coded.

I transcribed voice recordings, in addition to notes, into a summary sheet, to which I then added my own reflections. The most relevant ideas were written as direct quotes. Some Lao participants, especially from NGOs and donor organisations, wanted to be interviewed in English despite their imperfect English, and I partially corrected those mistakes for fluency, trying to maintain the meaning of those statements and their original structures. As safety is the issue that participants were most concerned about due to fear of negative impacts on their career and relationships between their organisation and the government, I replaced the names

of individuals and organisations with pseudonyms which are given in square brackets.

Interviews were analysed as soon as possible to prevent loss of information and for better reflection. Analysis results were categorised into thematic aspects, grouped by sectoral representation (government, NGOs, donors, education specialists), discussed and presented in both textual and diagrammatic patterns. In addition to interviews, I analysed relevant documents obtained before, during and after the interviews including government policy documents, evaluation reports, country strategies of NGOs and donors, Terms of References and so on. This helped me to compare and contrast the data gained from interviews with written documents in order to draw a more accurate conclusion (Luna-Reyes \& Andersen, 2003).

\subsection{Ethical Considerations}

Taking ethical issues into account provides safety and protection for both participants and researchers (Williman \& Buckler, 2008). Researchers are required to respect participants' confidentiality and minimise any risks that might harm 
participants, the researcher, or their institution (Wall \& Overton, 2006). Prior to research fieldwork, I sought ethical approval from Human Ethics Committee of Victoria University of Wellington (VUW). Through the application process I reviewed and understood all ethical requirements in compliance with VUW Human Ethics Committee Guidelines 2007.

Due to the nature of my research topic, I kept participant confidentiality at the forefront of the whole research process to avoid any harm to participants' professions and organisations as well as to avoid any damage to working relationships between participants. I came to realise during my fieldwork that relationships between NGOs and GoL had been recently undermined by the aftermath of the $9^{\text {th }}$ Asia-Europe People Forum held in 2012 in which an NGO staff member had criticised GoL in what was felt to be an unconstructive way with some negative repercussions (this is discussed further in Chapter 5).

Participants were informed about the research purpose and their rights to withdraw from research activities whenever they wished. All necessary documents namely participant information sheet, consent form, human ethics approval and supervisor support letter (see Appendices I, II, III, IV) were enclosed with emails and request letters when inviting participants to take part in my research. Verbal explanation through phone calls was also made before appointments were finalised and when clarifications were needed. To ensure that participants and their organisations are protected throughout the course of the research given that this thesis will be published, confidentiality protection was made a clear-cut issue in the consent form (Wiles et al., 2008). This included omitting names of participants and their organisations which were replaced with pseudonyms as demanded by participants during the fieldwork.

\subsection{Summary}

This chapter has outlined how the research was designed and conducted. For this study I employed a qualitative approach derived from a social constructivist epistemology. Data collection was undertaken through semi-structured interviews, documentary review and participant observation. The interviews were conducted 
in Vientiane capital with 24 participants from four main clusters, i.e. MoES, NGOs, donor agencies, and education specialists. Secondary data including policy documents, evaluation reports, country strategies and other relevant documents were collected and reviewed prior, during and after the interviews. Participant observation was also applied as a research method through attending an IEDWG meeting. Information obtained from interviews was coded and transcribed for analysis after the interviews and upon completion of the fieldwork. Researcher's positionality and ethical issues were also discussed in this chapter. Participants' identity and their respective organisations have been protected to the best capacity of the researcher throughout the research process and outcomes. 


\section{Chapter 4: The Social, Economic, Political and Educational Context of Laos}

\subsection{Introduction}

This chapter discusses key aspects of the social, economic and political contexts of Laos that inform the discussion and results of this research, particularly the focus on primary education. The first section of this chapter discusses broad contextual factors that shape Laos. The second section discusses the context of NGOs' aid in Laos. Finally, the third section presents an overview of the educational context in Laos with an emphasis on primary education. The chapter concludes by arguing that the uniqueness of the Lao context has a tremendous impact on the extent to which NGOs influence primary education policy in Laos.

\subsection{Broad Features of Laos' Social, Economic and Political Context}

In this main section, I discuss the country's geographical, demographical and political features that shape social and cultural constructs in Laos. National economic development with aid dependency as a driving force is also discussed.

\subsubsection{Geographical and Demographical Features}

Laos, also more formally known as Lao People's Democratic Republic or Lao PDR in short, is a small and landlocked country in Southeast Asia. It shares long borders with Vietnam to the east and Thailand to the west, and also has shorter common borders with China and Myanmar to the north and Cambodia to the south (see Figure 4.1). Laos has a land surface of 236,800 square kilometres, three-quarters of which is covered by mountains and plateaus. It has a population of $6,646,000$, of which approximately $42 \%$ are under 16 years of age (WHO, 2014). This demography has placed the expansion of education services as a priority of the Government of Laos (GoL) with consequent increased demand on services and resources (Phommalangsy, 2013). 


\section{Figure 4.1: Laos in the World Map}

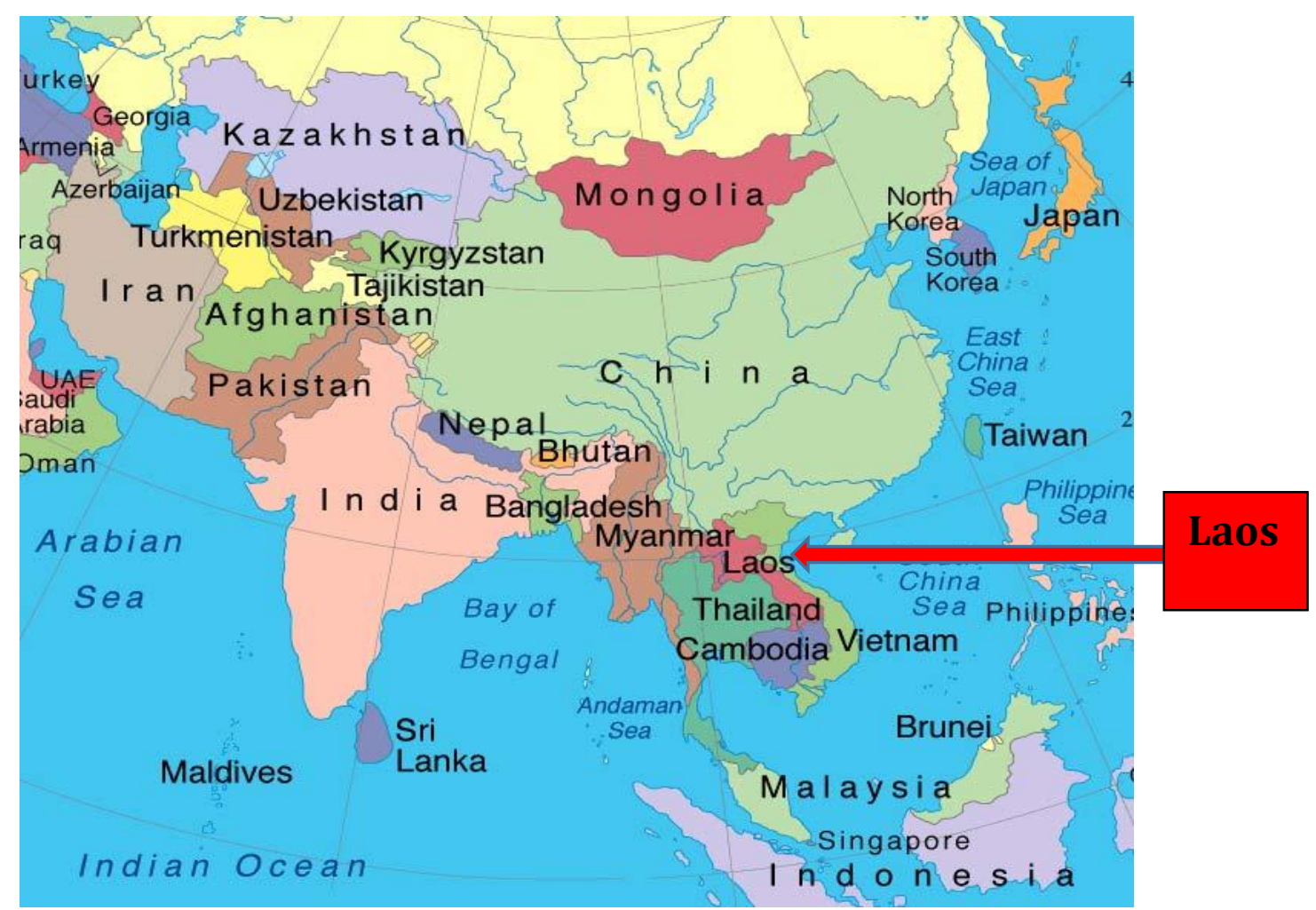

Source: http://www.archaeology.lk/http://www.archaeology.lk/wp content/uploads/ 2015/06/asia-map.jpg

Laos is one of the least developed countries (LDCs) in the world, ranked 139 among 187 countries and territories on the 2013 UN Human Development Index (UNDP, 2014). The Gross National Income (GNI) per capita was USD 4,351 in 2013 (ibid.). Laos has enjoyed a fast growing economy compared to other countries in South East Asia, with an average growth of $7.8 \%$ per annum over the last decade (World Bank, 2012). Nevertheless, the economic gap between urban and rural areas remains huge, particularly in remote areas which are home to the vast the majority of ethnic populations. The country is predominantly a rural society that depends on an agriculture-based economic structure with most people living in rural and remote areas. Poverty is particularly severe with a $28 \%$ poverty rate, according to a 2008 survey, and spread countrywide (ibid.). The poverty rate is undoubtedly higher in rural and remote areas due to poor access to economic opportunities. Livelihood and infrastructure development such as income generation activities, public healthcare and education services remain a formidable challenge for GoL. 
With an effort to achieve social and economic development and thereby graduate the country from the LDC list by 2020 (GoL, 2011), GoL has ratified several regional and international treaties and agreements in order to integrate itself into the global community. This includes the ratification of the MDGs in 2000 and World Trade Organisation membership package in 2013. At the regional level, Laos became a member of the Association of Southeast Asian Nations (ASEAN) ${ }^{3}$ in 1997. It is undeniable that this regional and global assimilation of Laos has influenced social and economic development of the country. For example, GoL has to upgrade compulsory education from primary to lower secondary level in order to align its education system with other ASEAN countries, and to reform its general education system to a 12-year system by adding one additional year in the lower secondary education as a result of EFA goals under MDG2 ratification (Phetsiriseng, 2009).

Laos is also one of the world's most ethnically diverse countries. It has 49 official ethnicities that can be grouped into four broad language families: Lao-Tai, Mon Khmer, Hmong-lu Mien, and Chine-Tibet (Fox, 2003) (see Table 4.1). Legally, those who are not Lao-Tai are described as an 'ethnic minority'. As Lao-Tai are ethnically and politically the largest group, the usage of Lao-Tai (officially called Lao) as the national language has been enforced in formal education, and no education texts for ethnic languages have been officially produced (Fox, 2003). Curriculum and teaching materials are only written in Lao-Tai, as a means to promote nationalism and assimilate ethnic minorities into Lao-Tai culture (Chithtalath, 2006; Fox, 2003).

Table 4.1: Population by Ethnicity and Age 0-16 Cohort

\begin{tabular}{|l|l|l|l|}
\hline $\begin{array}{l}\text { Ethno-Linguistic } \\
\text { Group }\end{array}$ & $\begin{array}{l}\text { Number of } \\
\text { Ethnic } \\
\text { Groups }\end{array}$ & $\begin{array}{l}\text { Percentage of } \\
\text { Total } \\
\text { Population }\end{array}$ & $\begin{array}{l}\text { Percentage of } \\
\text { Population } \\
\text { Aged 0-16 }\end{array}$ \\
\hline Lao-Tai & 8 & 64.9 & 59.8 \\
\hline Mon-Khmer & 32 & 22.6 & 25.1 \\
\hline Chine-Tibet & 7 & 2.8 & 3.0 \\
\hline Hmong-Iu Mien & 2 & 8.5 & 10.7 \\
\hline Other / No answer & & 1.2 & 1.5 \\
\hline
\end{tabular}

Source: National Census 2005, (MoES, 2008a)

\footnotetext{
${ }^{3}$ ASEAN was formed on 8 August 1967 by Indonesia, Malaysia, the Philippines, Singapore, and Thailand. To date (2015), there are 10 ASEAN member countries, since membership has expanded to include Brunei, Cambodia, Laos, Myanmar, and Vietnam.
} 


\subsubsection{Political Context}

After the collapse of the Kingdom of Laos in 1975, Lao PDR was established and has been ruled as a single-party state since then by the Lao People's Revolutionary Party (LPRP) (Inthaboualy, 2012; Phetsiriseng, 2009). The foundation of Lao PDR changed the political system from a monarchy to a social republic (Inthaboualy, 2012), and the promulgation of Lao constitution in 1991 recognises LPRP as the nucleus of the political system (Phetsiriseng, 2009). The Party is headed by a Politburo of the Central Committee who is the supreme authority in the country and is elected every five years through the Party Congress. The Politburo formulates all policies in virtually every aspect of public life. As the country is driven by a single state administration, political power remains centralised in the Politburo Central Committee. Those who hold key positions in the government are usually Politburo members who possess absolute decision making power under direction of the Central Committee. This includes the president and Vice-President, Prime Minister and Deputy Prime Ministers, as well as the President of the National Assembly (NA) and Defence Minister.

All executive power remains with the central government through top-down administration from national to provincial, district, and village levels respectively. The structure of political power has remained unchanged since the foundation of the nation in 1975, despite the fact that there has been a slow transition in Politburo membership from mainly military members to a younger and more reform-minded generation with higher education and technical expertise (Phommalangsy, 2013).

The country is divided into 18 provinces including Vientiane capital. According to the Population and Household Census 2010, there were 142 districts, 10,500 villages, and 953,000 households (Phetsiriseng, 2009). The head of the state is the President, who is also the General Secretary of the LPRP. The head of the government is Prime Minister. Provincial governors are usually members of the Party's Central Committee, the district governors are Party's Provincial Committee, and village chiefs are members of local Party units. 
Like other socialist countries, the Lao NA possesses legislative power, while the People's Court and the People's Prosecutors administer the law (Jönsson, 2000). The members of NA are elected every five years, directly by people from a list of permanent Party candidates. However, some independent candidates may also be elected in some cases and when the candidates have some connection to the Party. There are, albeit restricted to Party approved membership, viable mechanisms of executive oversight within the NA. There are effective hearings on the budget and budget execution statements, increasingly questions are asked about corruption, and the legislature has established a popular hotline for the public to express its opinions and seek answers from the government. It has vetoed executive legislative proposals, demanded more effective action against corruption, approved controversial and mega development projects, and delayed land concessions (World Bank, 2012).

In general, Laos has enjoyed peace and political stability over the last four decades under the leadership of the LPRP (Bird \& Hill, 2010). GoL has prioritised political stability as the first and foremost factor, underpinning social and economic development (Phetsiriseng, 2009). Accordingly, all social and economic development priorities must be grounded in a political aim and aligned with its political direction. Directed by political will, GoL is taking a development approach that ensures the rights of citizens to social and economic opportunities, while at the same time promoting national unity (ibid.). Any development initiatives that may lead to disunity of the nation (as perceived by the party) are normally considered politically sensitive and counterproductive for the country's prosperity as a whole.

\subsubsection{Culture and Religions}

Culture and religion form a crucial part of Lao society. Preservation of cultural identity is commonly cited in all national development agendas as a means to maintain national identity (Phetsiriseng, 2009). It is also worth noting that although Laos has historically been influenced by Vietnamese and Khmer (Cambodian) culture, it has the strongest cultural link with Thailand (Waby, 2006). This might be 
due to the fact that the vast majority of both Lao and Thai share the same religious belief - Theravada Buddhism - despite different economic and political paradigms. Laos is considered a conservative society and there are barriers set to prevent the perceived menace of 'bourgeois liberalism' from Thailand and the West (ibid.).

As mentioned earlier, Lao-Tai are the largest ethnic group in Laos inhabiting the lowland areas and most of them are Buddhist. Therefore, Buddhism is usually considered the national religion of Laos and citizens are expected to follow it if they want to assimilate to the national identity. The notion of 'national identity' has been unprecedentedly propagated across the country after the LPRP came into power in 1975 for the sake of political stability and it is argued to bring about development (Phetsiriseng, 2009). This propaganda has been carried out through the so-called national religion and education curriculum in order to "encourage national pride and a 'Lao' identity despite the fact that more than $30 \%$ of the country is made up of non-Lao speaking and non-Buddhist hill tribes with little connection to traditional Lao culture" (Waby, 2006, p.349).

Other ethnic minorities such as Hmong-lu Mien and Khmu practice animism which is often considered as superstition and has been discouraged by the government and wider society. In recent years, Christianity and Islam have emerged in Lao society despite close supervision by the state. The GoL has been vigilant on the expansion of these two religions, especially through the forms of religious missionaries, philanthropic organisations and NGOs, as some of these organisations at times acted against the government through educating people on politically sensitive issues such as democracy and human rights without the government's approval. GoL perceives this action as inappropriate and threatening to political stability as it is carried out in the absence of state authorities and outside formal mechanisms. Therefore, religion affiliated NGOs are rigorously scrutinised and monitored by the government, particularly by the Ministry of Foreign Affairs (MoFA), and the Ministry of Culture and Information. 


\subsubsection{Aid Dependency}

Laos relies heavily on foreign aid (DFAT, 2014). International funding and technical assistance, which have been channelled through Official Development Assistance (ODA), has contributed considerably to the country's economic growth in recent decades. The World Bank's World Development Report 2015 revealed that ODA to Laos was USD 421 million in 2013, and ODA per capita of Lao was about USD 62, which is twice as high than the low income country average of US\$ 31 (World Bank, 2015).

Among other sectors, education has received a massive influx of international funding, making it the most aid-dependent sector. For example, over the period 2011-2012, ODA to the education sector accounted for USD 44,653,116 which was higher than public expenditure on education (GoL, 2012). ODA came from different sources including bilateral governments, multilateral organisations and NGOs (see Figure 4.2). This high dependence began when GoL changed the direction of its external assistance, moving from dependence on the former Soviet Union after its collapse (Tekala \& Piattoeva, 2012) to opening the door for the support of Western capitalist countries and international agencies, while still retaining good relationships with Vietnam and China (Lam, 1997). 
Figure 4.2: ODA and NGOs Disbursement to the Education Sector in Laos in the fiscal year $2011-2012$

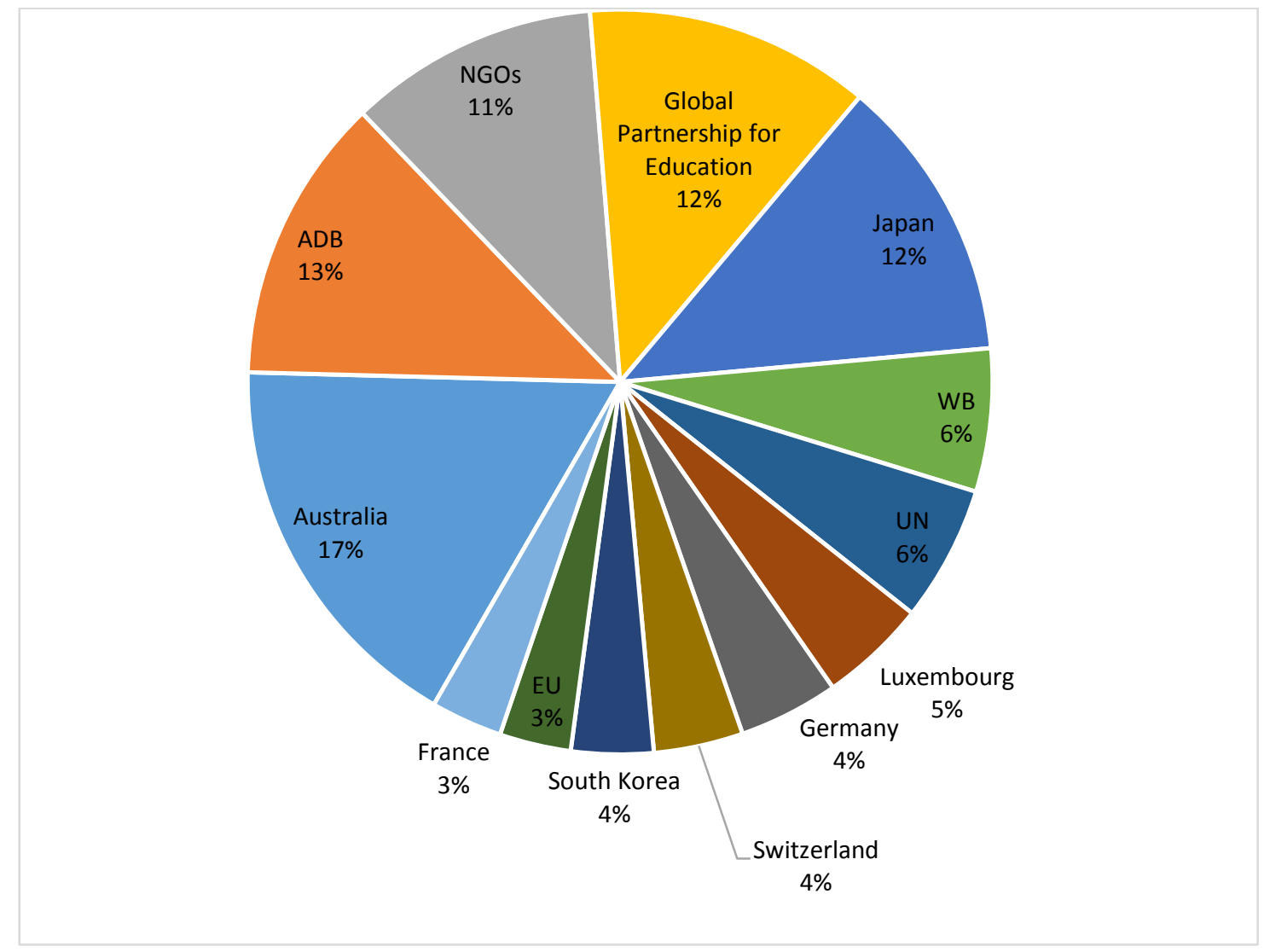

Source: Adapted from BEQUAL, (DFAT, 2014).

In recent years, especially after Laos acceded the Dakar Framework for Action in 2000, Development Partners (DPs) have provided both more technical and financial assistance to the education sector in Laos based on their funding priorities and intervention strategies (see Table 4.2). The Australian Department of Foreign Affairs and Trade (DFAT), European Union (EU) and the World Bank (WB) focus on supporting primary education. The German development cooperation, the Luxembourg government and Asian Development Bank (ADB) focus their aid on technical and vocational education and training. Other DPs including UN organisations and NGOs, have also supported education programs with an emphasis on primary education. Some emerging donors such as Vietnam, China, Korea, 
Thailand, and India have also provided assistance to education development in Laos (Tekala \& Piattoeva, 2012).

Table 4.2: Development Partners' Support to Lao Education Development

\begin{tabular}{|l|l|}
\hline Areas of Support & Development Partners \\
\hline Early Childhood Education & DFAT, UNICEF, WB, some NGOs \& NPAs \\
\hline Primary Education & DFAT, EU, WB, UNICEF, NGOs \& NPAs \\
\hline Lower Secondary Education & ADB, JICA, some NGOs \\
\hline Upper Secondary Education & ADB, China, Korea (KOICA), Vietnam \\
\hline $\begin{array}{l}\text { Technical and Vocational } \\
\text { Education and Training }\end{array}$ & ADB, Germany (GIZ), Luxembourg \\
\hline $\begin{array}{l}\text { Higher Education } \\
\text { Teacher Education }\end{array}$ & $\begin{array}{l}\text { DFAT, China, Vietnam, JICA, ADB, France, Thailand, } \\
\text { Switzerland }\end{array}$ \\
\hline $\begin{array}{l}\text { Literacy and Non-Formal } \\
\text { Education }\end{array}$ & WB, DFAT, UNESCO \\
\hline
\end{tabular}

Source: Adapted from BEQUAL, (DFAT, 2014).

It should also be repeated that primary education is the most aid-dependent level among all levels in Lao education. As noted by Kim \& Jeong, (2013), "Laos relies almost entirely on external funding for primary education" (Kim \& Jeong, 2013, p.174). Despite the fact that international funding spreads over all levels of the education sector, the biggest portion goes to primary education. For example, during the period in which this research was conducted (2015), DFAT was funding the largest ever- primary education programme called the Basic Education Quality and Access in Laos (BEQUAL) programme with a budget of more than 85 million AUD over a 10 year period starting in 2015 (DFAT, 2014). NGOs in particular have been most interested in funding primary education, especially to improve the access and quality of Lao primary education through school building, teacher training, textbook and material provision, school management support, and other capacity development activities.

Phraxayavong (2009) claims that it is undeniable that aid has created heavy dependence through which donor countries have exerted their influence over Laos' 
social and economic development. In a country like Laos that has been dependent on foreign aid for more than half a century, Phraxayavong, (2009) asserts that donor nations have exercised their development and political agendas through the aid process. He notes, 'dependency is usually accompanied by external influence as aid donations tend to be self-interested, and the exertion of influence is therefore unavoidable' (Phraxayavong, 2009, p.18). He also posits that ODA, especially in the form of loans, not only has failed to bring about a required level of change but also has created a "dependency trap", which allows donors leverage into Lao policy (ibid.).

Over the past decades the attitude of DPs in Laos seems to have moved from 'donorship' to partnership agreements as a consequence of the adoption of Vientiane Declaration on Aid Effectiveness (VD) in 2006 (Noonan et al., 2013). In response to low effectiveness and consequent criticism, a more coordinated approach to aid has been practiced since then in Laos. This shift in aid coordination has been marked by the introduction of Sector-wide Approach (SWAp) adapted to the Lao context (Phommalangsy, 2013). SWAp has been a political tool that requires DPs to improve harmonisation and alignment with government policies, and better modes of accountability (ibid.). Capacity development was supported by Swedish aid from 2002 to 2005 to assist GoL in putting SWAp in place (Sida, 2004). As a result, the harmonisation agenda forms a central part of the international aid discourse in Laos, and DPs try, and are expected to try, to align their assistance with the needs and priorities of the country.

\subsubsection{Aid from NGOs}

NGOs' aid to Laos significantly increased in 1986 after the adoption of the New Economic Mechanism through which the country opened the door to foreign assistance (ADB, 2011). Despite the unavailability of most recent data on financial support that NGOs have provided to development in Laos, it is highly possible that NGOs' financial contribution to development in Laos has continually increased since GoL started to accept assistance from the West in 1986. For example, financial aid from the NGO community increased more than ten times from USD 1.3 million in 1986 to more than USD 16 million in 1996 (Riska, 2008). More recently, in the fiscal 
year 2006 - 2007, NGOs' assistance accounted for USD 16.47 million (or 3.8\%) out of the total $\$ 432.76$ million foreign aid flows into Laos (ADB, 2011). In the fiscal year 2007-2008, this figure rose to USD 17.88 million (or 4.3\%) out of the total USD 413.44 million foreign aid (ADB, 2011). Most recently, according to the Foreign Aid Implementation Report of the fiscal year 2011 - 2012 of GoL, NGOs' financial aid to Laos in 2010 - 2011 accounted for USD 36.428 million equivalent to $6 \%$ of the total ODA to Laos (GoL, 2012). Although NGOs' assistance to Laos may not be as large as assistance from bilateral or multilateral sources such as WB, ADB, DFAT and EU, the figures reflect that the share of development funding brought by NGOs to the Laos has increased over the past few decades and is on the high side for the region (ADB, 2011).

There are about 170 NGOs operating in Laos, of which 78 have a representative office in the country (LNTV, 2014). NGOs' interventions in Laos range from humanitarian assistance to human resource development, and have been officially recognised by the GoL and wider DPs, especially for their capacity in reaching poor and vulnerable populations in the remote areas with efficient and effective approaches (Riska, 2008). In recent years, NGOs have slightly shifted their role from humanitarian and development interventions to policy advocacy. They have started to manage to influence government policy, particularly through the different Sector Working Groups and Round Table Meeting Process (ADB, 2011).

In relation to education, 37 NGOs have been running 68 thematic education projects across the country (INGO Network, 2015). NGOs' annual financial assistance to education development in Laos as of 2012 accounted for USD 12.04 million (DFAT, 2014). Their projects focus on 12 education subsectors, including school building and facility construction, curriculum development, formal education, education governance, inclusive education, non-formal education, peer education training, risk behaviour awareness and education, road safety awareness and education, teaching material provision, teacher training, and vocational training (INGO Network, 2015). It should be noted here again that although education NGOs work in different projects in different parts of Laos, their interventions mainly target primary education to assist GoL to achieve EFA goals by 2015. 


\subsection{The Context of Lao Education}

The Government's policy and strategy documents recognise that it is crucial to improve the national education system in order to foster social and economic development (GoL, 2011). Providing satisfactory levels of education is construed as the prerequisite for moving out of poverty and vulnerability, especially from the cycle of inter-generational poverty (MoES, 2000). The GoL's commitment to providing education for its citizens has been reflected in the national constitution and education law that all Lao children regardless of their gender, ethnicity and social and economic status have a right to education (MoES, 2008a).

\subsubsection{National Education System}

The Lao education system consists of five levels. The first level is the pre-primary level or early childhood education. It includes crèche and kindergarten schools for 3-5 year olds. This level is considered a crucial step, particularly for children from ethnic minorities who need more language preparation in order to ensure smooth transition to primary schools (which are taught in Lao-Tai, a point I return to). The expansion of this program has been relatively limited, especially in rural areas, due to a lack of public funding, inadequate DPs' interest, and limited awareness of early childhood development (MoES, 2008a). As a result, only $24.5 \%$ of children aged between 3-5 years old are enrolled in this level (MoES, 2011b).

The second level is general education, consisting of primary, lower secondary and upper secondary. As a result of the revised education law, the National Education System Reform Strategy (NESRS) and the Education Sector Development Framework (ESDF), the structure of the school system was transformed from an 11year system $(5+3+3)$ to a 12 -year system $(5+4+3)$ during the 2009-10 school year (Phetsiriseng, 2009). Therefore, the school system now consists of five years of compulsory primary, four years of lower secondary and three years of upper secondary.

The third level is teacher education, which has led to a sharper focus on teacher professional development (Phommalangsy, 2013). There are eight Teacher 
Education Institutes, three specialised colleges (fine arts, physical education and monk education), three university faculties of education, the teacher education administration development centre, the vocational education development centre, and the polytechnic college. All of these institutions directly deal with teachers' professional development.

The fourth level is Technical and Vocational Education and Training (TVET), which provides post-secondary education. Over the past decades, here has been a proliferation of private post-secondary, non-tertiary education and training institutions which provide one, two or three year syllabi with a wide range of specific courses. However, the most popular programs have been English, business administration, computer science, and more recently hospitality and tourism (Phommalangsy, 2013).

The final and highest level is tertiary education, which normally offers a three-year higher diploma program in educational institutions or a degree program of four years or more in universities. More recently, there are some faculties within the national university of Laos and some large private colleges that offer a Master's degree program in collaboration with neighbouring countries, especially Vietnam and Thailand. However, this scheme is not really popular among Lao students who would rather opt to pursue their postgraduate studies overseas under scholarship programmes and their own budget (Phommalangsy, 2013). A PhD programme is not currently offered in Laos, and thus is only undertaken in foreign countries for the same reason as with the Master degree.

\subsubsection{Education Management and Administration}

The education law (developed in 2008) legitimises GoL as having absolute control over the administration of education, and confers on MoES full autonomy in management and administration (MoES, 2008b). MoES is in charge of formal and 
non-formal education at all levels, and for both public and private ${ }^{4}$ education. Nonetheless, the decentralisation initiative under the education law that commenced in 2000 has transferred education management from central to local levels - from MoES to Provincial Education and Sports Services (PESS) and from PESS to District Education and Sports Bureau (DESB) respectively, as shown in Figure 4.4) (MoES, 2000). This shift is also aimed at enhancing shared accountability among different levels of education administrators (MoES, 2008b).

In response to the 1991 constitution, provinces are allowed to develop their annual plans and budgets to submit to NA for consideration and approval (MoES, 2008c). At the same, the provinces are also responsible for collecting revenue from all provincial sectors as targeted by NA. The decentralised yet unified fiscal structure is based on an 'upward revenue sharing' system in which most revenue is collected by the provinces (ibid.). The provinces that are able to collect more revenue and have budget surpluses compared to the targets set by NA are required to share those surpluses with the central level and other provinces whose revenues are under the target. At the provincial level, governors ${ }^{5}$ play an extremely important role in public financial management given that the plans and budgeting are developed by different provincial departments and districts while actual budgets are allocated by the central government. The governors have autonomy to allocate, authorise and revise both recurrent and capital implementations across sectors within the provinces and districts based on their judgement. Therefore, the implementation of education budgets and spending is dependent on governors, as well as on the provincial financial situation. The provinces with governors who perceive education to be a priority, and with sufficient revenue, can implement education development plans more easily and effectively, while others have to rely more on aid from DPs (Phommalangsy, 2013).

\footnotetext{
4 Private education is under the general oversight of MoES relevant departments. For example, private education at primary level is under supervision and oversight of the Department of Pre and Primary Education; private higher education is supervised and overseen by the Department of Higher Education in the Ministry. MoES is also responsible for quality assurance of private education, especially through the Ministry Center for Inspection and Quality Assurance.

${ }^{5}$ Governors at the provincial level in Lao context are like mayors in New Zealand and many Western countries. They are the top authorities in provincial governments.
} 


\subsubsection{Current Situation of Lao Education}

Despite the fact that significant progress has been made in education reform, there are several fundamental weaknesses to be addressed in Lao education. The fact that more than $80 \%$ of the population live in poverty in rural areas has undermined the country's capacity to provide education for all, and endangers the achievement of MDG2. The negative impact of poverty on dropout rates and transition rates are significant at all levels of general education. According to the most recent MoES report (MoES, 2011b), the primary enrolment rate has increased to around $94 \%$ in 2010-2011 of the age cohort, but repetition and dropout rates remain high, resulting in only $64 \%$ of students completing the full five years of primary schooling. About $30 \%$ of all primary schools do not offer all 5 grades of primary education with many schools being staffed by only 1 or 2 teachers (ibid.).

Participation in secondary education is low, with gross enrolment rates of only $62.9 \%$ at lower secondary schools and $33.4 \%$ at upper secondary level (MoES, 2013b). Transition rates from lower secondary school to upper secondary school are extremely low in rural areas. There are significant geographic, ethnic, gender, and wealth disparities in the distribution of education services. Studies (UNESCO, 2015; UNICEF, 2010) frequently note that girls from ethnic populations are the most disadvantaged in terms of student retention rates. Poverty affects the affordability of education through out-of-pocket expenses and opportunity costs related to the socio-economic context and geographical location of each family. Educational quality as measured by examination results is also significantly lower in rural areas (MoES, 2008a). Poorer settlements in rural areas perform worse than the poor in urban areas. In many rural areas, there are simply no schools, while those that have schools typically lack proper facilities and hygienic supplies in many schools including toilets, sanitation system and clean drinking water (MoES, 2011b).

It is also noteworthy that a feature of education in Laos is that the quality of teaching influences parental decisions about whether to keep their children in school or not (MoES, 2008a). Teachers, particularly in rural areas, are usually inadequately prepared, have few materials of instruction, lack skills in producing and using 
teaching materials, and are poorly and often infrequently paid. In the absence of adequate central support, many local areas, often with support from NGOs but with minimal guidance from central level, are making considerable sacrifices to maintain and repair school buildings, provide housing for teachers, and assist students with specific needs (UNICEF, 2010). In response to these issues, teachers have been trained in teaching methodology including child-centred teaching, multi-grade teaching, and material production and utilisation.

Despite the fact that MoES has made a significant move to improve the management of education at the central level as well as at provincial and district levels, there are, as the EFA Mid-Decade Assessment identified, still a number of challenges to be addressed (MoES, 2008a). These include a need to strengthen the frequency and quality of monitoring and support for schools by the DESB as well as the PESS to respond to the actual need at school level. There is a significant lack of human resource as well as the necessary knowledge and skills to provide quality support to schools. In addition, there are significant budget constraints for monitoring, support and supervision. The separation of the pedagogical support function from the traditional supervisory function at district level was an attempt to address this problem. However, this was often not accompanied by the creation of any new positions or recruitment of new staff with the appropriate skills to perform this role (ibid.).

Another key challenge is related to the education management information system (EMIS). A MoES taskforce, funded by WB, conducted an assessment of EMIS in 2006 and identified a number of areas that required closer attention, including staff capacity at all levels, incomplete data, duplication of DP-funded initiatives which focused on specific aspects within the system without taking a more holistic approach (MoES, 2008a). While initiatives undertaken since 2006 have gone some way to resolving these problems, it is obvious that there is more work to be done particularly at school as well as district level, where school principals and DESB staff are in need of training on data collection, management and analysis. More importantly, there is a need to change the way education administrators perceive the use of EMIS from previously as a set of data to meet information requirements 
of higher level to actually using data at school and district levels for planning purposes (ibid.).

As discussed earlier, a limited budget hinders effective education management and administration at all levels. National budget allocations to the education sector have been very low (11-12\%) over the period of fiscal years 2008-09 to 2011-12 (MoES, $2013 b)$. Despite the fact that a significant increase to $18 \%$ was approved by the NA for the fiscal year 2012-13 (ibid.), the actual implementation and expenditure still depend very much on provincial authorities, as discussed in the sub-section above, and they are not adequate given the need for investment in the education sector if Laos is to realise its ambitious education development goals. Although the budget allocated to education sector has increased, it remains inadequate to respond to poor education infrastructure (particularly in rural areas), low levels of recurrent expenditure, and very low teacher salaries. All these factors contribute to aid dependency in GoL relies on DPs for financial assistance.

\subsubsection{Primary Education in Focus}

Although it has been discussed in the previous chapters and in this one, it is worth reiterating that primary education is recognised as the most important level in Laos (MoES, 2011a). The Prime Minister Decree of Order on compulsory education in Laos states that "primary education is the first level of general education, and includes 5 years of schooling. It establishes the basic educational level that should be attained by all Lao citizens" (Phetsiriseng, 2009, p.269). The services in primary schooling, as stipulated in the education law developed in 2008 , are to be free of charge (MoES, 2008b). There have been different interpretations of this clause leading to different practices in different areas. While many school administrators interpret the idea of 'free of charge' as 'free of fee or tuition' and continue to request the so-called cash contribution for school maintenance from students, DPs (especially NGOs) perceive this practice as inappropriate and conflicting with the education law. In response to this discrepancy, during the most recent education law revision in June 2015 DPs expressed their grave concerns about the issue through a joint statement demanding the government make it crystal clear in the 
law that primary education should be absolutely free before the NA approves it (IEDWG 2015).

As discussed earlier, DPs (and particularly NGOs) target their interventions mainly towards primary education in order to support GoL to attain their EFA goals which means ensuring all Lao children complete primary school by 2015 (MoES, 2011b). Therefore, the largest portion of education investment by DPs has gone to primary education (see Figure 4.3). It is also reasonable to comment that although challenges are associated with all levels of Lao education, they have been most significantly addressed in primary education. A survival rate to grade 5 of $64 \%$ (ibid.) indicates that there are significant problems related to the quality and relevance of primary education in Laos, and this figure is undoubtedly higher in areas which are more remote and where there are higher concentrations of children from ethnic groups who do not have Lao as their mother tongue.

The figures related to teacher qualifications at primary level give a strong indication of the levels of quality and relevance of education at this level. Nearly half of primary school teachers are below the required level of qualification, either having received no training at all (11.6\%) or limited training (35\%) (MoES, 2008a). There are also disparities between qualification levels of teachers in more remote areas compared to less remote areas, which results in children in more remote areas receiving education of lower quality (MoES, 2011b).

Upgrading the teaching profession requires pre-service teacher6 training candidates to complete eleven years of schooling (graduation from upper secondary level) and undertake two years of specific teacher training. While this undoubtedly raises the quality and prestige of the profession, candidates from poorer districts, where completion rates at upper secondary level are low, naturally find it difficult to meet entry requirements for pre-service training.

\footnotetext{
${ }^{6}$ Pre-service teachers are those who wait for the government quota to become in-service teachers and then become permanent government officials and receive salaries from the public budget. The waiting time varies depending on locations but normally between 6 months and 2 years.
} 
In-service training offers important opportunities for teachers to upgrade their skills. Particularly valued by teachers are courses that upgrade the basic teaching qualification, enabling higher pay and more opportunities for promotion (MoES, 2008a).

MoES recognises teachers' right to continuous professional development and has worked with many donors and NGOs to develop training packages that are comprehensive, structured yet flexible in-service programme that can be applied nationwide (MoES, 2011b). The training programmes include child-centred teaching methodology, production and use of teaching and learning materials.

Under the School of Quality initiative, MoES has also promoted school and community collaboration as a key element in quality improvement. Community involvement in education has typically been limited in the past with the focus of village education development committees being mainly on raising money and the repair of school buildings (MoES, 2011b). MoES policy requires local committees to take a stronger role in managing the school, and monitoring access and quality. Together with DPs, MoES has also introduced a more holistic approach to working at school level to promote a 'school-community' model of school development with an aim to improve school facilities as well as capacity of school principals, teachers and village education development committees. 
Figure 4.3: Average Education Investment Share by Sub-Sector (2011 - 2015)

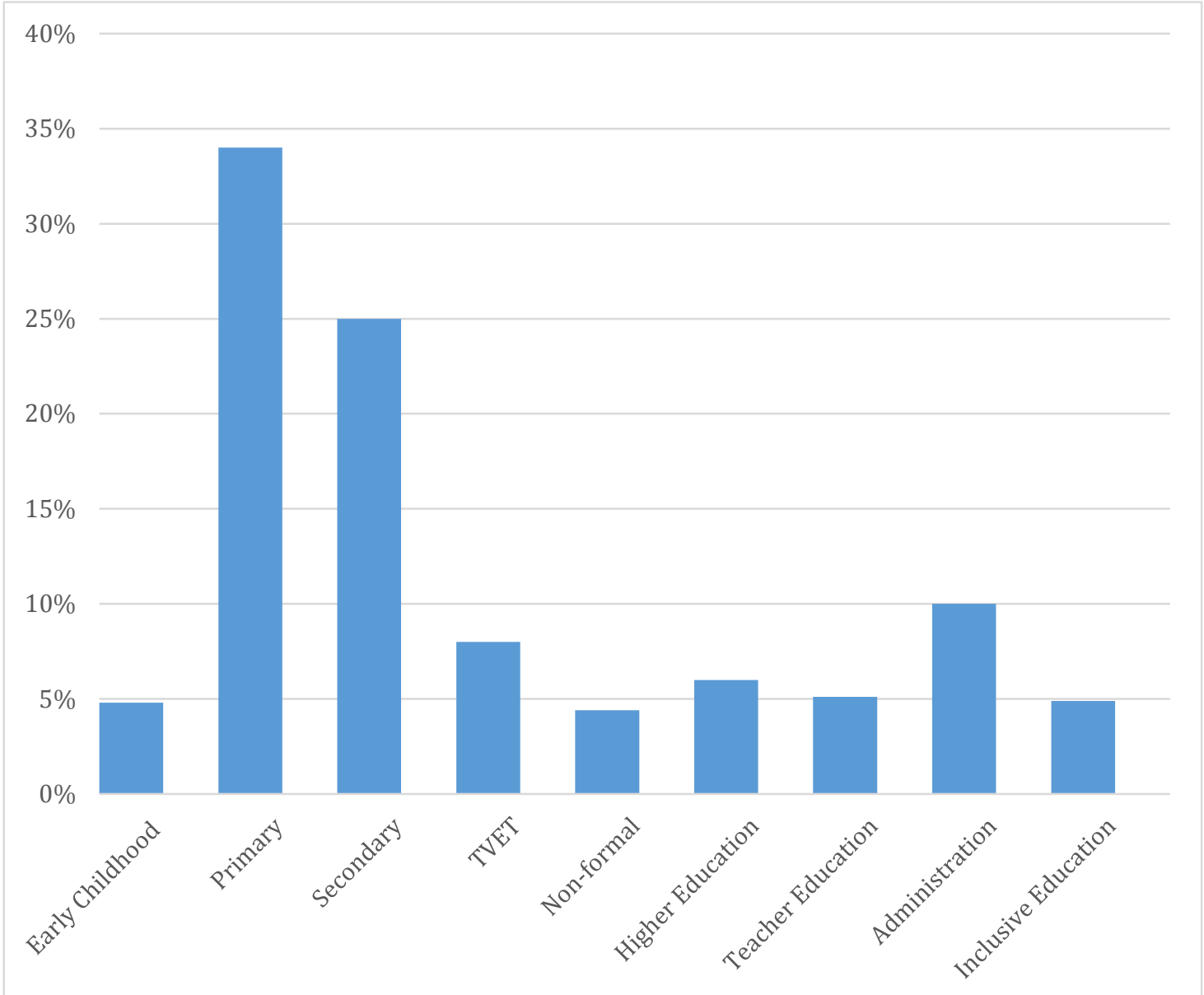

Source: Education Sector Development Plan 2011 - 2015, (MoES, 2011a)

\subsection{Summary}

In this chapter, I have discussed the social, economic, political and education contexts of Laos where this research is undertaken. Laos is a small, land-locked and least-developed country in South-East Asia and one of the most aid-dependent countries in the world. Among many others, the education sector, and specifically primary education, relies most heavily on international aid, making it most vulnerable to international influence.

However, the political nature of Laos has legitimised the absolute control of the state over the public sphere including social, cultural and religious practices, binding them all to an idea of a singular 'national identity'. While this political construction has succeeded in national unification (Bird \& Hill, 2010; Phetsiriseng, 2009), it has 
also posed some challenges for ethnic groups to assimilate to the vast majority of Lao population both socially and educationally. In an effort to maintain national identity and public security, the government has been particularly vigilant about international interventions, especially those associated with a hidden religious agenda as well as other politically sensitive issues as perceived by GoL and more importantly LPRP (including democracy and human rights).

Due to the need for international assistance, particularly for primary education development that faces a number of challenge in terms of access and quality, GoL continues to seek assistance from DPs while retaining its strong political direction. The fact that GoL holds political commitments beyond all national development agendas has inevitably shaped the extent to which NGOs influence primary education policy in Laos. This will be discussed in more detail in the following chapter. 


\section{Chapter 5: The Role of NGOs in Laos and their Influence on Primary Education Policy}

\subsection{Introduction}

This chapter examines the role of NGOs in Laos and the extent to which NGOs influence Lao primary education policy. It addresses research questions 1, 2 and 3 (see section 1.5 in Chapter 1). Discussion in this chapter is based on fieldwork findings from semi-structured interviews, participant observation and document review. The chapter is divided into four main sections. The first analyses the roles of NGOs in the education sector as perceived by NGOs themselves, GoL, bilateral and multilateral donors as well as other DPs. The second section investigates the differences between NGOs and major donors in relation to primary education policy. The third examines the extent to which NGOs can actually influence primary education policy in Laos. Finally, the fourth section discusses NGOs' influence on Lao primary education policy development in terms of the politics of participation.

\subsection{The role of NGOs in Lao's Socio-Political Context}

The operation of NGOs in Laos is governed by the Prime Minister's Decree 13 on INGOs and is closely supervised by Ministry of Foreign Affairs (MoFA). Decree 13 was revised from the previous one developed in 1998, and has been enforced since 2010. It prescribes the rules and regulations that govern NGOs' operations in Laos with an aim to facilitate their effective operation and enable them to contribute to the implementation of the government's poverty eradication and socio-economic development plan (PMO, 2010). The Decree stipulates that NGOs' primary role, if not the only legal role, is to provide humanitarian aid and development assistance in the country. Although it is not explicitly mentioned in the Decree, it is widely understood that providing humanitarian and development assistance means filling the gaps and reinforcing government efforts in achieving MDGs in general, such as Education for All (EFA) goals, by 2015 (Informant GOV3). As a senior government official highlighted, any NGOs' activities that contradict Decree 13, which prescribes the role of NGOs as 'providers' of development assistance and humanitarian aid, are likely to be disapproved by the government (Informant GOV4). The fact that NGOs' 
role is officially confined to that of 'service provider' in Lao makes them more appendages of the state than any other role (Roberts, 2004).

The Decree outlines the requirements for setting up an NGO, including the application for an operating permit, provision of a project proposal with detailed project activities, and budget plans before a Memorandum of Understanding (MoU) can be signed with appropriate government departments and ministries. Most importantly, any NGO project "should be in line with the plan approved and priority areas designated by the Government...and the project should have a clear objective, concrete activities and be in line with GoL's development strategy" (PMO, 2010, p.5). In order to ensure that NGOs are carrying out their activities in accordance with the government strategy, the implementing departments and ministries are assigned to work with, and closely monitor, the operation of NGOs and communicate any issues to MoFA, especially those deemed irregular and threatening to political security. In such cases, MoFA may then demand a suspension or close-down of such NGOs (Roberts, 2014). In some cases, and particularly in larger projects, MoFA are included in the quarterly, semi-annual and annual monitoring visits to the project sites in order to monitor progress and compliance of NGO projects. NGOs are required to submit annual reports to their counterpart ministries and a final report to the Department of International Organisations in MoFA on completion of their projects.

Due to state legitimacy to supervise NGOs' operations, and despite the emergence of nominally independent NGOs in Laos, most NGOs operate in uncontroversial and/or apolitical areas such education and health, supporting the government in their priority areas such as MDGs (Creak, 2014). Although they are nominally independent, NGOs maintain, and are often required to maintain, healthy relationships with the government if they are to operate smoothly and effectively. Most participants highlighted that maintaining relationships and partnership with the government was crucial in the Lao context (Informants DU3, ES4, NGO7, NGO9). NGOs that fail to maintain effective relationships with the government are perceived to be taking risks with their work. In more practical terms, NGOs are expected to 
comply with, rather than confront, government policy. In this regard, Informant NGO7 also commented that:

“While some NGOs are quite strong and confronting, and work very proactively to achieve their goals, to some extent they will have damage because of that and will take a risk for their organisation. We have to maintain relationships, otherwise we cannot work together in the context of Laos" (Informant NGO7).

Maintaining good relationships with the government is also NGOs' entry point for policy advocacy in Laos:

"If you want to change something, you also need to maintain good relationships. If you don't have good relationship with the government, your chance to have the policy dialogues is none, it is zero" (Informant DU3).

Batley (2011, p.3) also notes that "in all cases, the NGOs find ways to ensure a cooperative rather than conflictual relationship with government to pursue their goals. Strategies vary according to the strength of the national policy context and the formality of the relationship". While NGOs in Laos are committed to playing their role as catalysts, they are often criticised for overemphasising relationship development with the government. A senior staff member of an NGO explained that "in the context of Laos, there are often contradictions between pressing for change and working with the government. I would, though, argue that if you want to press for change you need to do so with the government, not against the government" (Informant NG09). This indicates that NGOs are very aware of the Lao context and have learned to adjust their working strategies in order not to confront the government while trying to advocate for change within the government system. It was not worthwhile for NGOs to risk the lives of their organisation and staff just for the sake of confronting the government, with whom they could find a better approach to work for the benefit of communities (Informant NGO7).

Despite the fact that most NGOs are aware of their lack of autonomy in the Lao context, they often face uncertainty about their role, which has implications for their ability to mobilise funds for their projects (ADB, 2011). While donor countries 
expect NGOs to create change for communities through policy advocacy, NGOs are often reluctant and restricted in performing such a role effectively and independently. Moreover, the fact that NGOs' assistance is welcome, but only when it is consistent with the government policy and under control of the government, has sometimes confused NGOs about their role and mandate (ADB, 2011; Frohofer, 2014). While many NGOs have strong technical relationships with ministry departments, provincial and district governments, there is still a level of wariness about central government. This is due to the fact that the process of decision-making within the government system, particularly for politically sensitive issues, remains 'centralised' despite nominal promulgation of so-called 'decentralisation' (Creak, 2014).

A senior NGO representative also commented that "in the centralised democratic structure, it's difficult to influence policy, because the policy is set...people are still not comfortable talking about the reality because of political pressure both internally and externally" (Informant NGO2). Specifically in regards to Lao education, the same participant further noted that policy was centralised and policy agendas were disseminated from central government to provincial and district governments, who were expected to implement what had been developed at the national level (Informant NGO2). The fact that inputs from local governments are not really taken into account was also due to limited capacity of the local governments that constrains their contribution to policy development at the central level (Informants NGO2, NGO7, NGO9). This lack of input indicates that NGOs' effort to advocate change in primary education policy through working with local governments tends to be unsuccessful, because local governments are not capable of persuading the central government.

NGOs are sometimes viewed as donors, while at other times they are viewed as civil society actors (ADB, 2011), activists, or even government opposition, as suggested by their name: 'non-governmental' organisations (Kunze, 2012). In regards to the connotation of the term 'NGOs', a senior government official I talked with also tried to avoid using the term 'NGOs' to deflate the implication of NGOs as being government opponents. They asserted that "in fact, the government does not call 
those organisations 'NGOs' anymore. We call them DPs as an effort to avoid discrimination and to harmonise all donors, NGOs and Non-Profit Associations (NPAs) into a concerted effort for development in Laos" (Informant GOV2). Thus, NGOs' position in Laos is quite unique. They are somewhere between donors and civil society organisations. They are 'small' donors who reinforce government priorities and sometimes attempt to advocate policy change under state control. Subsequently, most NGOs tend to see themselves as 'development NGOs' rather than 'advocacy NGOs' (ADB, 2011; Korten, 1987).

Those NGOs who are perceived to focus more on policy advocacy than reinforcing government efforts are often bound to more vigorous scrutiny and delays in project approval (ADB, 2011; Frohofer, 2014). In the Lao context, consistent communication and diplomatic skills play a crucial role that NGOs have to learn when discussing sensitive issues with their government counterparts (Informants DU2, GOV3). Most participants acknowledged that diplomatic communication is critical for working with GoL. For instance, a participant from a donor agency asserted that "in the Lao context, you need to be diplomatic when discussing with government counterparts. It helps a lot in an effort to avoid confronting any possible issues that you don't really agree with" (Informant DU2).

NGOs are also becoming more aware of the repercussions if they raise sensitive issues with the government in the face of increasing tensions, mistrust and suspicions between GoL and NGOs. As a participant who has worked for education development in Laos for many years noted, "there are suspicions of NGOs and NPAs within the government, and so the government is a bit wary of taking influence from NGOs" (Informant ES1). The fact that NGOs recently criticised the government quite severely and raised issues sensitive to the government has created a barrier to NGOs' engagement in policy development (Informant ES1). There was perhaps no more remarkable event than the Asian Europe People Forum 9 (AEPF9) and its aftermath, in which NGOs and other civil society organisations criticised GoL on human rights issues, land compensation for communities affected by government development projects and other sensitive issues (Creak, 2014; Frohofer, 2014; Kepa, 2013). 
The $9^{\text {th }}$ Asia Europe People Forum (AEPF9), a state-sanctioned civil society meeting preceded the Asia -Europe Meeting (ASEM), held on 16 th $19^{\text {th }}$ October 2012 in Vientiane. It was said to be the most open forum through which NGOs and other civil society organisations could discuss a wide range of policy issues, including those sensitive to GoL (Creak, 2014; Frohofer, 2014; Kepa, 2013). However, there were two incidents that many people understood as marking the aftermath of this forum. The first incident was that an NGO country director was expelled from Laos, because she criticised GoL on human right issues by circulating a critical personal letter to DPs. The second incident was the mysterious disappearance of a highly respected director of a civil society organisation in late 2012. The two directors were among AEPF9 co-organisers.

The aftermath of the AEPF9 has not only tightened state control over NGOs' operations, but also severely undermined relationships between NGOs and GoL. A senior NGO representative also posited that "the relationships between NGOs and the Lao government have been dramatically shaken, driven backwards and are much worse than before the AEPF9 event. There are unprecedented tensions and mistrust between the government and NGOs nowadays. Everybody is just wary, nervous and confused about anything" (Informant, NG08). This indicates that currently, NGOs are closely monitored by GoL which has also made an effort to minimise NGOs' influence at policy level (Informant ES1; Kepa, 2013).

This does not mean, however, that NGOs have relinquished their attempt to drive policy change. Their deliberation about possibilities to put more sensitive issues on the agenda with GoL is persistent, but they try to 'play it safe' and act in a more collective approach through NGO networks and consortiums (Delnoye, 2010). In addition to the country's unique socio-political context, there are a number of reasons why NGOs in Laos are required to take precautions in taking challenging standpoints vis-à-vis government policy. Among other factors, Lundmark and Malmberg (2008) conclude that the cautiousness of NGOs is partly attributed to the fact that major donors and the international community are not adequately backing up NGOs' position on more daring and challenging agenda setting in dialogue with GoL. This conclusion is likely to be accurate given that donors themselves tend to 
focus more on maintaining relationships with the government through avoiding any confrontation that might bring harm to their organisation (Informants DU2, DU3, ES2, NGO2).

At times, however, based on my observation in a Donors-NGOs meeting organised in June 2015, influential donors seemed to show strong commitment to speaking on NGOs' behalf in policy negotiation with GoL. Although both donors and NGOs shared equal concerns about free education at the primary level, the latter were more reluctant to take a lead in reemphasising this with the government, as they felt the former were more able to influence the government and less vulnerable should the government take their concern as opposition (IEDWG, 2015). It seemed that NGOs were more critical than donors about the revised education law in this meeting despite the fact that they generally take a cautious role in policy discussions (ibid.). Nevertheless, at the end of the day, "soft' diplomacy seems to be the mutually accepted limit and the most appropriate route" for all stakeholders (Delnoye, 2010, p.34).

A participant who has worked in education development in Laos for several years highlighted the significance of soft diplomacy in working with GoL:

"The problem with the government is you can't do a piece of research on teacher quality and come back and say: 72\% of teachers cannot do their job...that's confronting for the ministry. They're not gonna like that. You have to think of a way...internally, you go wow, that's very bad! But, when you go to the ministry you have to put it in a different way: $72 \%$ of teachers need the support to appropriately teach children or to implement the curriculum or whatever. You have to make it softly, softly. If you can get the message across, if you can keep the evidence but show it in a way that the ministry doesn't find threatening, directly threatening or insulting or make them lose face then I think you can influence the discussion in a way that there is an issue here, this is what we found, we think this is a way to address it, let's have a dialogue about that...that's a good approach, that works" (Informant NGO3) 
One of the more positive aspects of this situation is that several NGOs have gained valuable experience over many years working in Laos' unique social and political context, especially in participatory community development (ADB, 2011), as discussed further in Section 5.5. Staff members in some of the more established NGOs have acquired linguistic and cultural resources and familiarised themselves with working procedures in Laos, leading to a more effective coordination with government officials.

\subsection{Differences between NGOs and Major Donors at the Policy Level}

Despite the fact that NGOs are sometimes considered 'small' donors, their roles are quite distinct from those of 'major' donors such as multilateral, bilateral donors and development banks when it comes to policy influence. Major donors engage more than NGOs engagement in sensitive issues such as human rights and democracy (Delnoye, 2010). For instance, the Swedish International Development Agency (SIDA) has engaged in dialogue about human rights in Laos with GoL for more than ten years without worrying that their organisation will be ordered to shut down (ibid.). NGOs, on the contrary, take very cautious steps in their dialogues with the government on sensitive issues, as they feel vulnerable to intimidation, suspension, close-down and/or expulsion (Delnoye, 2010; Informants ES1, NG08 ).

In the education sector, the role of donors and NGOs are quite distinct, especially at the policy level. Most interviewees in this research asserted that there is a big difference between NGOs and major donors such as the Australian Department of Foreign Affairs and Trade (DFAT), Asian Development Bank (ADB), the World Bank (WB), Japanese International Cooperation Agency (JICA) and the European Union (EU). These big donors are understood to be influential in framing education policy due to their substantial financial support to education development in Laos (Phommalangsy, 2013). Some UN agencies such as UNESCO and UNICEF also have a certain degree of influence due to their considerable technical support. During the time this research was conducted, DFAT had been investing in the Basic Education Quality and Access in Laos (BEQUAL) programme with a budget of more than AUD 85 million, ranking it the largest and most influential donor in primary education. In this regard, a senior government official also noted that: 
"For NGOs, we discuss issues at department level and it is more flexible. For big donors, discussions take place at government level and agreements are made at macro level which can be quite difficult...For big donors, their assistance usually comes with conditionalities: I assist you with this, so you should do like this. For example, DFAT is now funding BEQUAL, which they tend to control. They want to manage the programme themselves. They want to influence the policy; you must do this, you must do that." (Informant GOV2).

It is also noteworthy that despite the fact the aforementioned donors are signatories of Vientiane Declaration on Aid Effectiveness, big donors like DFAT, ADB, WB and JICA still wield influence due to the scale of their financial assistance. Those whose influence at policy level has significantly decreased are NGOs, most of whom not only have limited financial power but are also perceived as oppositional by GoL (Informants ES1, NGO6, NGO8; Kunze, 2012). Another senior government official explained the differences between NGOs and donors as follows:

"Big donors they also deal with both macro and micro levels while NGOs mainly focus on micro level, for example at project level. However, when it comes to policy negotiation, big donors with big pockets will have more negotiation power with the government. For NGOs who are regarded as small donors, they may also negotiate but not on major policy, for example the implementation process or the utilisation. But, they also contribute to education quality improvement. They do their best based on their available budget" (Informant GOV1)

Furthermore, one participant argued that NGOs' minimal role at policy level is attributed also to their lack of expertise (Informant GOV1). For instance, when engaging in curriculum development, NGOs do not really have specialised experts to provide input, which is different from big donors who can deploy experts to take part in the project (ibid.). As a result, the Ministry of Education and Sports (MoES) is more willing to take advice from donor experts, which in turn allows donors to have greater influence over Lao primary education policy. Realising that demonstrating expertise is one of the most critical factors for policy influence, 
donors hire highly qualified specialists and experts to work with MoES. For example, during the time of this research, DFAT was bringing in a number of specialists from Australia to work with MoES on BEQUAL. Some donors such as DFAT, JICA and ADB have also deployed their experts to be based directly in MoES. This mechanism has been regarded as an effective way to influence education policy change, and there is a possibility that some NGOs will replicate this strategy for similar reasons. This strategy will be discussed in more detail in Chapter 6.

Although finance and expertise differ between NGOs and donors at policy level, the fact that GoL (not just MoES) perceives NGOs' mission as opposing that of the government appears to be the most important factor in the capacity to influence education policy (Informants ES1, ES3). There is no wider divergence of opinion between NGOs and government than on the enforcement of a monolingual curriculum in primary education policy. GoL refuses to consider the introduction of a multilingual curriculum in primary schooling and this has long polarised NGOs and GoL, although attempts have been made to avoid palpable tensions and obvious confrontation (Informants DU1, ES1, GOV5). A senior education specialist emphasised that:

"The Ministry knows that the NGOs are pushing very strongly to introduce mother tongue and the government is trying to oppose that, [because the government see it as] a sort of language and identity. They don't want education instruction being given in the ethnic language. The influence comes from outside education, I think. It's about public security and nation building. Nation building and language go together. And this is the influence from others as well, but the government is strongly opposed to mother tongue and I suspect they wish development partners will just stop talking about it" (Informant ES1).

Knowing that NGOs have pushed very strongly to introduce mother tongue-based curriculum, which is suspected of causing disunity and disorder in the country (Informants ES2, NGO5), the government has prevented NGOs from influencing Lao primary education policy (Informant ES1). Donors, while supporting NGOs' efforts by providing financial support and echoing NGOs' voice to push for the introduction 
of mother tongue based curriculum, have taken a relatively weak standpoint towards the issue despite their financial strength (Informant GOV5). Although donors might take a leading role in influencing other policy issues such as free primary education and government budget allocation for education, they tend to let NGOs lead when it comes to suggesting the government address more sensitive issues like applying mother tongue based curriculum in primary schools (ibid.). Donors' lack of willingness to take the leading role is often attributed to the claim that NGOs know better about what happens in the field and have compelling research-based evidence on linguistic difficulty faced by ethnic children, which NGOs can use to convince MoES (Informants DU2, GOV5). Donors, at times, tend to encourage NGOs to initiate policy advocacy on the introduction of multilingual curriculum, while the former try to stay behind the scenes and provide financial to support the latter effort when possible.

The government has a number of strategies for distancing NGOs from occupying a position of influence. For instance, in the Education Sector Working Group (ESWG), NGOs can be co-chairs only at focal group level, which is the lowest level in ESWG, while donors are co-chairs act at the executive level (MoES, 2013). DPs suggested that NGOs be co-chairs at executive level when the position was vacant after UNICEF's tenure ended, but the government opposed this. In the end, the EU became the second co-chair in conjunction with the Australian Embassy as the first co-chair and MoES as the chair of the ESWG (ibid.). With regard to differences between NGOs and donors within ESWG, a senior education specialist commented that:

"There is a distinction between donors and NGOs and NPAs [Non-Profit Associations]... the government would be quite happy for UNICEF or UNESCO to be a co-chair, and the NGOs as a group put in much more money than they [UNICEF and UNESCO] do, and there's a handful of NGOs that have very big budget, more than million dollars a year, which is more than what UNESCO provides, but it's something about the organisation that prevents them from becoming the co-chair" (Informant ES1). 
Despite the fact that donors and UN agencies may wield much more influence than NGOs on primary education policy in Laos, their roles are interdependent. While donors can use their financial strengths to influence policy, they also rely on the grounded experience from NGOs who understand the needs of local communities better than donors. Zeiser (1998) also notes the fact that NGOs are strong in demonstrating actual needs from the local level and providing evidence-based information that governments and donors might lack also gives them some influence at policy level. In fact, both donors and NGOs see their roles as complementary to each other. For example, in the Basic Education Quality and Access in Laos (BEQUAL) programme, Australian Department of Foreign Affairs and Trade (DFAT) has contracted an NGOs consortium to directly manage some key programme components (DFAT, 2014).

NGOs operate their projects with communities and produce evidence-based success stories, while donors, who have better access to policy dialogues with high-ranking ministry officials, often convey NGOs' messages to advocate for policy change (Informants DU2, DU3, NG05). Donors can also provide financial resources for NGOs to carry out their projects at local levels. NGOs usually initiate their projects from small scale pilots, and when they are successful, they use the results to seek funding from big donors (Informant DU2).

Most donor participants admitted that donors have learned a lot from NGOs in terms of issues happening at the field level through joining monitoring visits and reading reports on the projects that they fund (Informants DU1, DU2, DU3). The lessons learned from NGOs help donors to implement their own projects (Informant DU2). For example, a donor representative explained that their organisation used lessons from Room to Read for its Early Grade Reading project (ibid.). Another donor representative also described how their organisation used the lessons from Save the Children's Mobile Teacher Project for its Global Partnership for Education Fast Track Initiative (GPE FTI) project (Informant DU1). The lessons learned from NGOs not only helped donors implement their projects efficiently, but also helped to determine effective and realistic policy negotiation with the government (Informants DU1, DU2). In other words, NGOS do have influence but not always, and 
often partially and always indirectly. In fact, even for powerful donors, it is not easy to influence government policy in Laos' unique socio-political context, but "a combination of 'track team' between NGOs and donors would be helpful to move this forward" (Informant DU3). This indicates that by working hand in hand or as a 'track team', there is a higher chance for NGOs and donors to successfully drive change in government policy.

Nevertheless, although both NGOs and donors are committed to driving policy change, their priorities areas are at times different (Informants DU2, DU3, NGO5, NG07). For instance, in the early childhood education programme, NGOs want to expand it to more schools, whereas donors such as EU are more concerned about management issues such as budget allocation and teacher deployment (Informant DU3). Another example of divergent priorities is curriculum revision (ibid.). NGOs mainly push for revising the curriculum, while the EU is more concerned about the budget for printing. The mismatches between NGOs' policy priorities and that of donors frequently result, at times, in donors not supporting NGOs' policy advocacy (Lundmark \& Malmberg, 2008).

\subsection{The Influence of NGOs on Lao Primary Education Policy}

The key areas in which NGOs focus their advocacy in primary education are related to both the relevance and the implementation of the policy. This section outlines issues about which NGOs have long advocated for change, and which were recently brought up again in the education law revision workshop and a multi-stakeholder workshop for ESDP 2016 - 2020, which took place during May - June 2015.

\subsubsection{The Introduction of a Multilingual Curriculum}

The Lao primary education policy issues for which NGOs have advocated for change relate to the curriculum which they perceive as weakly relevant or irrelevant to the needs of children, particularly those from ethnic minorities. This includes enforcement of a monolingual curriculum in primary schooling and weak relevance of the curriculum itself in terms of the content and time allocated for teaching. As discussed in Chapter 4, only Lao-Tai or Lao have been used in Lao formal education, and teaching and learning materials are only developed in Lao language despite the 
fact that Laos is one of the most linguistically diverse countries in the world (Chithtalath, 2006; Fox, 2003). Believing that a monolingual curriculum is key to national unification and identity, GoL is strongly opposed to the introduction of mother tongue based instruction or multilingual curriculum even though the government is aware of the proposed curriculum's benefits (Informants ES1, ES2, NGO2, NG05). There are also concerns about financial and technical capacities within the government agencies, as a senior government official highlighted:

"We can't develop mother tongue-based curricula at the moment. We don't have expertise in anthropology. We need to do research in order to develop any mother tongue based curriculum. We don't have budget for that either" (Informant GOV5).

Many NGOs seem to hold a different perspective. They are more concerned about the learning performance and outcomes for children whose mother tongue is not Lao. The Mid-term Review of Education Sector Development Plan (ESDP) (20112015) conducted in 2013 acknowledged that non-Lao speaking children face considerable language barriers in their learning, which leads to high dropouts and affects the quality of Lao primary education as a whole (MoES, 2013b). In fact, not only NGOs but also donors and other DPs disagree with the enforcement of monolingual curriculum at the primary school level. The monolingual curriculum is perceived to considerably affect the quality of children's learning performance, especially non-Lao speaking children in rural areas, which account for more than $30 \%$ of the whole population of Laos (MoES, 2013b). There has been widespread criticism among DPs and civil society about the Lao education law that legitimises Lao as the only language of instruction in primary school. As a senior staff member of an NGO commented:

"Laos has no policy on language in education. In the education law, there's only one sentence talking about the language: Lao is the only language taught in the school...we are not thinking of the needs of children who are coming from ethnic minorities, who don't have Lao as mother tongue. So, when they come to school many of them drop out in grade 1, 2 or 3, because they cannot continue their 
study. They don't understand when they come to school, for example. The benefit of education is for the Lao children. Education is for the Lao-speaking communities, and children who have Lao as their mother tongue can do better at the school while the students from ethnic minorities are not benefiting from the education system at all" (Informant NGO5).

The same participant further described how their organisation has tried to work with other NGOs and DPs to advocate for change through providing information about the issue to technical staff and policy makers at MoES (Informant NG05). However, policy advocacy gets stuck when the government is more concerned about political security and national unity than responding to the actual need of citizens (Informants ES2, NG05). Another senior NGO participant who has worked in Laos for many years commented that their organisation has worked on advocating change in language of instruction. They admitted that it is very hard, almost impossible, to influence change on the issue, because "the ministry is reluctant to explore anything to do with having children taught in a language other than Lao" (Informant NGO3). It is a political decision beyond the autonomy of MoES, made by higher authorities such as the National Assembly, and most importantly, the Politburo, as to whether or not another language can be used to instruct children in a Lao classroom (Informants DU2, DU3, NGO3).

Apparently, this is not an area that MoES is willing to compromise on, despite that fact some influential NGOs such as Save the Children, Plan International, ChildFund and World Vision have specifically mentioned this issue with the ministry in every single meeting they have had to discuss the new education law (Informants NGO2, NGO3). Article 40 on language of instruction in the new education law revised in 2015 states that "Lao language and Lao character is official language and character to be used in teaching-learning within education venues" (MoES, 2015, p.18). The message remains unchanged from that stipulated in the previous education law developed in 2008 (MoES, 2008b).

Even major donors who are perceived to be the most influential DPs in Laos are not willing to press issues sensitive to the government. Donors' reluctance raises the 
question of whether donors actually influence Lao education policy. The enforcement of monolingual curriculum in Lao primary school is perhaps the best example that reflects the limited influence of donors as a senior representative of a well-recognised donor noted:

"There are some issues that the government has closed the door on for negotiation, for example the proposal of multilingual curriculum for primary school, which has been advocated for a long time by development partners. We knew that it was impossible to push the Ministry of Education to change the curriculum as it involves other ministries and even national assembly, so we decided to step back. It is a political issue and we try to avoid any political engagement" (Informant DU2).

This example of donors having limited influence on Lao primary education policy, especially on sensitive issues, contradicts the claim of other researchers, particularly Phommalangsy (2013, p.2), who describes the power relations between donors and GoL as "the former seem to be in authority in giving out assistance, whereas the latter feel unable to challenge and negotiate the relevance of aid and policy suitable in the Lao context”. His claim does not reflect my discussions with some major education donors (Informants DU1, DU2, DU3, DU4, DU5). Moreover, the case appears to be that donors are more willing to compromise with government policy, especially policy that involves politically sensitive issues, despite the fact that donors may acknowledge them to be irrelevant or inappropriate. All donor representatives I interviewed posited that donors are committed to supporting GoL's efforts to implement their education development, and thus are willing to align their policy with government strategy rather than influencing (controversial) policy change (ibid.). For example, a senior staff member from a donor agency also noted that:

"Even the big development partners or donors still have kind of limited influence on the government policy. We have to understand that policy changing takes time and some of the policy issues are top down from the Party level, it's not only from the government and the planning of the Ministry is 
already dictated by the planning of the government. For example, the socioeconomic development plan, some of the targets and indicators are already set under the socio-economic development plan, for example the indicators that link to the LDCs graduation...even though we have discussed and also provided our advice to the Ministry of Education that their target will not be achieved, because some of the indicators, for example the primary survival rate is very low and you cannot put higher indicators for the lower secondary by 2020...you may not achieve... but then because the Party and the government already set the ambitious goal that they are going to exit the LDCs by 2020, and those indicators had to be put in the education development sector plan" (Informant DU3).

The fact that donors have limited influence on Lao primary education policy could be partially attributed to the repercussions of AEPF9 (Informant NG08). Although the aftermath of the AEPF9 had a more direct impact on NGOs, it undeniably had a tremendous overall impact on other DPs in terms of their willingness to drive policy change. Even donors who have financial power are not willing to take a critical standpoint to convince GoL to adopt multilingual curriculum for primary school, let alone NGOs, given their minimal autonomy. There are, of course, more issues that donors do not agree with the government on, but donors choose to compromise and continue to provide aid to Laos (Creak, 2014).

This situation does not mean that NGOs and donors have not done anything about these issues, but that they just try to play it safe, as suggested by Delnoye (2010). In regard to the issue of monolingual curriculum, for example, NGOs and donors have opted to compromise and explore other possibilities to 'add to' government's existing policy rather than introducing a new policy (Delnoye, 2010; Informant NG08). NGOs and other DPs support an approach where the Ministry opens the door to teachers and schools using mother tongues to support ethnic children to learn better in Lao language. In other words, teaching is not undertaken in other languages, but teachers use other languages to help ethnic children to learn Lao. Save the Children, Plan International and Norwegian Church Aid, for example, have invested in teacher training by selecting young people from ethnic minorities to 
attend teacher training college and return to their community to teach ethnic children (Informants NG05, NG06, NG07). Some donors, such as WB and UNICEF, also focus on early grade language acquisition through programmes such as the School Readiness Programme that supports young ethnic children to acquire basic Lao language skills through preschool attendance and playgroups before they go to primary school. There has also been a great deal of support from NGOs and donors to produce teaching and learning materials to help teachers better teach Lao to ethnic children, albeit not in dialects (Informant DU4). These initiatives are in line with the government policy, and DPs seem content to feel they have a certain level of influence on the policy (Informants ES3, GOV2, NGO7).

In addition, during the most recent education law revision, some NGOs and donors tried to convince the government to adjust the education law by stipulating that "other approaches including the use of dialects to help non-Lao speaking children can be practiced at school level" (Informant DU2). This attempt, however, was not successful. The newly revised education law, includes only a vague statement which reads:

"Contents of educational curriculum shall be unified [harmonized] within the country, for those locals who have unique identity, potential and outstanding intelligence, with the agreement of Ministry of Education and Sports can be adopted as supplementary curriculum" (MoES, 2015, p.15).

The fact that MoES accepts NGOs' initiatives as supplementary curriculum also corresponds with the views of some informants who asserted that no matter how good the initiatives are, they cannot replace what has been developed and dictated by the government (Informants ES3, GOV1). Nevertheless, NGOs seem to have different viewpoints on this issue. Some NGOs felt that they invented a certain policy initiative that the Ministry accepted, so they could claim that they had a certain degree of influence at policy level. Of course, in this sense, they feel their inputs are an exception from typical political processes. For example, an NGO representative claimed that their organisation was developing a new version of grade 1 and grade 2 textbooks, including teaching manuals for primary schools in conjunction with the 
concerned government offices, which have the potential to supplant existing textbooks and manuals (Informant NG01). However, a government representative provided an opposing view on the issue. They emphasised that such textbooks and manuals were developed under a pilot project within the NGOs-funded project schools and even if the textbooks and manuals are good, they will only be used as supplementary materials and cannot replace the ones developed by the government (Informant GOV1).

In the same manner, another NGO representative claimed that their organisation has some extent of influence on Lao education policy, though not exactly at primary level. They explained that their organisation piloted a one year pre-primary education programme in 2004 in Northern Laos, starting from a few schools and increasing the number of schools year by year to other parts of the country, and based on this success, MoES adopted and formally incorporated this programme in the existing basic education policy in 2013 (Informant NGO7). A government official who was heavily involved in this pre-primary education programme, however, provided a different view on the issue, indicating that the programme was only active in the project areas funded by NGOs and donors, and not beyond that (Informant GOV6). They further argued that the 30 weeks preschool teacher training scheme, which was the key component of the programme, was only accepted in an exceptional case where there was a dire shortage of teachers, particularly in the remote and ethnic areas where most NGOs operate (Informant GOV6). They also concluded that this initiative was discontinued since the programme ended, due to the fact that it was not consistent with the government's formal preschool teacher training curriculum, which is much longer (ibid.).

A senior education specialist also disputed the claim that NGOs have influence on Lao pre-school and primary education curriculum:

"Such NGOs may claim 30 weeks preschool teacher training course as their policy influence, because this claim has always been reflected in donor reports and fund-raising documents. However, when you ask the government, especially the Department of Teacher Education, they would probably give you 
different answers. The department also advised that if development partners wish to assist teacher training course, they should support the formal government programme not the 30 weeks preschool teacher training programme, because it created gaps of difference between teachers trained from the two programmes. This case is similar to the mainstreaming disaster risk reduction in education curriculum scheme. Some NGOs always claim that they have influenced government policy by integrating DRR in lower secondary school. In fact, it is just a supplementary curriculum or extra reading materials that MoES allowed to be used in addition to the formal curriculum. It should be understood that the government prefers NGOs' interventions to assist the government system to work better rather than creating another initiative. In other words, SWAp funding approach works best in foreign aid, based on the government's opinion" (Informant ES3).

This indicates that different actors perceive and interpret their influence in different ways. It is also interesting that although most NGOs admit that they align their policy with the government policy, they continue to claim that some of their works have initiated a certain government education policy Having worked in the Laos education sector for several years, I witnessed a mixed legacy and have mixed feelings towards the issue of NGOs' influence on government policy. Perhaps, as Informant ES3 puts it, NGOs' influence on policy outcomes are described more positively in their reports for donors and fund-raising project proposals to keep funding going. NGOs might not claim this in their reports to MoES or MoFA. They would instead frame how they report to the government as supporting the government to implement government policy.

\subsubsection{Retention of Local Curriculum}

There are several NGOs that promote indigenous knowledge through locally specific curricula or what is widely understood as 'local curricula' among DPs in Laos. Local curricula are different from mother tongue based or multilingual curricula. The former is about location-based indigenous knowledge and skills, while the latter is directly about the introduction of ethnic languages in school instruction. Local curricula are developed under the leadership of the local community, especially 
Village Education Development Committees (VEDCs), through using community resource persons who have particular skills as demonstrators. The education law developed in 2008 states that the formal primary education system must include at least $20 \%$ local curricula (MoES, 2008b). After implementing this policy for some years, the government wanted to remove local curricula from the primary education curriculum as they perceived that it did not really work in practice (Informant NGO4). Some NGOs whose projects focus on local curricula also acknowledged that implementation of local curricula is sometimes difficult, because teachers do not have indigenous knowledge, making it very hard for them to teach local curricula (Informants NG06, NG08).

This difficulty does not mean that NGOs agree with the government on abandoning local curricula. In contrast, they remain committed to keeping and pushing local curricula forward. They attempt to work with lower government authorities, for example teacher training colleges, PESS and DESB to maintain local curricula or indigenous knowledge based curricula (Informants NG06, NG08). A senior NGO representative who insisted on retaining local curricula during the education law revision workshop in June 2015 explained that:

"There is a policy issue about curricula, the local curricula that the government said that if we can't implement, we should leave it out. I strongly disagree with that idea, because I want the primary education curriculum to be flexible to be developed further. If we read it through, the current curriculum is closed for creativity from implementers. Because of this, we may not see the development which moves very fast. So, I emphasised that we should keep the local curricula for those who have creative ideas. I strongly emphasised that this meeting should keep the local curricula" (Informant NGO4).

Nevertheless, it seems the attempt of the above participant (Informant NGO4) was not really successful. Article 34 in the new education law drafted in 2015, states that local curricula derived from area-based knowledge and skills may be adopted as a supplementary curriculum and only subject to MoES' approval (MoES, 2015). This is quite different from the 2008 education law that made local curricula mandatory 
in formal primary education. Therefore local curricula are no longer a part of the formal curriculum, but a supplementary curriculum, like other curricula initiated under NGO support as discussed in Section 5.4.1. Although NGOs' commitment to maintaining local curricula as supplementary in Lao primary schooling does not directly conflict with government's political agenda, it lacks the interest and support of GoL and other major donors, which in turn results in NGOs' minimal influence on higher policy development in this area.

\subsubsection{Enforcement of Free Primary Education}

As discussed in Chapter 4, the 2008 education law proclaims that primary education is free for everyone (MoES, 2008b). In practice, however, this is not always the case. People are not required to pay fees to send their children to school, but they are still required to provide support to the school as community contribution. The reason behind the community contribution requirement is that education, based on the Lao constitution and the 2008 education law, is everyone's duty and obligation (Informant GOV2; MoES, 2008a).

Accordingly, communities are required to contribute to education development for their children in the form of labour and/or cash for school construction, maintenance and renovation, which can be decided by school management in consultation with VEDCs (MoES, 2008a). Additionally, some money contributed by communities is also claimed to be spent for school administrative costs and payment for pre-service teachers who have yet to receive their salaries.

Community cash contributions have been widely criticised by DPs who interpret this contribution as a burden for communities and a barrier to parents sending their children to school, especially in rural poor communities where it is hard enough for parents to afford buying clothes and basic education materials for their children (IEDWG 2015). NGOs, in particular, interpret the call for community cash contributions as an inappropriate practice given that public investment in education sector has considerably increased and more funding for school construction and maintenance has been provided by DPs. There have been considerable school construction costs and block grants provided by donors and 
NGOs to support school maintenance and administrative costs (Informants NGO1, NGO2, NG04, NG07), for example, under the World Bank's Global Partnership for Education (GPE) project and Save the Children's School Quality Improvement Programme (Informants DU1, NG07). Community contributions have continued, however, in the form of cash (or labour).

Although there has been a significant increase in public investment in primary education over the last decade (MoES, 2008a, 2008b, 2013b), that increase has not really contributed to abolition of cash contributions from communities. Despite strong pressure from NGOs and donors and other DPs, the government remains adamant about maintaining community cash contributions through invoking communities' obligation under the Lao constitution. The government's position is illustrated in the revised 2015 education law which clearly states that:

"Families are obliged to contribute to education development in form of intelligence, funds, vehicles, in kinds, teaching and learning materials, construction, maintenance, and renovation of education venues together with educational development committees (VEDCs) and teachers to create a conducive environment for children's learning" (MoES, 2015, p.33).

The fact that community cash contributions are still required by the newly revised education law has brought about doubt, frustration and criticism among DPs given they tried very hard to press for change (IEDWG 2015). Whether or not the improved public investment in primary education will contribute to ending community cash contributions remains an open question, and one likely to be further pursued by NGOs and other DPs.

NGOs have used a variety of strategies to try to influence policy in regard to free education. NGOs have worked collaboratively with larger donors, by developing, for example, a joint statement demanding GoL clarify that "access to primary education is free of fees and other associated costs" (IEDWG 2015) during the development process of the 2015 education law. A donor agency, who was considered most influential and having the healthiest relationship with the government was assigned 
to deliver the joint statement to the Ministry on behalf of NGOs and other donors (ibid.). Currently, the revised law is still under National Assembly (NA) consideration. It appears that NGOs and donors are optimistic that their influence on this issue will be approved by NA, despite scepticism about the actual implementation once it is approved (ibid.). This potential success illustrates that unlike the introduction of multilingual curriculum, GoL is more willing to compromise on this issue, mainly because it is related to more budget than politics.

\subsection{Politics of Participation and Rhetoric of Recognition?}

Political language and rhetoric play a pivotal role in any political setting (Creak, 2014). While participatory approaches have become the cornerstone of development, an awareness of the politics of 'participation' and the rhetoric of recognition, especially in decision-making processes have been used widely among development stakeholders as strategies to maintain relationships and exert both overt and covert influence over one another. Particularly in developing countries with young democracies, the politics of participation and rhetoric of recognition of various development actors' activities remain crucial tools through which governments mobilise external assistance while retaining state legitimacy over public political space by defining acceptable limits of stakeholders' engagement or 'participation' in policy development (ibid.).

The term 'participation' exists in most policy documents concerning cooperation between GoL and NGOs as well as other DPs. Nevertheless, the way in which the government has opened the door to NGOs' participation involves political strategies to maintain mutual relationships and state power, and most importantly, the funding influx that flows into the primary education sector. Simon Creak notes that “as the leaders' more sophisticated response to its budgetary woes indicated, Laos has changed profoundly in the past two decades, including in the ways the LPRP [Lao People's Revolutionary Party] utilizes language, rhetoric and other forms of communication in reinforcing state power" (Creak, 2014, p.151).

In relation to NGOs' engagement in primary education policy development in Laos, despite the fact that the government claims that they 'value', or in a more frequently 
used term 'welcome' the inputs and recommendations from NGOs in policy dialogues, the extent to which NGOs' inputs and comments are integrated into policy is limited as discussed in this chapter. As a senior NGO staff member explained:

"We provide input, we provide feedback to the development of the education development plan. Again, it's not clear how or if our inputs are considered. This is one of the challenges. It's good that the ministry says please provide your feedback. We provide feedback but we don't know where it goes" (Informant NGO2).

Most interviewees, particularly from NGOs, indicated that they were included in almost all education policy consultation meetings organised by MoES. Some interviewees also described that they witnessed a significant increase in government's willingness to include NGOs as well as other DPs in policy dialogues over the last decade, although that inclusion rarely translated into acting on NGOs' recommendations (Informants NGO1, NGO7). Most government participants also acknowledged that GoL valued NGOs' engagement in Lao primary education policy development. For example, a senior government official commented that "we open the floor for all DPs to provide their inputs and comments...we don't limit any opinions; our ministry is always open to all inputs...we don't set any restriction to opinions [from DPs] in order to improve our work" (Informant GOV3). GoL's willingness to include NGOs in policy dialogues is also supported by a comment from a high-ranking government official who stated that "education development is the duty of everyone in the society and responsibility of all stakeholders. Therefore, GoL is open to inputs and recommendations from all stakeholders including donors, NGOs and civil society" (Informant GOV2).

The same official asserted that NGOs participated in all the development processes of important education policy, most recently the development of the ESDP 2016 2020 which took place in May 2015 (Informant GOV2). Moreover, the government is open to all inputs and recommendations from NGOs and other DPs for the development of revised education law, which is Laos' highest education document (ibid.). The workshop on the development of the revised education law took place 
in May 2015 and was recognised as the most inclusive workshop, with participation of the widest group of stakeholders, especially NGOs and NPAs, which had never happened before in Lao education history. This inclusion may, however, be taken to be largely a political strategy given that the government remains the only actor who has the final say and considers only what they think corresponds with national priorities, perceiving national unity as the first and foremost factor (Informants DU4, ES1, ES2, NG02, NG05, NG08; Phetsiriseng, 2009). Having said that, some degree of influence of NGOs and donors in some apolitical areas and a certain level of influence on primary education policy development process as discussed earlier should not be disregarded.

While such comments suggest that GoL highly appreciates participation of DPs and truly values external inputs, the same official and others also provided the conflicting opinion that the government only considers inputs and recommendations from DPs that are in line with government policy and the Party's political direction (Informants GOV1, GOV2, GOV3, GOV4, GOV5, G0V6). Furthermore, the rhetoric of recognition appears to be a common strategy used by the government and NGOs in Laos. A senior education specialist described this as a "game" that the government and NGOs use to please each other in order to keep projects going (Informant ES2). The latter's contributions in the form of financial and technical support have been publicly recognised by the former through reports and meetings.

The most recent and most public recognition of the importance of NGOs was in the $2^{\text {nd }}$ National Conference on the Cooperation between GoL and NGOs in Vientiane on 28 ${ }^{\text {th }}$ October 2014. The Deputy Prime Minister and Minister of Foreign Affairs officially conveyed that "GoL continued to attach great importance to and appreciated the role and contribution of NGOs to social economic development and poverty reduction throughout the past decade" (LNTV, 2014). It appears that this comment of the Prime Minister contradicts that of some senior government officials who asserted that the government has stopped calling NGOs 'NGOs' but 'DPs' in order to avoid discriminating or seeing them as oppositional (Informants GOV2, GOV3). 
This research indicates that how feedback is taken depends on the issues. For some issues, such as the improvement of primary school teaching methodology and early childhood development, the government needs external inputs, and therefore they are very open to hearing opinions from NGOs and DPs, and partly integrate those inputs into policy (Informants DU2, NGO3). Conversely, for issues that are politically sensitive and considered threatening to public security and national unity, or other issues that are not government priorities, the government has made no or very little change in policy, even though they may be open to discussions (Informant NGO3, NG06). Having said that, as this informant sums up, "it's not that they [the government] are not interested, not that they aren't gonna change anything...there's a lot of polite head nodding; there are a lot of 'yes, thank you. We'll take that on board'...they don't say don't, don't talk to us. Go, go away, but it's not gonna immediately impact any change" (Informant NGO3).

The conclusion that NGOs are 'welcome' to provide inputs to policy development, while the government retains the final say as to whether or not such inputs are taken up, is congruent with all the interviews with government informants. Nonetheless, it appears that MoES has not communicated with DPs regarding how inputs from NGOs and other DPs are considered and which inputs are taken into account and which are not, although some NGO representatives pointed out that they could find some inputs from their organisation in some final review meetings they participated in (Informant NG05). The majority of NGO representatives, argued that they could not really see where and how their inputs were reflected in the primary education policy (Informants NGO2, NGO3, NGO4, NGO6, NGO8). Therefore, I would conclude that the fact that the GoL invites NGOs to provide inputs in the development of most education policies seems to be largely attributed to a politics of participation and a rhetoric of recognition as a means of maintaining mutual relationships in order to allow education projects to continue.

\subsection{Summary}

In this chapter, I discussed the role of NGOs and their assistance to Laos. I argued that the constant increase of NGOs' assistance to Laos since 1986 after Laos adopted the New Economic Mechanism has made NGOs' profile more visible to GoL. 
However, within the unique socio-political context of Laos, NGOs have to take very cautious steps towards policy negotiation with the government, including employment of diplomatic skills and allying with other NGOs, donors and other DPs. I argued that maintaining relationships with the government is key for NGOs as well as other DPs to advocate for policy change. Nevertheless, it is extremely hard and almost impossible for NGOs to negotiate major policy issues, particularly issues that are considered sensitive to the government, as NGOs are naturally and historically viewed as government opposition. The distance between GoL and NGOs was exacerbated in the aftermath of AEPF9, which prompted the government to impose more restrictions and scrutiny on NGOs' missions and operations. Although this imposition has affected all DPs as a whole, NGOs are understood to suffer the most due to their identity (as potentially opposed to the government) and their limited financial power.

I also examined the differences between NGOs and major donors at the policy level in relation to primary education. I argued that GoL perceives the roles of NGOs and donors distinctly in terms of policy development. While financial strength plays a pivotal role in enabling donors' influence over primary education policy, this is not the case for NGOs, due to the fact that GoL is not willing to allow NGOs to be policy counterparts. This resistance is clearly manifested in the structure of ESWG, in which NGOs are placed at the lowest level of decision making. The fact that NGOs are recognised at a technical level but not really at a policy level suggests a politics of participation where NGOs are 'welcome' to participate in policy dialogues but GoL remains very reluctant to incorporate their comments into primary education policy, especially on issues that the government considers politically sensitive.

The key policy areas in Lao primary education in which NGOs have advocated for change are the primary education curriculum, free primary education, and the development of a local curriculum that supports relevant education for all. NGOs have pushed most strongly for the introduction of multilingual curricula or mothertongue based instruction. The extent to which NGOs can actually influence such policy issues, however, is limited. In summary, I conclude that NGOs have a certain level of influence on the process of policy development and they are invited to 
provide inputs in policy dialogues. NGOs have very limited influence, however, on the decision making process and policy outcomes, although they do adopt strategies such as collaborating with more powerful DPs in order to advocate for change. These strategies are the focus of the following chapter. 


\section{Chapter 6: NGOs' Mechanisms and Strategies for influencing Primary Education Policy in Laos}

\subsection{Introduction}

This chapter investigates the mechanisms and strategies that NGOs use to influence primary education policy in Laos. It expands analysis of the second research subquestion and specifically addresses the third research sub-question (see section 1.5 in chapter 1). The first section examines how effectively NGOs use their role in the ESWG Focal Groups (ESWG FG) for policy influence. The second section investigates how NGOs work with major donors through the Informal Education Sector Working Group (IEDWG) to influence Lao primary education policy. The third section analyses how NGOs' strategies for developing government policy makers' capacity affects NGOs' policy influence. Finally, the fourth section discusses how other external forces such as Association of South East Asian Nations (ASEAN), the ASEAN Economic Community (AEC), and social media might influence changes in Lao primary education policy. While demonstrating evidence-based successes is considered the best strategy for NGOs to convince the Government of Laos (GoL) to change Lao primary education policy, I reiterate that politically sensitive issues remain untouchable by NGOs as well as other Development Partners (DPs).

\subsection{Education Sector Working Group and NGOs' Policy Influence}

The ESWG was established in 2007 as a result of the Round Table Implementation Meeting in 2005 and the adoption of the Vientiane Declaration on Aid Effectiveness (VD) in 2006. The ESWG management is delegated into three levels: executive, technical and focal groups. At the executive level, ESWG is chaired by MOES and currently co-chaired by DFAT and the EU (the successor of UNICEF whose term ended in January 2014). It also involves other government ministries such as the Ministry of Foreign Affairs, Ministry of Home Affairs, Ministry of Finance, Ministry of Planning and Investment and Lao Women's Union as well as relevant NGOs and NPAs. At the lower level, some well-recognised NGOs namely Save the Children and Plan International are currently co-chairing a basic education focal group, and an education research and analysis focus group respectively (see Figure 6.1). ESWG is 
a joint government-DPs platform for coordinated education policy development, which promotes education sector development through ensuring Lao education policy frameworks are designed and implemented in accordance with international commitments, particularly the Millennium Development Goal (MDG) education targets within Education Sector Development Framework (ESDF) (GoL, 2010; MoES, 2013b; Phommalangsy, 2013).

ESWG is the main platform that NGOs and other DPs use for negotiating and advocating change in primary education policy. McCormick (2012) notes that among other consortium and alliance working approaches ESWG has increasingly played a significant role in distilling and harmonising DPs' interventions in education development in Laos. It also significantly increases NGOs' access to policy dialogues compared to the time prior to the establishment of ESWG (Informants DU1, DU2). This does not mean, however, that NGOs utilise the ESWG forum effectively to influence Lao primary education. There are mixed views on how effective the ESWG is. For example, a senior NGO representative described the effectiveness of ESWG as:

"Sometimes it works. Sometimes, on a particular issue, the government is willing to take on board the views of development partners and incorporate them into a policy or plan or whatever is being discussed. And sometimes it's quite successful, and I think that works very well when the topic is one that the Ministry is comfortable development partners having inputs to. And then there are topics that are off-limits for development partners like the mother tongue instruction in the new education law. In my opinion, they went through the consulting process with development partners, but changed little based on the feedback from NGOs and others" (Informant NGO3).

The above comment indicates that the effectiveness of ESWG is subject to the political nature of the issues that are brought up for discussion. While ESWG, particularly at the focal group level, is an effective coordination mechanism for issues consistent with government priorities (AusAID, 2010; MoES, 2012; Phommalangsy, 2013; UNICEF, 2009), it does not seem to work for issues that 
contradict the government's political will (Informants DU3, ES2, NGO7, NGO8). The fact that GoL has a very clear leadership direction (Bird et al., 2010; Frohofer, 2014; Informants DU4, NGO2) and the Ministry of Education and Sports (MoES) has taken a strong leading role in ESWG indicates that NGOs have little possibility of influencing Lao primary education policy through ESWG FG.

However, working in alliance through ESWG FG is recognised as at least an entry point to influencing Lao primary education policy (Informant NGO2). NGOs could use the ESWG FG forum to disseminate their success stories and research-based evidence (Informants DU2, GOV2, NGO7). Donors also consider ESWG FG an effective mechanism that increases the profile of both NGOs and donors at the policy level (AusAID 2010; Informant DU2; UNICEF, 2009). Through their stronger influence, donors can (although they don't always) use this forum to help NGOs voice their concerns and deliver their evidence-based successes, which could lead to policy change (Informants DU2, NGO7).

Since its establishment, ESWG FG has provided the opportunities for MoES to discuss and endorse policy issues face to face with NGOs and donors in a formal and constructive way (Phommalangsy, 2013). There were a number of key education policies that have been discussed at the ESWG FG level and endorsed at the ESWG executive level, such as ESDF, National Education Sector Reform Strategy (NESRS), Education Law, Education Sector Development Plan (ESDP), Education For All National Plan of Action (EFANPA), School of Quality (SoQ) Initiative, as well as other key policy issues (Informants DU2, GOV2, NG07). Most recently during the time of this research, the revised Education Law and ESDP 2016-2020 were also developed and discussed in the ESWG. 


\section{Figure 6.1: Education Sector Working Group Structure}

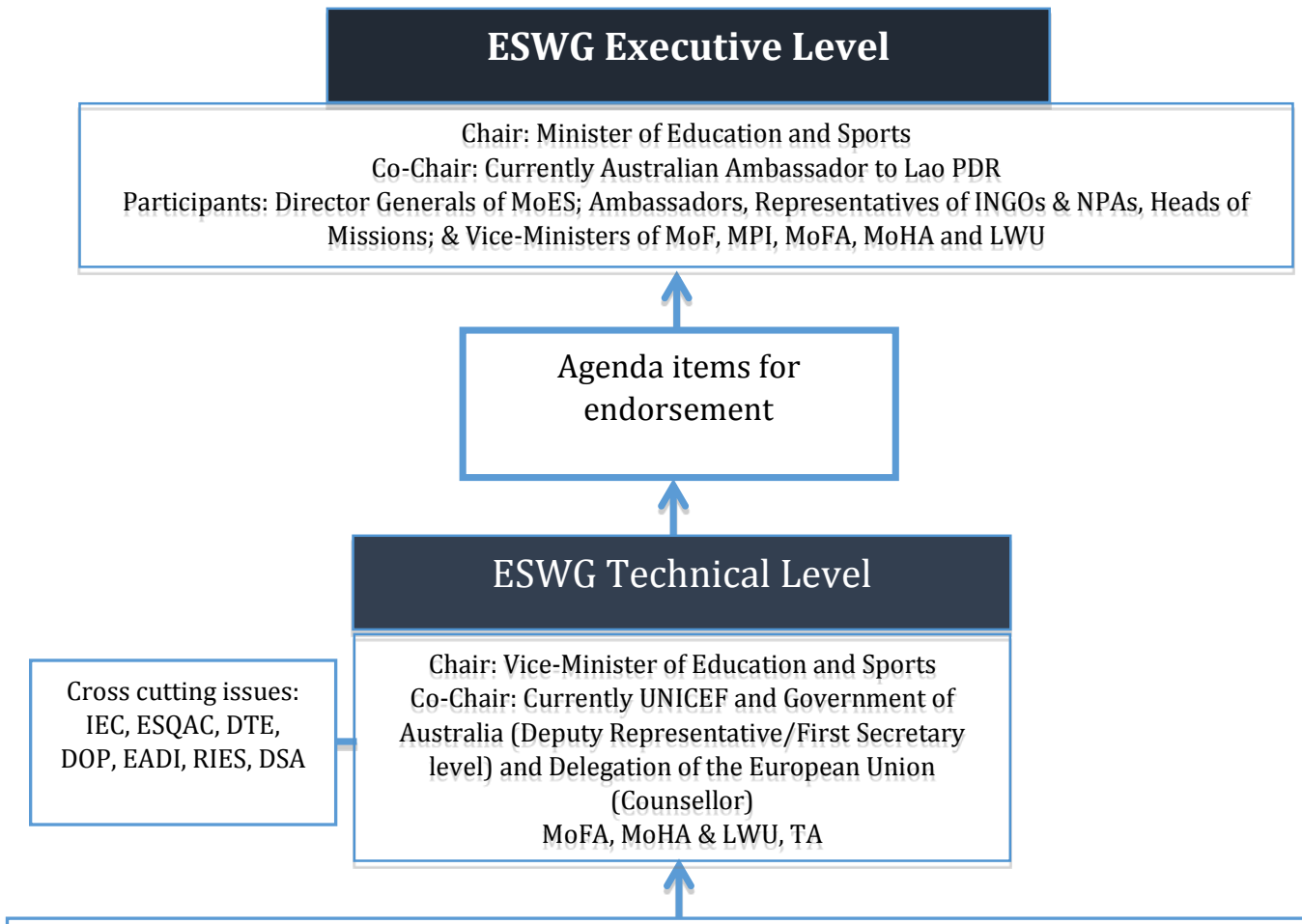

Recommendations and Action Plans for approval from each Focal Group inclusive of cross sub-sectoral issues. These will form the agenda for Technical ESWG meetings

\begin{tabular}{|c|c|c|c|}
\hline \multicolumn{1}{|c|}{} & \multicolumn{1}{|c|}{$|c|$} & \multicolumn{1}{c|}{ Focal Group 3: } & Focal Group 4: \\
\hline Focal Group 1: & Focal Group 2: & Planning, & Education Research \\
Basic Education & Post Basic & Budgeting and & \& Analysis \\
Chair: MoES & Education & Monitoring & Chair: MoES \\
Co-Chair: UNICEF & Chair: MoES & Chair: MoES & Co-Chair: World \\
\& Save the & Co-Chair: GIZ \& & Co-Chair: EU \& & Bank \& Plan \\
Children & ADB & IICA & International \\
\hline
\end{tabular}

Technical Dialogue on key issues according to TOR of individual Focal Groups - in depth evidence and analysis. Focal Groups $3 \& 4$ support other Focal Groups as necessary
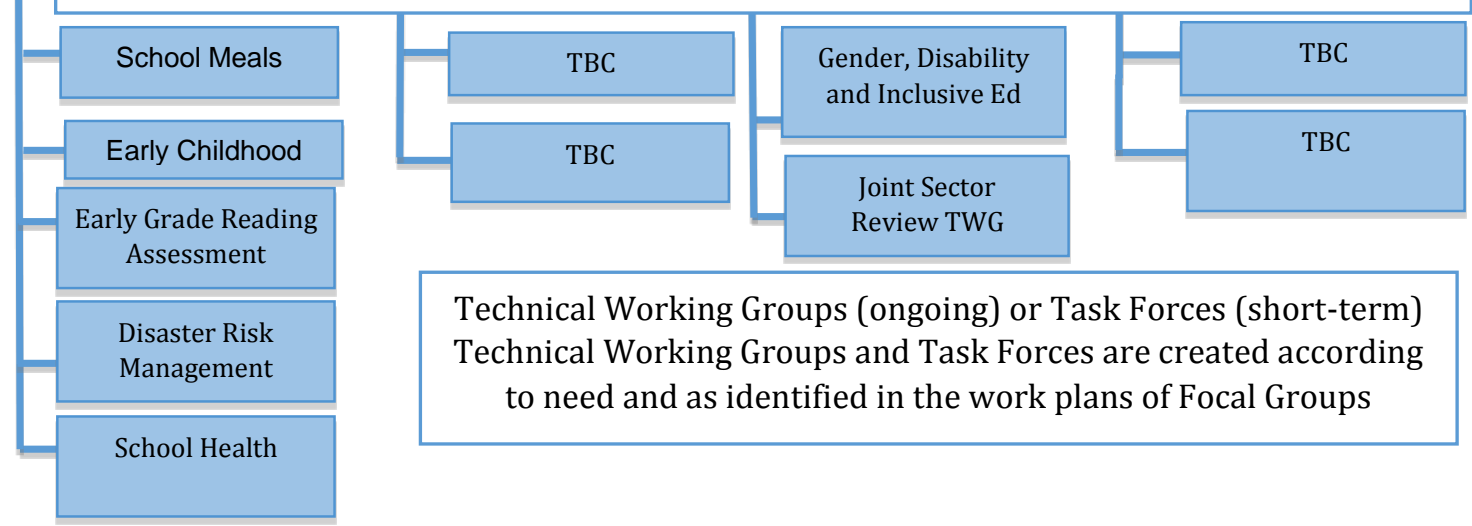

Technical Working Groups (ongoing) or Task Forces (short-term) Technical Working Groups and Task Forces are created according to need and as identified in the work plans of Focal Groups

Source: Lao Education Sector Working Group Structure, (MoES2013). 


\subsection{Informal Education Donor Working Group and NGOs' Policy Influence}

The Informal Education Donor Working Group (IEDWG) is an unofficial forum of NGOs and donors. According to my communication with an officer involved in IEDWG, there is no formal binding document between NGOs and donors except a one page 'Shared Understanding of the Purpose of the Informal Education Development Partners Working Group' developed in 2014 (IEDWG, 2014). The Group consists of the Asian Development Bank (ADB), Australian Department of Foreign Affairs and Trade (DFAT), European Union (EU), Japanese International Cooperation Agency (JICA), United Nations Children's Fund (UNICEF), the World Bank (WB), and INGOs (Informant NGO7). For NGOs and donors, the IEDWG has a direct link with the formal ESWG. Its monthly meeting is normally chaired by donors who are ESWG co-chairs, and co-chaired by one rotating NGO co-chair, and open to all development partners and some invited individuals (such as researchers, consultants, government bodies, and private businesses) working in the education sector (IEDWG, 2014). The role of IEDWG, based on the shared understanding document, is to:

- Network and exchange information

- Strengthen collaboration and effective co-ordination for the sector

- Have open and frank discussions about the policy and implementation challenges of the sector to assist with identifying future shared actions

- Learn more about Lao Government Policy and plans, and

- Discuss education related issues locally, regionally and globally (ibid.).

IEDWG plays a very important role in creating a collective position for NGOs and aligning their policy advocacy efforts (IEDWG 2015, Informant NGO3). The IEDWG meeting is a comfortable forum, where NGOs and donors discuss their dissatisfaction with the government's performance without having to be diplomatic (IEDWG 2015). It should also be noted here again that public conflict is unacceptable in Lao culture and public criticisms are not allowed (Evans, 2002; Waby, 2006). These cultural and political values are observed in order to maintain national unity (Phetsiriseng, 2009). As such, issues that may lead to disunity, differing ideological choices and possible confrontation cannot be discussed in ESWG meetings (Phommalangsy, 2013). However, these issues can be, and are, 
discussed in IEDWG meetings. NGOs and donors often thrash out the issues that they think may create conflict and affect their relationships with each other and withthe Ministry in IEDWG meetings (ibid.). In light of the significance of the IEDWG forum, a senior NGO representative emphasised that:

"I will say I think the informal education donor working group meeting which happens monthly with just donors and NGOs is really valuable. I think that probably in terms of its ongoing consistency this is of most the value. In that it gives partners and NGOs an opportunity to discuss, to share and to come up with consistent messaging on policy issues and on areas where they think we need to put the most focus in terms of influencing change. It's a positive meeting every time" (Informant NGO3).

From this Informant's point of view, IEDWG works better than ESWG as a forum for open discussions in relation to primary education policy influence (Informant NGO3), but they are closely connected. Indeed major donors who are ESWG cochairs and also chairs in IEDWG, might be able to lobby their government counterparts outside ESWG meetings. Phommalangsy (2013) describes such lobbying as 'behind the scene discussions' that are normally in the form of informal meetings between the Ministry and individual donors. It is not certain, however, the extent to which this mechanism works, especially for sensitive issues that require higher pressure and more inputs from wider stakeholders. Moreover, IEDWG is a platform in which NGOs and donors only try to agree on the issues to be brought to the next level discussions in formal ESWG FG meetings. The discussed issues, especially policy, are then finalised at the ESWG executive level in which those who make the final decisions are the government (Informants NGO2, NGO5, NG07, GOV3). The fact that education policy issues are approved at the executive level indicates that even NGOs' influence in the ESWG FG level has a limited impact, let alone their influence through IEDWG which is even a further removed from policy decisions.

Although the IEDWG is considered an important channel for NGOs to identify issues and focus collectively, consensus is not always achieved (Informant NGO2). NGOs 
have different approaches to different issues (Informants NGO2, NGO3). It can be even harder to bring NGOs and donors to consensus on some issues, given that they have quite different strategic intents and priority areas (Informants DU3, NG05, NG07). Sometimes NGOs and donors compete with one another for the same sources of funding through making their advocacy focus distinct from each other (Kim, 2011). Phommalangsy (2013) notes that there is often competition among DPs in education policy development. For example, during the development process of ESDF 2009 - 2015 and ESDP 2011-2015, DPs tried to push for their individual policy agendas to be integrated into Lao education policy as a means to achieve visibility and recognition from the government and other DPs (ibid.). Therefore, although IEDWG can be an effective policy mechanism in itself, it is more likely to be used as a discussion forum among NGOs and donors to probe what and how to advocate for policy change. Such attempts to agree on joint policy advocacy, nevertheless, are not always successful due to differing strategic priorities and competing concerns for their organisational visibility.

\subsection{Capacity Development for Policy Makers as an Influencing Strategy}

Capacity development for government officials is a long-term goal that potentially influences policy change (Informants NG02, NG04, NGO5, NG07, NG08, NG09). This strategy avoids confronting government policy directly, and brings about 'within system' change (Informants DU4, NGO4, NGO5, NGO9).

In order to ensure effective discussions, NGOs work to develop the capacity of their government partners, broadening their perspectives which in turn paves the way (at least in theory) for a greater openness to policy change (Informants DU4, NG04). As GoL has a strong political direction, exposing government policy makers to other types of policy with different kinds of knowledge and experience in other countries can be an indirect political tool to advocate for change (Informants DU4, ES2, NG05). However, this does not ipso facto mean that NGOs are trying to undermine Lao political stability through injecting new knowledge and experience which may not suit the Lao context. Rather, it means that NGOs support the Ministry policy makers to broaden their perspectives and view policy issues from different angles. This support also reinforces the effort of GoL which is committed to leading its own 
development agenda since the adoption of the Vientiane Declaration on Aid Effectiveness (GoL, 2006; Noonan et al., 2013). In this regard, a senior participant from a donor agency noted that:

"I think yes! I think that exposure to other experiences in other countries can be very useful, because the government is very often requesting various study tours to go and see various elements of successful implementation" (Informant DU4).

As pointed out by Informant DU4, capacity development, especially through study visits and training, also aligns with the government's priority areas. Most, if not all, education sector plans and reports prioritise and recommend capacity development within the sector as a significant need (MoES, 2000, 2008a, 2011a, 2011b; UNESCO, 2015). For example, the ESDP 2011-2015 highlights that GoL together with DPs need to "ensure that education officers are adequately trained to support education service delivery at all levels of education administration" (MoES, 2011, p.6). The national Education for All (EFA) review report for Laos conducted most recently in 2015 also states that "the MoES will draw an implementation plan on how to strengthen the capacity of the human resources in their system vertically and horizontally" (UNESCO, 2015, p.46). Therefore, NGOs' influencing strategy through capacity development for MoES officials serve both NGOs and GoL interests, and will thus likely be one of the best entry points for policy change. A senior donor representative revealed during their interview that their organisation supported Lao government officials on a study visit to a foreign country to learn about education budget allocation (Informant DU4). They further explained that the government officials gained a comprehensive understanding of legal and financial frameworks after they were exposed to different experiences throughout the fieldwork (ibid.). As a result of this study tour, the government started allocating funding for the budget lines that their organisation had long advocated for, because the government understood that if they had the budget line, donors could fund directly to that budget line (ibid.).

Similarly, a senior NGO representative pointed out that their organisation invested in capacity development, including training and study visits, as a long term strategy 
for policy influence (Informant NG05). Their organisation particularly supported government officials who were involved in policy making in order to change their way of thinking (ibid.). For example, their organisation supported some highranking government policy makers for several study visits in Asian countries to learn about multilingual curriculum as a means of reducing their fear of national disunity (ibid.).

The government's level of capacity has a considerable impact on their willingness to embrace change in Lao primary education policy (Informants GOV5, NGO5, NGO7, NG09). For example, a senior government official repeatedly emphasised that the government was unable to introduce multilingual curriculum due to their shortage of technical and financial capacities (Informant GOV5). Among many other capacity shortfalls, MoES always cites financial capacity as the biggest concern given that Lao primary education relies almost entirely on financial support from DPs (Kim \& Jeong, 2013). That said, if the government adopts any change in primary education policy, for example the introduction of multilingual curriculum, there is concern that it will create a massive financial burden for the government in terms of curriculum development, teacher training, recurrent expenditure and other operating costs which usually comes from the government's own budget and finances (Informant GOV5). Therefore, exposing GoL policy makers to different ways of thinking through training and study visits could contribute to improved budgeting within primary education and increased willingness to explore policy options in the long run (Informants GOV5, NG05).

Nevertheless, when NGOs and donors support government officials' study visits, it is often unclear how much those officials actually learn from such visits and how much the knowledge and experience gained can be put into practice in the unique context of Laos (Informants DU4, ES2). There is also criticism that some officials only take pleasure, leisure, and financial benefit from the study tours, but fail to bring knowledge for policy improvement (ibid.). Some participants commented, however, that NGOs should make an agreement with their government counterparts that the latter have to develop action plans by integrating knowledge and experience gained from study visits, in order to ensure that the money spent on such 
visits has an impact on primary education policy (Informant NGO4). An NGO Informant highlighted that "it's not that they go for a study tour just for the sake of going. There's a need for a follow-up plan about what we are going to do in the future after such tour. It's not just a study tour and nothing happens" (Informant NG04). After the visits and training, government officials are expected to be able to analyse what works and what does not work to some extent in their policy frameworks (Informants DU4, NGO4). Therefore, supporting government officials for study tours and training is a long term investment to change ways of thinking; and even though the impact may not happen immediately, it is considered better than doing nothing (Informant NG05).

Engaging high-ranking government counterparts in project monitoring and evaluation to develop capacity is another pathway to policy influence (Informants NG04, NG06, NG08, NG09). Due to the centralised nature of Lao's education management system, primary education policy is mainly developed by central policy makers in Vientiane (Informants NG02, NGO6, NGO7, NG08). In other words, policy development is based on a top-down rather than a bottom-up process, despite government claims that they have applied a participatory bottom-up approach in developing Lao primary education policy (Informant NG06). This results in a huge gap between policy development and policy implementation, as policy is sometimes unrealistic, too ambitious, and beyond the capacity of the local level to implement (Informants NG06, NG07). Therefore, including national level policy makers in monitoring and evaluation and other project activities provides them with grounded knowledge and experience that can bridge the gap between policy and actual implementation (Informants DU5, NG06, NG09). A senior NGO representative also highlighted that:

"Within Laos, something that works much better is to take people from the central level down to the implementation level to show and demonstrate concretely how it works and what it means there. And to have the central level talk to the sub-national level, policy makers at the national level discuss with officials from the PESS [Provincial Education and Sports Services], officials from the district. I mean simply the fact of where NGOs are effective in, it's 
simply to facilitate the exchanges between policy development and implementation levels. Bringing the central level down to the implementation level and having people who are generally interested within the education development system to share experiences" (Informant NGO9).

Informant NG09's comment suggests that policy makers should conduct their own research by seeking evidence from the field, with support from NGOs. This process is more likely to bring about within-system change through improved internal communication, rather than direct influence of NGOs and donors (Informants NGO5, NG07, NG09). Engaging central policy makers in project monitoring and evaluation at the field level is regarded as a quick and effective mechanism to influence policy change in primary education because policy makers learn the benefits and drawbacks of the policies for themselves, rather than just relying on evidence from NGOs and other DPs (Informants NG06, NG09).

Recognising that they have very limited direct influence on primary education policy in Laos, and given the fact that PESS and the District Education and Sports Bureau (DESB) are in a better position to convince MoES to change some policy issues, many NGOs have focused on strengthening their relationships with local authorities (Informants DU1, NG06, NGO7). Most NGOs' strategies have focused on improving coordination with district and provincial levels of government. For example, a programme strategy of a well-known education NGO in Laos states that:

"More recent developments at central level have included improvements in coordination and cooperation among Government and development partners and yet this has not always been matched by similar developments at provincial level. The programme will give specific attention to supporting improved coordination among education stakeholders within target provinces as well as helping to ensure linkages with coordination processes at central level. The establishment of improved coordination mechanisms at provincial level and, where appropriate, at district level, will strengthen the Province's management of resources and will be led by PESS with SC [Save the Children] providing logistical and some small scale funding support." (Save the Children, 2009, p.11) 
Some participants pointed out that NGOs can influence policy more significantly by working at the provincial level and through the Provincial Coordination Mechanism (PCM) (Informants DU1, ES1). A senior education specialist commented that "I went to a couple of that [PMC] meeting. My own impression was that the NGOs had a lot of more inputs through the provincial coordination mechanism. They knew a lot of players. So, I think they have a lot of influence at those meetings." (Informant ES1). The significance of PCM was confirmed when it was introduced as one of the key coordination mechanisms in the upcoming Basic Education Quality and Access in Laos Programme (BEQUAL) with an aim to facilitate policy dialogues between local authorities and DPs (DFAT, 2014). The introduction of PCM into BEQUAL suggests an effort by NGOs and donors to increase their influence on Lao primary education indirectly from the bottom up.

Instead of directly influencing policy change at the national level, therefore, NGOs try to create a platform for dialogue between central and local levels and voice concerns through the PESS and the DESB (Informants NGO2, NGO6, NGO7). A senior NGO representative characterised this strategy as "work with the micro level with the expectation that the micro level will convey the message to the macro level" (Informant NG06). They explained how this strategy worked:

"We work with the district level and we involve provincial authorities for monitoring our activities. So, what we have been working for policy changing are that we work at the micro level and we hope that from our experience it will be like a model or a case study for the provincial authorities to bring up to the central government for change" (Informant NGO6).

The fact that NGOs work closely with PESS and DESB allows them to influence policy implementation through providing knowledge and skills to local authorities and creating evidence-based success stories with them (Informants DU2, NGO2, NGO6, NGO7). In turn, DESB and PESS are increasingly willing to speak on behalf of, or with, NGOs to advocate for primary education policy change at the central level (Informant NGO7). In this regard, another senior NGO representative commented that: 
"We are working with the government at the local level, so we bring the knowledge and skill. So they appreciate that if we come up with the evidence. We are not coming from the district and sound [speaking] alone. We ask local people from the district level to come and stand with us and sound [speak]. No, not good! Change this, change this, and then the ministry listens" (Informant NGO7).

Again, the capacity of the national government to 'listen' depends on the type of issue and its political sensitivity. NGOs, PESS, and DESB are successful in advocating some changes in primary education policy, for example, in teaching methodology and the integration of indigenous knowledge within primary school teacher training courses through evidence-based successes (Informants GOV6, NG04, NGO6, NG07).

\subsection{Specialist Deployment as an Influencing Strategy}

Another mechanism that NGOs may use to influence primary education policy is deploying education specialists to be based in MoES (Informants DU4, ES2, ES3, ES4, NGO3). Despite the fact that over the past decades only major donors such as Swiss International Development Agency (SIDA), DFAT and JICA have seconded their specialists to MoES, most participants asserted that NGOs can do the same thing, as MoES is open to technical support from all DPs (Informants ES1, ES3, ES4, GOV1, GOV2, GOV3). In fact, some NGOs such as Save the Children, Plan International and Catholic Relief Service are in the process of preparing to deploy their specialists to MoES in due course, with the aim of gaining better access to policy influence (Informants ES2, ES3, NGO3).

Phommalangsy (2013) notes that DPs who have deployed their education specialists to MoES have significantly increased access to policy dialogues as the deployed specialists can provide direct technical advice to the relevant Ministry departments. They can also work closely with government policy makers in the ESWG secretariat which is located in the Department of Planning and Cooperation in MoES (ibid.) Therefore, deploying their specialists to be based directly in relevant MoES departments, such as the Department of Pre and Primary Education and the Department of Planning and Cooperation, would allow NGOs to pursue effective 
communication on policy issues with Director Generals (DG) of those departments as well as other ministry leaders (Informants ES1, ES4). A senior education specialist explained that:

"[I have some influence on education policy] through discussions with the DG and through involvement in the agenda setting for various meetings, inputs for the joint sector review mission which we had for the last four years, being involved in the midterm review of the education sector plan. We had a midterm review in 2013 that produced the report which led to many recommendations... and also provide advice to [my organisation] for our development plan. That's the chance for influence" (Informant ES1).

Through their guidance on agenda setting and planning and reporting processes, the deployed specialists have potential to influence decision making processes and policy outcomes (Informants ES1, ES3; Phommalangsy, 2013). Furthermore, deploying specialists to MoES also allows NGOs to have better access to information about changes in government direction, under which NGOs are required to adjust their strategy in order to advocate change effectively (Informant ES4).

The fact that deployed specialists work closely with policy makers at the Ministry also provides an opportunity for the former to develop professional and personal relationships with the latter (Informants ES1, ES3). Personal relationships are crucial for working in the Lao socio-political context. Government officials were more likely to trust individuals than their organisation, and thus officials stated that they felt more comfortable discussing policy issues with specialists who demonstrated honest and constructive concerns and recommendations (Informants ES3, GOV2, GOV3). Based on my own experience being seconded to a government ministry (although not MoES) in 2009, I also felt that I developed significant personal relationships with Ministry policy makers and we became very good friends. These relationships in turn resulted in their trust and willingness to integrate my inputs in policy frameworks. While my case may not represent what might typically happen between NGOs and MoES, as I was deployed as a United Nations (UN) staff, the fact that effective personal rapport is crucial to working with 
government officials remains plausible and applicable across the full government spectrum. Moreover, some senior NGO representatives also revealed that they had better access than others to policy dialogues with high ranking government policy makers, not only because their organisation had long established healthy relationships with MoES, but also due to their outstanding personal relationships with senior ministry policy makers (Informant NGO7). In regards to the significance of deploying specialists to MoES, a senior government official noted that:

"We have some specialists from development partners, for example from JICA, based in our department to assist us. In fact, they play a crucial role in policy development to link our education system with international standards and make sure that we don't lead our education only in our own way per se. Those specialists help us in this regard" (Informant GOV2).

As illustrated in the above comment, the deployed specialists are likely to influence primary education policy to meet international standards, for example MDGs and EFA Goals, through their advice and recommendations in key policy documents such as ESDP, EFANPA, and even education law (Informants ES1, GOV2,). Through their engagement in such processes, the deployed specialists also represent their organisation in framing Lao primary education policy towards the global environment which is usually aligned with their organisational agenda (Informant ES3; Phommalangsy, 2013).

Deploying specialists to MoES was also considered an indication of NGOs' serious investment in policy influence. A senior education specialist asserted that "if NGOs want to have more influence on government policy, they have to invest seriously in their policy advocacy and not just sell their [ideas] occasionally through the meetings" (Informant ES3). The comment of this specialist (ibid.) also links to reports from an influential donor stating that their organisation has gained significant visibility at policy level, because it has invested considerably in providing technical support for ESDPs as well as the overall development of Lao education policy (AusAID, 2011, 2012). 
Many NGOs admit that their investment in policy advocacy is hindered by budget constraints and human resource capacity (Informants NGO2, NGO3, NG08). For example, two senior NGO representatives acknowledged that their organisations are not really apparent at policy level, because they cannot afford hiring highly qualified experts to advise the Ministry on policy issues as practiced by major donors (Informants NGO2, NGO3). Some NGOs are also unable to attend sector working group meetings due to their limited staff members who are capable of representing their organisation in various policy dialogues (Informants ES3, NGO1, NGO2, NG03, NG08).

Likewise, a senior government official also commented that NGOs have not sufficiently invested in engaging in primary education curriculum development by not deploying specialised experts to provide technical advice in the process (Informant GOV1). In contrast, influential donors with far larger budgets have invested massively in education policy influence. For example, DFAT deployed two specialists to MoES to advise planning and reporting processes as well as to coordinate ESWG at the Ministry (Informants ES1, ES3). JICA also deployed two experts to the Department of Pre and Primary Education at MoES to closely advise the department on various policy issues (Informants ES4, GOV2). Therefore, if NGOs invest more in policy by deploying specialists to MoES (as some NGOs are preparing to do), it is likely that they will have more influence on primary education policy.

Participants interviewed noted that the deployed specialists also need to have both diplomatic skills and negotiation experience, and properly understand the sociopolitical context of Laos (Informants ES2, DU4). Moreover, due to the fact that seniority matters in the Lao social context, NGOs should deploy senior specialists with solid experience in education to work with MoES counterparts (ibid.). Otherwise, they might just work as a secretary to the ministry, and their inputs would not be taken into consideration. In the worst case scenario, these specialists might undermine relationships between their organisation and MoES (ibid.). For example, a senior donor representative admitted that their organisation made a big mistake by deploying a junior staff member without specialised expertise and 
proper diplomatic skills to MoES, which in turn undermined the relationship between their organisation and MoES (Informant DU4). They explained that:

"[Some organisations] have people deployed to the Ministry at the senior level, expats, farang ${ }^{7}$ that are sitting a few days a week providing technical inputs for the Ministry. [Our organisation] used to have something similar, but we only had junior staff and not technical staff that was sitting and assisting the Ministry in helping out writing the policy. So, because [our organisation] only provided junior staff who are not technicians, our inputs were probably not valuable. I think it was more like people sitting and translating things. [By deploying an expert not ordinary staff to be based in the ministry], NGOs can definitely have more influence on the policy, because they can provide the real technical inputs...I think the government are sometimes looking for the technical expertise and the NGOs many times have been able to provide that and have an invest in that. I mean [our organisation] has invested in that as well but not just at the right level. So, that was our problem" (Informant DU4).

While deploying farang expatriates or other foreign advisors rather than local specialists to MoES is a trend in Laos, many participants believe that it would not make a major difference if NGOs deployed local specialists to the Ministry (Informants DU4, ES3, NGO3). What defines the degree of specialists' influence on policy is their expertise to advise the Ministry on education policy development as well as their diplomatic skills to convince MoES to make changes in such policies (Informant ES3). Some NGO participants did argue that there was a distinction between deploying foreign specialists and Lao specialists to the Ministry (Informant NG08). They explained that the Lao government is more willing to listen to expatriates than local people, although this does not necessarily mean that foreign experts have more influence than Lao experts on policy development (ibid.). This argument reflects a common assumption among many Lao people that people from developed countries are more knowledgeable than Laotians. A senior government official also admitted that "they [foreign specialists] have a lot of ideas. Sometimes

\footnotetext{
${ }^{7}$ Farang means 'white people' (or foreigner from the West) and is a well-known phrase in Laos. Sometimes expatriates also call themselves 'farang'.
} 
what we couldn't think of, those people came to assist us to figure out" (Informant GOV2). Nevertheless, in many cases deploying local specialists to work with policy makers at the Ministry could have more benefits, because local specialists share not only the same language but also social and cultural commonalities, which normally pose challenges for foreign experts (Informant ES3). One local senior NGO representative claimed to have been involved in internal MoES policy discussions more than other NGO representatives (Informant NGO7) and they attributed this to the fact that they are local staff, with whom MoES feels more comfortable and has a stronger sense of trust to discuss both internal (sensitive) and external policy issues.

Currently, many NGOs and donors are also shifting from deploying expatriates to deploying local experts to government ministries where possible in response to the ministries' preference (Informants ES3, NGO8). Also, donors and NGOs are opting to hire local specialists not only because they are far cheaper than expatriates, but also because they believe this option better strengthens relationships between their organisation and the government. For example, an NGO is planning to deploy a local education advisor to MoES in due course to work closely with Department of Pre and Primary Education as well as ESWG FG (Informants ES3, NG03). Therefore, while it is impossible to say whether local education specialists would have more policy influence than foreign specialists, it seems reasonable to expect that capable local specialists can develop both professional and personal relationships with MoES policy makers faster and more effectively, which in turn creates a viable entry point for convincing MoES to make some changes in Lao primary education policy.

\subsection{Other External Influences on Lao Primary Education Policy}

Many participants asserted that external forces are one of the key factors that contributed and would contribute to changes in Lao primary education policy (Informants DU4, ES1, ES2, ES3, GOV1, GOV2, GOV4, GOV5, NG05, NG08). Some even commented that external pressure from global and regional changes was more powerful than NGOs' influence (Informant NGO8). Forces from ASEAN and AEC (ibid.), and the advent of social media in a more liberal Lao society (Evans, 2002; 
Informant NG05), are often cited as examples of external powers that will drive change in Lao primary education policy.

Participants described Laos' integration into ASEAN and AEC as the most influential external force that would push GoL to change primary education in the long run (Informants ES2, NG05, NG08). For example, a senior NGO representative highlighted that:

"The government [of Laos] is also having pressure from outside, from the ASEAN community and we are becoming a member of AEC very soon. So, our policy must be in line with other ASEAN countries as well, including the education" (Informant NGO5).

The pressure from the ASEAN and AEC has gradually moved Lao primary education towards regional standards (Informants GOV1, NG05). Perhaps the most significant move is the enforcement of English language as a compulsory subject from grade 3 of primary schooling as stated in the 2015 amended law (Informant GOV1; MoES, 2015). A senior government official commented that the introduction of English at primary school level is directly influenced by regional and global forces, especially the ASEAN, given that English has become necessary in international communication (Informant GOV1). He further explained that as AEC is becoming fully operational by the end of 2015 English will be made compulsory across the Lao education system in 2016. From then on English will be taught in all schools, and university entrance will include English language exams (ibid.). Undeniably, external forces have already played an important role in shifting Lao education policy.

The fact that education is one of the most discussed issues in ASEAN meetings has gradually shifted the political will of GoL, especially MoES, which has become more willing to embrace change than other ministries (Informants DU5, ES2, NGO2). Exposure to new knowledge and experience in other ASEAN countries, for example Singapore and Cambodia, has also impelled GoL towards a more open view on how to improve the quality of Lao primary education (Informant ES2). Having said this, 
how influential the ASEAN and AEC forces are or will be for politically sensitive issues, for example, the introduction of multilingual instruction in Lao primary schools remains an open question. As a senior education specialist noted, GoL's refusal to adopt mother tongue based instruction indicates its lack of political will to change (ibid.). The potential of ASEAN to convince GoL to apply multilingual curriculum in Lao primary schools appears doubtful given that Laos has joined ASEAN since 1997 and no change has been made to the enforcement of monolingual curriculum since then. Moreover, Laos is not the only country that has not applied multilingual curriculum among the ASEAN members. Brunei, for example, despite its different socio-political context, has enforced monolingual curriculum for the same concerns as Laos (Informant NG05). Therefore, while the claims made by some participants that ASEAN and AEC are more powerful than NGOs (Informant NG08), and that Lao primary education policy will be eventually be assimilated into a system like other ASEAN members (Informant NGO5) may have validity, whether or not this is applicable to politically sensitive issues remains an open-ended question.

However, a clear example of the actual influence of the ASEAN and AEC on Lao primary education policy is the fact that Laos has more widely used mass media, albeit under a certain degree of state control, to communicate within the country and with other neighbouring countries, especially among young people (Evan, 2002). This potentially means those young people have used social media such as Facebook and Twitter widely, to express their views on social problems and government policy (Informant NG05). A senior NGO representative asserted that working with young people, like some NGOs have been doing, to train them on how to use social media could work better than other long-term mechanisms to influence government policy (ibid.). They commented that:

"In today's development, media is the best. The social media is the best mechanism to influence policy change, for example. In today's situation, to educate young people to have access to social media, internet access, for example, is the best way for Laos. I mean it's an immediate influence on the change from the families, communities to the town and to the country, I mean. 
It's like it's a very good process and it's a good mechanism for policy change" (Informant NGO5).

Although using social media might be a useful way to advocate change in government policy (Informant NGO5), much of the traffic on social media is not particularly well informed, which can be misguiding for youth without proper discretion. More importantly, it should be noted that public criticism is disallowed in Laos. Therefore, while this strategy may work to some extent and in some contexts, particularly for apolitical issues, it is often associated with risks to safety for both people who use social media to criticise issues sensitive to the government, and for NGOs who support those people. Criticising politically sensitive issues in government policy, particularly outside the official formal forums provided by the government, can bring more harm than good for any person or NGO (Creak, 2014; Delnoye, 2010; Informants GOV3, NGO7). As discussed in Chapter 4, an NGO country director was expelled from Laos for criticising government policy through social media (Creak, 2014; Frohofer, 2014; Kepa, 2013), and this is the most troubling, yet remarkable, example of the repercussions from using social media to confront GoL. Therefore, the safest, albeit not the most direct, ways to advocate change in government policy, and in primary education policy in particular, is through mutually accepted and formal mechanisms such as ESWG, specialist deployment, and capacity development for government policy makers.

\subsection{Summary}

In this chapter, I have discussed the strategies and mechanisms that NGO use to influence Lao primary education policy. I examined the effectiveness of ESWG, particularly at the focal group level, which is the main official forum provided for NGOs and other DPs as a policy consultation platform. I argued that while ESWG FG serves as a very useful mechanism for discussions of the issues where MoES really seeks input from NGOs and other DPs, it fails to advocate for change on politically sensitive issues which remain untouchable by any means. I also argued that while IEDWG serves as an effective mechanism among NGOs and major donors to identify advocacy priorities and develop joint initiatives for policy advocacy, it sometimes fails to produce and convey strong messages to the government, as NGOs and 
donors at times have different priorities and approaches. Subsequently, IEDWG serves as a 'think tank' for advocacy areas among NGOs and donors, rather than a vehicle for driving changes in primary education policy.

I further investigated the implications of capacity development activities for government policy makers that NGOs have invested in as a long-term influencing strategy, predominantly in the form of overseas study visits, training and field monitoring and evaluation. While this strategy appears to be a worthwhile investment, given that it also responds to GoL's needs, I argued that the improved capacity of government policy makers can have very little impact, if any on NGOs' key advocacy areas, like the adoption of multilingual curricula. Nevertheless, this strategy might work for certain issues such as budget allocation for budget line, teaching methodology, and integration of indigenous knowledge in primary school.

Looking forward to the near future, deploying specialists to MoES is also considered an effective mechanism for NGOs to obtain better access to policy dialogues with Ministry policy makers. Through working closely with high-ranking government officials, the deployed specialists can develop professional and personal relationships, which can in turn result in trust and create more room for policy influence. While there are mixed views on the advantages and disadvantages of deploying foreign versus local specialists to MoES, deployment of specialists (whether foreign or Lao) with solid specialised expertise and diplomatic skills is most recommended to enable NGOs' better access to high level policy dialogues and possibly increased influence.

Last but not least, other external forces such as the pressure from ASEAN and AEC are considered influential factors for driving change in Lao primary education. However, I argued that such pressures may not have much impact on the issues for which GoL lacks political will, such as the introduction of multilingual curriculum. Whereas social media may be a powerful tool to advocate change in government policy in general and primary education policy in particular, I suggest that advocating change through formal and mutually accepted forums is the safest and most constructive mechanism. 


\section{Chapter 7: Discussion and Conclusion}

\subsection{Introduction}

This chapter discusses the research outcomes and concludes the entire study. The chapter begins by summarising the key findings to the research questions. It then assesses the findings in relation to key literature and other relevant studies. Finally, it offers some concluding thoughts and recommendations for future research.

\subsection{Addressing the Research Questions}

This research examined the extent to which NGOs have influenced Lao primary education policy through their roles as perceived by development partners in the socio-political context of Laos, through answering the following research questions:

1. How do Government of Laos and major donors perceive the role of NGOs at policy level?

2. How has the relationship between the Government of Laos and NGOs changed since the adoption of Vientiane Declaration on Aid Effectiveness in 2006 in relation to primary education policy?

3. What mechanisms and strategies have NGOs used to influence Lao primary education policy?

The findings illustrate that NGOs have limited influence on Lao primary education policy. Although NGOs may, to some extent, have influence on the process of policy development through their participation in policy dialogues, they have very little influence on the outcomes of policy development. The fact that NGOs have limited influence on policy outcomes is due partly to their limited financial capacity and lack of specialised expertise to support and convince the government for policy change. The most important factor, nevertheless, appears to be the government's reluctance to incorporate NGOs' inputs into Lao primary education policy due to its wariness of NGOs' influence, particularly on politically sensitive issues. 


\subsubsection{NGOs' Roles in Laos: Service Providers vs. Policy Advocates}

The results of my analysis in this research results suggest the operation of NGOs in Laos is closely supervised by the Ministry of Foreign Affairs (MoFA). Through the enforcement of Decree 13 on the operation of NGOs, the role of NGOs is confined to that of 'service provider' rather than 'policy counterpart' (PMO, 2010). Such confinement has had an overarching impact on the manoeuvring of NGOs in Laos as a whole with no exception to those operating in education sector. A senior government official argued with me that the enforcement of Decree 13 was intended to facilitate effective NGOs' operation rather than to control them. However, the way this Decree defined the role of NGOs seems to indicate GoL's commitment to keep NGOs in their 'service-provider' role, assisting the government to address needs at the community level, rather than contributing to policy direction.

Cleary (1997) notes that in strictly state-controlled or authoritarian regimes, a common measure that governments use to hamper NGOs' role in policy advocacy is a draconian law on NGOs' operation, that keeps them an apparatus of the state. He further notes that such laws can legitimise governments' suspension of NGOs' operations and can even be used to dissolve an NGO if it does not conform to, or threatens, public security and national unity (Cleary, 1997). Specific to Laos, Roberts (2004) concludes that NGOs are strictly supervised by MoFA which intends to keep NGOs as an appendage to the state. My research findings, as presented in Chapter 5, are in agreement with both Cleary (1997) and Roberts (2004). They also align with several scholars who assert that governments commonly perceive NGOs as service providers who largely conform to, rather than challenge, government policies (Coston, 1998; Banks \& Hulme, 2012; Korten, 1987; Willis, 2011).

As discussed in Chapter 5, NGOs that are perceived to be acting more as policy advocates than service providers are bound to be closely supervised by the government. A high-ranking government official reported that some advocacy NGOs, which often have a hidden religious agenda, have criticised the government through what the official described as misleading propaganda related to social and political issues such as democracy and human rights (Informant GOV2). This has prompted the government to keep advocacy NGOs under even stricter surveillance. 
Furthermore, although government officials who participated in research interviews did not mention it directly, they did allude to GoL's preference for development NGOs over advocacy NGOs. This observation corresponds with Chum's (2010) reflection that the "[Cambodian] government seems to value development NGOs rather than advocacy and human rights NGOs" (p.133). Cambodia and Laos share several aspects in common, and that most NGOs in Laos, particularly education NGOs, have a very close connection and even share the same parent NGOs with NGOs in Cambodia. Therefore, it is logical to conclude that governments in this region are reluctant to promote NGOs as policy counterparts for fear that their influence would undermine public security, and most importantly, political regimes, as also discussed Howell et al. (2008) and Bennett (2000). My research, however, examined the role of NGOs in Laos, a single-party state, where the results even more strongly substantiate the claim that development NGOs who act as service providers are preferred by the government.

Roberts (2004) in his research on the role of NGOs in developing countries in Asia, drew a conclusion specific to Laos that, under the current political context where a one-party government controls virtually all aspects of public life, NGOs have extremely limited influence on government policy. He further observed that NGOs' role in Laos mainly focuses on substituting public goods and services at the local level that GoL cannot provide due to its budget constraints. My research findings closely correlates with this argument in the respect that NGOs have built primary schools and provided teaching and learning materials at the community level where GoL lacked the budget to do so. NGOs also opted to assist the government to develop a teaching methodology to help ethnic children to learn in Lao (Informants GOV5, NG03, NG07), although their desired advocacy was the introduction of mother tongue based instruction. My research, however, has identified different mechanisms and strategies that NGOs have used and may use to shape policy discussion process in this context and, in doing so, it has filled a gap in the literature

As discussed in Chapters 4 and 5, GoL under the leadership of Lao People's Revolutionary Party (LPRP) has placed political stability and so-called 'national unity' at the top of all development agendas. The LPRP has striven to build the 
national identity and unity through a very clear and defined political direction and has reserved certain issues from the influence of DPs, especially NGOs who often press for change on politically sensitive issues. With its absolute autonomy, GoL can politicise certain development issues as politically or publically sensitive by invoking national unity and public security as a means to limit the influence of NGOs and other DPs. This has directly affected the influence of NGOs in Laos, especially at policy level. Kim (2011) notes that the socio-political contexts of the countries in which NGOs operate are the key determinants of NGOs' space in policy arena: NGOs can have more influence on policy development in countries where a democratic system is strong; while in countries with a young democracy, NGOs tend to have minimal influence on public policy. Kim's observation was indeed reflected in my research in Laos, where I found that NGOs had limited influence on primary education policy even though they were engaged in the policy development process in various ways. Laos is a country with young and still highly centralised democratic structures.

My findings, as presented in section 5.5, also extend the understanding of how the rhetoric and the politics of participation are used in the relationship between GoL and NGOs as a means to keep development projects going while avoiding confrontation. I described this as a 'politics of participation and rhetoric of recognition' in which a 'game of diplomacy' is being played between GoL and NGOs or as a senior education specialist puts it: "the government tried to push NGOs to do something while NGOs also try to push the government to do something. They have to get on. They please each other, but sometimes they kick one another out" (Informant ES2). Both the government and NGOs have their own agendas and try to promote their agenda through diplomatic strategy in order to avoid explicit tensions and mistrust between the two parties. The former officially recognises the latter's role in policy development by 'inviting' them to consultation meetings and 'welcoming' their inputs while the latter try to convince the former through evidence-based information and success stories. These findings, to my knowledge, have not previously been identified in other research in Laos. 


\section{Differences between NGOs and Major Donors at Policy Level}

As discussed in Chapter 5, GoL views major donors such as the Australian Department of Foreign Affairs and Trade (DFAT), Asian Development Bank (ADB), the World Bank (WB), Japanese International Cooperation Agency (JICA) and the European Union (EU) as policy counterparts with a certain level of legitimate influence on Lao primary education. Distinctions in the power relations between GoL and NGOs, and GoL and major donors are evident in the structure of the Education Sector Working Group (ESWG) where major donors are the co-chairs at the executive level while NGOs are placed at the focal group level with very limited influence on policy outcomes. However, the extent to which even major donors can actually influence the policy is controversial. All donor representatives asserted that donors cannot really exert influence over Lao primary education policy given that GoL has a very clear policy direction. They further explained that donors are largely willing to support rather than challenge government policy. Such assertions by donor representatives strongly support Simon Creak's observation that "Lao leaders uphold their side of the bargain by maintaining the government's commitment to [national development] goals" (Creak, 2014, p.165). Creak concludes that such commitment continues to ritualise donor aid to Laos, although many donors have witnessed the government's failure to execute appropriate and viable policies.

Most NGO representatives and education specialists, on the other hand, confirmed that donors do have a certain degree of influence on education policy and development policy in general in Laos due to their substantial financial assistance. This view is consistent with Munier (2011) and Phommalangsy (2013) who conclude that international institutions and donor agencies have significant influence on Lao education policy, especially at the primary level. Phommalangsy (2013, p.2), in particular, posits that "because of the government's fear of losing aid, as well as desperate need for finance to support the sector, the government appears to have no room for manoeuvre". His position in this regard seems to contradict the view of all high-ranking government officials participating in my research, who confirmed that GoL has assumed full ownership on its development and thus has 
rejected donor assistance that conflicts government's priorities. While this contradiction suggests a need for further research on the issue, I may conclude that the fact that Phommalangsy's (2013) study overlooked donors' ability to press for change on politically sensitive issues in Lao education policy, could have led him to his conclusion. Moreover, Phommalangsy's (2013) argument rests on donors' influence specifically on the development of the Education Sector Development Framework (ESDF) in which GoL was very open to advice from donors and DPs as a whole. ESDF, however, did not seem to be the NGOs' main area of influence, based on my research.

Another difference between NGOs and donors is the level of their hands-on experience and grounded expertise. Most research participants share the same view as Zeiser (1998) that NGOs are better than donors in producing evidence-based information, which can be used to advocate for change in government policy. This does not, however, suggest that NGOs' position at policy level is equal to that of donors as suggested by some literature reviewed in Chapter 2. On the contrary, as this research suggests, NGOs' role in the decision-making process of policy dialogues is very limited and far less than donors despite the fact that they may have a similar role to donors in terms of taking part in discussions with GoL. These findings correspond with the study by Chum (2010) on the role of NGOs in Cambodia at the policy level. Chum (2010) observes that the role and space of NGOs to engage in policy decision-making are minimal, even though they have extensively participated in policy consultations with the government and donors. He further argues that in many occasions "their [NGOs'] inputs have never been discussed on the table" (Chum, 2010, p.138).

My research evidence also suggests that NGOs' capacity and expertise affects their influence at the policy level. As most senior government officials argued donors have invested heavily in making themselves visible at the policy level. They have hired highly qualified specialists to support the Ministry in policy development. NGOs, on the other hand, are unable to do so due to their budget constraints. As a result, their profile at the policy level, especially in terms of decision making, is less apparent than donors. Chum's (2010) research found that large donors in Cambodia 
often spent a huge amount of money on costly consultants to gain the government's recognition in the policy arena. NGOs are often unable to afford what donors do (Chum, 2010). My research found Chum's (2010) observations to be accurate in the case of Laos.

\section{Relationships between NGOs and Major Donors at Policy Level}

As discussed earlier, major donors perceive NGOs as valuable partners who are endowed with hands-on experience and success stories. They often work with NGOs to advocate for change in Lao primary education policy, as illustrated in the recent amendment of the Education Law in 2015.

Duffield (1997) and Gibbs et al. (1999) note that donor agencies have become more and more interested in partnering with NGOs in development projects, because NGOs are strong at the grassroots level and can efficiently respond to the need of communities. Similarly, Strand (2005) asserts that donors consider NGOs more trustworthy than recipient governments in terms of fund utilisation, particularly in countries with corruption problems and poor governance. The findings of my research similarly show that donors in Laos, especially in the education sector, perceive NGOs as a more efficient and reliable partner. Most donor representatives in my research agreed that NGOs can efficiently run projects, and have thereby gained trust from donors. Mutually supportive relationships between donors and NGOs in Laos are also illustrated in their partnerships in the Basic Education Quality and Access in Laos (BEQUAL) programme in which an NGOs consortium has become a managing contractor.

The results of my study also substantiate McCormick's (2012) argument that NGOs can increase their influence on the process of education policy development in Laos (to some extent) when they work together and in alliance with major donors, although their influence on policy outcomes remains limited. My research found that, in general, NGOs work hand in hand with major donors to drive changes in Lao primary education through the ESWG Focal Group (ESWG FG) and the Informal Education Sector Working Group (IEDWG). However, despite some successes as a result of their joint advocacy (as presented in Chapters 4 and 5), both NGOs and 
donors have not been able to push for changes in politically sensitive issues in Lao primary education policy. The evidence also suggests that while major donors are considered more powerful and acceptable than NGOs to negotiate change on sensitive issues with GoL, NGOs are often expected by the donors to take the lead, which in turn results in failure at times. Lundmark and Malmberg (2008) argue that one of the main reasons behind NGOs' unsuccessful advocacy on sensitive issues is because donors are not adequately backing up the NGOs' position. This argument was also found to be valid in my research. A remarkable example is that donors are not really willing to reinforce NGOs' position in pushing GoL to introduce the mother tongue based instruction in primary schools, because donors are more concerned about their relationships with the government.

Furthermore, Kim (2011) observes that although NGOs and donors tend to work together, they sometimes counterbalance or even act against one another. My research, although it does not substantiate Kim's observation, found that NGOs and donors at times have different advocacy priorities and working approaches, which impact their relationships and weakens their message to the government. Therefore, it is too early to conclude that collaboration between NGOs and major donors has significantly contributed to increase NGOs' influence at policy level in the context of Laos.

\subsubsection{NGOs-GoL Relationships after the Adoption of Vientiane Declaration}

As discussed in Chapters 4 and 5, the adoption of the VD in 2006 has significantly impacted the role of NGOs in Laos. As many participants pointed out, NGOs had a lot of influence on government policy prior to the existence of VD. The introduction of VD represents GoL's commitment to leading its national development (GoL, 2006). At the same time, NGOs as well as other DPs are required to and have aligned their policy with national development goals, especially the National Socio-Economic Development Plan. In turn, as my research suggests, NGOs' influence on government policy has dramatically decreased as they have to compromise with the nationally constructed agenda. In relation to the education sector, the key achievement of the adoption of VD was the establishment of the ESWG which the Ministry of Education and Sports (MoES) has used as a mechanism to manage policy advocacy of NGOs 
and other DPs. While Phommalangy (2013) and Silaphet (2008) have discussed the adoption of VD in relation to aid coordination and effectiveness, neither of them examined how VD affected the role of NGOs, who are unarguably one of the main actors in development in Laos.

\section{The Aftermath of the $9^{\text {th }}$ Asia-Europe People's Forum}

As analysed in Chapter 5, the aftermath of the $9^{\text {th }}$ Asia-Europe People Forum (AEPF9) that took place in 2012 has also had a direct impact on the role of NGOs in Laos. My research found that while many NGOs were gaining trust from GoL by demonstrating their outstanding works, the two incidences of the AEPF9 (see detailed discussion in Chapter 5) have dragged relationships between NGOs and GoL backward. NGOs have become extremely cautious in playing an advocacy role for fear of repercussions. NGOs' unprecedented cautiousness was reflected in their interviews with me. Although most NGO representatives felt comfortable to share their views on several issues, they seemed to be somewhat self-censored in discussing issues that they perceived fragile to the relationships between their organisation and the government. The impacts of the AEPF9 aftermath on NGOs and other civil society organisations have been assessed by some scholars, who concluded that the aftermath of AEPF9 has dramatically affected progression of NGOs and civil society as a whole in the policy arena (Creak, 2014; Frohofer, 2014; Kepa, 2013). My findings reinforce such a conclusion.

\subsubsection{The Mechanisms and Strategies that NGOs use to Influence Lao Primary Education Policy}

Batley (2011), who analysed collaboration between NGOs and governments in basic education, healthcare and sanitation in Bangladesh, India and Pakistan, claims that although NGOs' autonomy is restricted by political contexts, NGOs can and have deployed a wide range of strategies and mechanisms to determine their room for manoeuvre and influence over policy development. My research found his claim to be accurate in the context of Laos where, although NGOs are closely monitored by the state, they try to exercise their influence over Lao primary education policy through a range of strategies. 
As examined in Chapter 6, the key mechanisms and strategies that NGOs use to influence Lao primary education policy are through the ESWG FG, the IEDWG, and by supporting government policy makers for training and study tours overseas. NGOs are also in the process of deploying education specialists to MoES with the aim of wielding more influence on Lao primary education. These mechanisms and strategies have increased NGOs' participation in policy discussions. They have not, however, increased NGOs' influence on policy outcomes, although the imminent deployment of capable education specialists to MoES is likely to provide NGOs' better access to policy dialogues with the Ministry decision makers.

Despite the fact that most interviewees acknowledged that the aforementioned mechanisms and strategies, especially the ESWG FG, have increased or are likely to increase NGOs' role at policy level, they seemed uncertain about the extent to which those strategies and mechanisms have actually contributed to NGOs' influence on policy outcomes. As ESWG FG is the only multi-stakeholder forum officially approved by GoL for open discussions of education policy, all government officials participating in my research enthusiastically and proudly described ESWG FG as a very effective mechanism that NGOs could use and have used to increase their profile at policy level. However the views of NGO representatives are consistent with those of Noonan et al. (2013) and Phommalangsy (2013) who describe the ESWG platform as a 'ceremonial' meeting in which GoL and DPs talk about what to be agreed upon, but the 'real' discussion and decision making are done at higher levels in the government.

Donor representatives and education specialists while viewing ESWG FG as NGOs' entry point for policy engagement argued that in the Lao context it is difficult for NGOs to influence Lao primary education policy at the outcome level through ESWG FG and other mechanisms given their perceived identity (as oppositional) and current legal status (as service provider). This argument builds on that of Banks and Hulme (2012), and Kingsbury et al. (2008) who assert that the legal status of NGOs as service providers and independent organisations who operate in the nonpolitical arena provides NGOs minimal political legitimacy to influence the outcomes of policy change. Banks and Hulme (2012) further note that although 
NGOs may deploy different strategies to influence changes in government policy, they have extremely limited capacity to deal with structurally entrenched problems such as social and political exclusion. Subsequently, NGOs often depoliticise such problems by treating them as technical problems (ibid.). My findings support those of Banks and Hulme's (2012), especially in respect of NGOs' influencing strategy for politically sensitive issues. As discussed in Chapter 6, NGOs keep mentioning to GoL that the enforcement of monolingual curriculum in Lao primary schools has socially excluded ethnic children from their full learning potential. However, as NGOs are well informed that this issue is political, and they cannot push the government to introduce multilingual curriculum, they opt instead to assist the Ministry in developing strategies to help ethnic children to learn better in the Lao language.

The political context also determines how NGOs exercise their mechanisms and strategies for policy influence. For example, Simpkins (2003) who conducted a study on NGOs and their political potential in Thailand, reveals that because there are several political parties in the country, most NGOs often work with certain political parties to increase their influence on government policy. The findings of Simpkins (2003), like those of Hyden (1997), Ife (2002), Krut (1997), Mcllwaine (1998), and Tvedt (2002) suggest that NGOs in more liberal or plural-party states (like Thailand) can act as a counterweight to the government in order to drive policy change. My research reveals that such a strategy is not present in Laos. Given that Laos is a single party state, rather than confronting state power to challenge the government system, NGOs in Laos focus on 'within system' change (discussed in Chapter 6). In general, NGOs' strategies to influence Lao primary education policy follow Christina's (2001) observation that NGOs need to adapt their strategies and mechanisms by taking into account socio-political contexts of the countries in which they operate in order to advocate for policy change effectively and safely. Above all, maintaining healthy relationships with GoL, as well as donors, is NGOs' key strategy to increase their influence at policy level.

\subsection{Concluding Thoughts}

In this section, I provide some concluding thoughts, which are a reflection on the arguments and discussions that I have made throughout the research. This 
reflection is framed through my social constructivist point of view as I discussed in Chapter 3. The concluding thoughts rest primarily upon a more constructive and holistic approach for more effective development in Laos.

\subsubsection{Government Takes Lead with More Inclusive Decision-Making Process}

The adoption of the Paris Declaration on Aid Effectiveness (PD) in the development landscape in 2005 emphasised a shift in aid management from the 'tied' to 'untied' model (OECD, 2005). Laos signed the PD in March 2005 and localised it as VD. The adoption of VD by GoL and DPs in November, 2006 has shifted aid coordination from the 'conditionality' approach towards one of 'partnership' (Robertson et al., 2007). GoL has increasingly taken leadership of its national development agendas, while DPs seem to have gradually reduced their influence on policy development.

The fact that GoL has assumed greater ownership of its national development with a clear direction is very positive in that it means that education delivery is likely to be better contextualised, and therefore more effective. For development either in the education sector or any other sectors to be successful and sustainable in any country, the government needs to own their development agenda as guided by the Paris Declaration on Aid Effectiveness (OECD, 2005) as well as the Busan High Level Forum on Aid Effectiveness (OECD, 2011). Taking this perspective on board, it is both the responsibility and legitimacy of GoL to lead Lao primary education policy development as deemed suitable for the national context. As most participants agreed, the government is the leader of the country who should have the final say for its policy development. In legitimately wanting to maintain sovereignty, the government need not do whatever NGOs or donors tell them simply to keep the flow of aid going.

On the other hand, in my professional experience, most NGOs came to Laos with a good volition to assist the government to respond to the need of communities. As widely accepted, NGOs work closely with communities and thus understand the needs of local people more accurately. In many cases, NGOs can deliver and link communities' concerns with governments' wider priorities. Therefore, instead of an opponent, NGOs should be viewed as a valued partner in development. 
Genuine discussions through effective communication are critical to minimise mismatches of priorities that may lead to suspicion or tensions between GoL and NGOs. The government, in fact, has a very good mechanism to allow fruitful discussions with NGOs to take place, for example ESWG FGs with regard to education policy. Moreover, the government has a system in place to supervise NGOs' operation either through MoFA or the line ministries that they work with. Specific to the education sector, as some senior government officials confirmed, most NGOs working in education have accordingly registered in the ESWG FGs and operate in compliance with the Memorandum of Understanding (MoU) that they signed with the government. Therefore, there is little need for the government to be wary of NGOs' mission. And the government could be less concerned that NGOs' influence will always be threatening to policy decision making processes as most education specialists and NGO representatives recommended. There could be other approaches that GoL could adopt to minimise public criticisms that may trigger interference from outsiders or the international community. Lingard \& Jn Pierre (2006) notes that governments mediate external influence through their clear leadership and most importantly through democratic and participatory consultation with their citizens.

Recently, GoL, especially MoES has been very open to accept inputs and recommendations from NGOs and DPs in general. However, it is not clear how their inputs are considered and whether or not their recommendations are incorporated into policy. Obviously, more effective communication is needed if misunderstandings and tensions are to be avoided.

Donors play a critical role in mediating disagreements between GoL and NGOs given that they are respected by both NGOs and the government. As research evidence suggests, donors are ostensibly perceived as government's policy counterparts who have a certain degree of influence on Lao primary education policy. It is also likely that donors have a certain level of influence on policy in other sectors. Therefore, their role in enhancing government's commitment to creating a conducive environment for genuine policy dialogues is crucial for holistic policy development to happen. As well, donors should take a more critical role in convincing GoL to 
improve education policy as well as other development agendas given that they have better access than NGOs to policy dialogues with high-ranking government policy makers. Having said this, donors are not expected to dominate policy development in Laos. Conversely, they are encouraged to assist GoL to improve its development policy in such a way that the policy does not overlook priorities of minority groups while serving the interests of the majority of population.

\subsubsection{Appreciation of Socio-Political Context}

Christina (2001) notes that appreciating the socio-political contexts of the countries in which they operate is crucial for NGOs to establish an effective role at policy level. Such understanding determines how NGOs establish their relationships with governments through which they can advocate for policy change. Unfortunately, while many NGOs understand the socio-political context in Lao, it appears that others are not so clearly aware. This lack of understanding has made NGOs vulnerable to suspicion and scrutiny.

NGOs need to be aware that some of the mechanisms and strategies that they have used elsewhere may not be appropriate in the Lao context. The case of the NGO director circulating a letter to criticise government policy through social media is an example. While this action might not have arisen from bad intentions, it appears to have been counterproductive in the Laos context, and having a devastating consequence (as discussed in Chapters 5 and 6). This consequence has affected not only that NGO director and her organisation but also the NGO community as a whole. As some research participants described, the fact that GoL has prevented NGOs from influencing Lao primary education can be partly attributed to the way in which some NGO staff outside the education sector recently criticised government policies without understanding the potential impact of that in the context of Laos.

As most participants emphasised, maintaining good relationships with government partners is crucial for working in Laos. Evidently, the most acceptable though not necessarily the most effective strategy to advocate for change in government policy is through the formally provided mechanisms, such as the ESWG in the education sector. Importantly, advocacy needs to be carried out constructively through 
diplomatic means. While sincere discussions are encouraged, criticising government policy publicly is not allowed. Bearing this in mind, people are expected to be patient with the slow process of change in Laos. Change must be made through partnership with the government not by confronting it.

\subsubsection{People as the Centre of Development}

Above all, it is important to appreciate that people, especially marginalised local communities, are the centre of development. Chambers (1997) and Ife (2002) emphasise that contemporary development policy is mainly developed by policy makers within governments and DPs, particularly at the central level, which in turn results in mismatches between development policy and the actual needs of the people.

In the case of Laos, many participants in my research described the process of Lao education policy development as a top-down approach through a centralised democratic process. This results in a huge gap between the policy and implementation, because it is difficult for the local level to put the policy into practice. Some participants also explained that local authorities are not really playing their role in communicating people's need to the central government, because they are not confident to talk about the reality at the local level. In this regard, I believe that there is a need to establish a more appropriate mechanism to ensure that community voices are being heard and better reflected in wider government policy, in addition to the sector working groups and Provincial Coordination Mechanism (PCM) that were discussed in Chapter 6.

On a more positive note, some NGOs have a long history of working with local governments to develop community capacity as well as to bring local needs and concerns to policy makers at the central level. Nevertheless, NGOs may not provide confusing or conflicting advice to local authorities and people that may lead to public misunderstanding or the so-called national unity. The government, on the other hand, while legitimately taking the lead in policy development, could be more open to genuine discussions and consideration of input from NGOs rather than just perceiving NGOs as 'service providers' or 'opponents'. 
As UNDP (2013) confirms, appreciating the roles of different actors at the policy level results in better development outcomes. Indeed, the findings of this research provides grounds for urging GoL and DPs, including policy makers, practitioners and researchers alike, to work more holistically and constructively by appreciating the roles of different actors in policy development and practice in the education sector and more generally in all development agendas for the maximum benefit of all Lao people.

\subsection{Future Research}

This research has provided an understanding of the role of NGOs and the extent to which NGOs have actually influenced Lao primary education. With a hypothesis that NGOs in Laos had increasingly targeted their interventions at the policy level, the focus of analysis was on the process and outcomes of policy development. Accordingly, target participants were those who had been heavily involved in primary education policy development in Laos at the central level. This methodology had similarities with some existing research and analysis (Phommalangsy, 2013; McCormick, 2012; Fox, 2004; Roberts, 2004; Adam et al., 2001), although none of them specifically focused on NGOs' influence on Lao primary education policy.

Nevertheless, it appears that none of those studies, including mine, were able to thoroughly examine the role and influence of NGOs on Lao education at local levels. Research findings were extensively analysed based on views of participants at national level and what was available in documents. The views from education administrators and relevant authorities at local levels were not present in this analysis. Thus, there is still space for wider research in this area.

Given that some NGOs have signed MoU and project agreements directly with local governments, there might be policy issues that NGOs and local authorities have agreed upon beyond those at the national level. Moreover, as most NGOs have their own offices at provincial and district levels in which their staff work closely with local authorities, they may be able to significantly shape the implementation 
process. Therefore, further research is needed to investigate NGOs' influence on policy implementation other than policy development.

Many studies, especially Phommalangsy (2013) and McCormick (2012), attributed external influence on Lao education to global commitments such as the Education for All (EFA) goals and the MDGs which GoL had to align its education policy with. My research also found that GoL's commitment to achieving EFA goals and MDGs by 2015 had opened the door for NGOs to extensively engage in education development in Laos, although their role at policy level was not as significant as donors. Both EFA goals and MDGs are now officially ended (end of 2015) and the Sustainable Development Goals (SDGs) will take their place. The SDGs have placed an emphasis on strong engagement of civil society, including NGOs in policy development (UN, 2015). Therefore, further research on NGOs' influence on Lao education policy is suggested after SDGs have been established in Laos. 


\section{References}

Adams, D., Kee, G \& Lin, L. (2001). Linking research, policy and strategic planning to education development in Laos. Comparative Education Review, 45(2), 220-241.

Ahmed, S. \& Potter, D. (2006). NGOs in International Politics. USA: Kumarian Press, Inc.

Asian Development Bank (ADB). (2011). Civil society briefs: Lao People's Democratic Republic. Vientiane. http://www.adb.org/publications/civil-society-briefs-lao-peoplesdemocratic-republic

Auerbach, C. F., \& Silverstein, L. B. (2003). Qualitative data: An introduction to coding and analysis. New York: New York University Press.

AusAID. (2010). Australia - Laos development cooperation strategy 2009-2015. Canberra: Australian Agency for International Development.

Bäcktorp, A.L. (2007). When the First-World-North goes local: Education and gender in post-revolution Laos. (Doctoral Dissertation). Umeå University, Sweden.

Banks, N., \& Hulme, D. (2012). The role of NGOs and civil society in development and poverty reduction. Brooks World Poverty Institute Working Paper, 171.

Basit, T. (2003). Manual or electronic? The role of coding in qualitative data analysis. Educational Research, 45(2), 143-154.

Batley, R. (2011). Structures and strategies in relationships between nongovernment service providers and governments. Public Administration and Development, 31(4), 306-319.

Bertelsmann Stiftung's Transformation Index. (BTI). (2014). Laos Country Report. Gütersloh: Bertelsmann Stiftung. www.bti-project.org/uploads/tx itao download/BTI 2014 Laos.pdf

Boyatzis, R. E. (1998). Transforming qualitative information: Thematic analysis and code development. Thousand Oaks, California: Sage.

Bennett, J. (2000). Inter-agency coordination in emergencies, in Robinson, D., Hewitt, T. \&Harriss, J. (Eds). (2000). Managing development: Understanding inter-organisational relationships. London and New York: Sage. 
Bird, K., \& Hill, H. (2010). Tiny, poor, land-locked, indebted, but growing: Lessons for late reforming transition economies from Laos. Oxford Development Studies, 38(2), 117-143.

Boli, J. \& Thomas, M. G. (1997). World culture in the world polity: A century of international non-governmental organisation, American Sociological Review, 62 (2), 171-190.

Bryman, A. (2008). Social research methods. Oxford and New York: Oxford University Press.

Burnett, N. (2008). Education for all. Annals of the New York Academy of Sciences, 1136(1), 269-275.

Chithtalath, S. (2006). Community development projects and the status of ethnic minority women in the Moksuk-Tafa area, Bokeo province, Laos. Community Development Journal, 42(3), 299-316.

Christina, R. K. (2001). NGOs and the negotiation of local control in development initiatives: A case study of Palestinian early childhood programming. (Dissertation/Thesis). Department of Educational Leadership and Policy Studies, Indiana University, ProQuest, UMI Dissertations Publishing.

Chum, S. (2010). NGO coordination and the changing aid environment in Cambodia: Challenges and opportunities (Unpublished master's thesis). Victoria University of Wellington, Wellington, New Zealand.

Clarke, G. (1998). Non-governmental organizations (NGOs) and politics in the developing world. Political Studies 46: 36- 52.

Cohen, N., \& Arieli, T. (2011). Field research in conflict environments: Methodological challenges and snowball sampling. (Report). Journal of Peace Research, 48(4), 423-435.

Corbin, J. M., \& Strauss, A. L. (2008). Basics of qualitative research: Techniques and procedures for developing grounded theory. Los Angeles: Sage.

Coston, J. M. (1998). A model and typology of government-NGO relationships. Nonprofit and Voluntary Sector Quarterly, 27(3), 358-382.

Couture, L.A., Zaidi, U.A., \& Tyndale, M.E. (2012). Reflexive accounts: An intersectional approach to exploring the fluidity of insider/outsider status and the researcher's impact on culturally sensitive post-positivist qualitative research. Qualitative Sociology Review, 8(1), 86-105.

Creak, S. (2014). Laos in 2013: International controversies, economic concerns and the post-socialist rhetoric of rule. Southeast Asian Affairs, 2014(1), 149-171. 
Creswell, J. W. (2009). Research design: Qualitative, quantitative and mixed methods approaches (Third Edition). Thousand Oaks, California: Sage.

Creswell, J. W. (2013). Research design: Qualitative, quantitative, and mixed method approaches. Los Angeles, California: Sage.

Davidson, C., \& Tolich, M. (2003). Social science research in New Zealand: Many paths to understanding. Auckland, New Zealand: Pearson Education New Zealand.

Delnoye, R. (2010). Survey on civil society development in the Lao PDR: Current practices and potential for future growth. SDC Mekong Region Working Paper Series. No. 2. Vientiane.

Denzin, N., \& Lincoln, Y. (2011). The Sage handbook of qualitative research (Fourth Edition). Thousand Oaks, California: Sage.

Department of Foreign Affairs and Trade (DFAT). (2014). Investment design document: Basic education quality and access in Lao PDR (BEQUAL). Vientiane: Australian Embassy in Laos. http://aid.dfat.gov.au/countries/eastasia/laos/documents/bequalinvestment-design-doc.pdf

Desai, V. (2002). Role of non-governmental organisations (NGOs). In Desai, V. \& Potter, R. (Eds). 2002. The companion to development studies. London: Arnold, Hodder.

DiCicco-Bloom, B., \& Crabtree, B. F. (2006). The qualitative research interview. Medical Education, 40(4), 314-321.

Dingwall, R. (1997). Methodological issues in qualitative research: Accounts, interviews and observation. In Miller, G. and Dingwall, R. (Eds). (1997). Context and method in qualitative research, London, Thousand Oaks, and New Delhi: Sage.

Dowling, R. (Ed.). (2005). Power, subjectivity and ethics in qualitative research (Second Edition). Melbourne, Australia: Oxford University Press.

Duffield, M. (1997). NGO relief in war zones: Towards an analysis of the new aid paradigm. Third World Quarterly, 18 (3), 527-542.

Evans, G. (2002). A short history of Laos: The land in between. Crow's Nest, New South Wales: Allen \& Unwin.

Fereday, J., \& Muir-Cochrane, E. (2006). Demonstrating rigor using thematic analysis: A hybrid approach of inductive and deductive coding and theme development. International Journal of Qualitative Methods, 5(1), 1-11. 
Fitzgerald, G. (2006). Computer-Based Qualitative Data Methods. In Becker, H.A., Vanclay, F. (Eds). (2006). The international handbook of social impact assessment: conceptual and methodological advances. UK and USA: Edward Elgar.

Fox, C. (2003). No place for girls? Gender, ethnicity and citizenship education in the Lao People's Democratic Republic. Compare: A Journal of Comparative and International Education, 33(3), 401-412.

Fox, C. (2004). Disrupting preconceptions of postcolonial education in Laos. In A. Hickling-Hudson., J. Matthews \& A. Woods (eds.), Disrupting preconceptions: Postcolonialism and education, (pp.91-108). Brisbane: Post Pressed Flaxton.

Frank, D. J., Longhofer, W., \& Schofer, E. (2007). World society, NGOs and environmental policy reform in Asia. International Journal of Comparative Sociology, 48(4), 275-295.

Frohofer, L. (2014). People's participation in the one-party state: The role of civil society in the Lao People's Democratic Republic. Essay on development policy. NADEL MAS Cycle 2012 - 2014. www.nadel.ethz.ch/Essays/MAS 2012 Frohofer Lukas.pdf

Gibbs, C., Fumo, C., \& Kuby, T. (1999). Nongovernmental organizations in World Bank-supported projects: A review. Washington, D.C: World Bank.

Government of Laos (GoL). (2004). National growth and poverty eradication strategy. Vientiane: Ministry of Planning and Investment.

Government of Laos (GoL). (2006). Vientiane declaration on aid effectiveness. Vientiane: Ministry of Planning and Investment.

Government of Laos (GoL). (2010). Sector working groups: Education sector. Background paper for the high level round table meeting, 20-21 October 2010. Vientiane: Ministry of Education and Sports.

Government of Laos (GoL). (2011). The seventh five-year national socioeconomic development plan (2011-2015). Vientiane: Ministry of Planning and Investment.

Government of Laos (GoL). (2012). Foreign aid implementation report (FAIR) (2011-2012). Vientiane: Ministry of Planning and Investment.

Government of Laos (GoL). (2014). The round table meeting implementation. Vientiane: Ministry of Planning and Investment.

Green, D. (2008). From poverty to power: How active citizens and effective states can change the world. Oxford, Herndon, VA: Oxfam International. 
Hofer, B. K. (2001). Personal epistemology research: Implications for learning and teaching. Educational Psychology Review, 13(4), 353-383.

Hopkins, P. E. (2007). Positionalities and knowledge: Negotiating ethics in practice. An International E-Journal for Critical Geographies, 6(3), 386-394.

Howell, J., Ishkanian, A., Obadar, E., Seckinelgin, H. \& Glasius, M. (2008). The backlash against civil society in the wake of the long war on terror. Development in Practice, 18 (1), 82-93.

Howell, J., \& Pearce, J. (2002). Civil society and development: A Critical exploration. Colorado and London: Lynne Rienner Publishers.

Hulme, D. \& Edwards, M. (1997). NGOs, states and donors: Too close for comfort? Nova Iorque: St.Martin's Press.

Hyden, G. (1997). Civil society, social capital, and development: Dissection of a complex discourse. Studies in Comparative International Development, 32(1), 3-30.

Ife, J. (2002). Community development. Community-based alternatives in an age of globalisation. French's Forest NSW: Pearson Education Australia.

Informal Education Donor Working Group (IEDWG). (2014). Agreed purpose and function of the informal education development partners working group. Vientiane.

INGO Network. (2014). INGO key messages for the 2014 round table implementation meeting. Vientiane: The INGO Network in Lao PDR.

Inthaboualy, P. (2012). How can national competitiveness of less developed countries be enhanced? : A case study of Laos (Unpublished master's thesis). Victoria University of Wellington, Wellington, New Zealand.

Johnson, B., \& Christensen, L. (2008). Educational research: Quantitative, qualitative, and mixed approaches. Thousand Oaks, California: Sage.

Jönsson, K. (2000). Policymaking in transitional economies: Poverty reduction and health care in Cambodia and Laos. Health and social protection: Experiences from Cambodia, China and Lao PDR. Antwerp, Belgium: ITG Press.

Kepa (2013): Working papers: Reflections on Lao civil society. Bangkok: Kepa Mekong. http://www.kepa.fi/tiedostot/lao cs 2013.pdf

Kim, D., \& Jeong, M.K. (2013). Insufficient partnership, ineffective foreign aid, and public education in Laos. KEDI Journal of Educational Policy, 10(1), 173-193. 
Kim, Y. (2011). The unveiled power of NGOs: How NGOs influence states' foreign policy behaviors. (Dissertation/Thesis). Graduate College, the University of Iowa, ProQuest, UMI Dissertations Publishing.

Kindon, S. L. (2012). Thinking-through-complicity with Te Iwi o Ngāti Hauiti: Towards a critical use of participatory video for research: (Dissertation/Thesis). University of Waikato, Hamilton, New Zealand.

Kindon, S. L., Pain, R., \& Kesby, M. (2007). Participatory action research approaches and methods: Connecting people, participation and place. New York; London: Routledge.

Korten, D. C. (1987). Third generation NGO strategies: A key to people-centered development. World Development, 15(1), 145-159.

Krut, R. (1997). Globalization and civil society: NGO influence in international decision-making. Geneva: United Nations Research Institute for Social Development.

Kunze, G. (2012). Nascent civil society in Lao PDR in the shadow of China's economic presence, in Moksens, Heidi \& Melin, Mia [Ed.]. Global civil society: Shifting powers in a shifting world (pp 154-158). Uppsala: Uppsala University.

Lam, N. (1997). External assistance and Laos: Issues and implications for development policy. In M. Than \& J. Tan, Laos' dilemmas and options: The challenge of economic transition in the 1990s, (pp.267-307). Singapore. Institute of Southeast Asian Studies.

Lao National Television (LNTV). (2014). INGOs recognised as important development partners: LNTV English News broadcasted on 30 October 2014. Retrieved date June 3, 2015, http://www.tnl.gov.la

Lavergne, R. \& Wood, J. (2006). Aid effectiveness and non-state partnerships: Analytical considerations, Retrieved on 5 June 2015, http://www.ccic.ca/e/docs/002_aid_2006-12-06_cida_doc_aid_effect_ partners.pdf.

Lingard, B \& Jn Pierre, K. (2006). Strengthening national capital: A postcolonial analysis of lifelong learning policy in St Lucia, Caribbean. Pedagogy, Culture and Society, 14(3), 295-314.

Longhurst, R. (2003). Semi-structured interviews and focus groups. In N. Clifford, S. French \& G. Valentine (Eds.). Key methods in geography, (pp. 117-132). London: Sage.

Luna-Reyes, L. F., \& Andersen, D. L. (2003). Collecting and analyzing qualitative data for system dynamics: Methods and models. System Dynamics Review, 19(4), 271-296. 
Lundmark P. \& Malmberg L. (2008). Cooking in someone else's kitchen: The Influence of INGOs on civil society in the Lao PDR. (Dissertation/Thesis). Department of Political Science, Lund University, Lund, Sweden.

Lunsford, T. R., \& Lunsford, B. R. (1995). The research sample, part I: Sampling. JPO: Journal of Prosthetics and Orthotics, 7(3), 17A.

Makuwira, J. (2006). Aid partnership in the Bougainville conflict: The case of a local women's NGO and its donors. Development in Practice, 16(3-4), 322333.

Martinussen, J. D. \& Pedersen, P. E. (2003). AID: Understanding international development cooperation. London \& New York: ZedBooks.

McCormick, A. (2012). Whose education policies in aid-receiving countries? A critical discourse analysis of quality and normative transfer through Cambodia and Laos. Comparative Education Review, 56(1), 18-47.

Mcllwaine, C. (1998). Civil society and development geography. Progress in Human Geography, 22, 415-424.

Mercer, C. (2002). NGOs, Civil society and democratization: A critical review of the literature. Progress in Development Studies, 2(1), 5-22.

Mikkelsen, B. (2005). Methods for development work and research: A new guide for practitioners. Thousand Oaks, California New Delhi: Sage.

Ministry of Education and Sports (MoES). (2000) The education strategic vision up to the Year 2020. Vientiane.

Ministry of Education and Sports (MoES). (2004). Education for all national plan for action (EFANPA) (2003-2015). Vientiane.

Ministry of Education and Sports (MoES). (2008a). Educationfor all mid-decade assessment (EFAMDA): Lao country report. Vientiane.

Ministry of Education and Sports (MoES). (2008b). Education law of Laos: Revised version. Vientiane.

Ministry of Education and Sports (MoES). (2008c). National education system reform strategy (NESRS) 2006-2015. Vientiane.

Ministry of Education and Sports (MoES). (2009). Education sector development framework (ESDF) 2009-2015. Vientiane.

Ministry of Education and Sports (MoES). (2011a). Education sector development plan (ESDP) (2011-2015). Vientiane. 
Ministry of Education and Sports (MoES). (2011b). Annual report 2010/2011 on the implementation of education development plans. Vientiane.

Ministry of Education and Sports (MoES). (2013a). Aid coordination arrangements: Terms of Reference for Education Sector Working Group (ESWG). Vientiane.

Ministry of Education and Sports (MoES). (2013b). Mid-term review of the education sector development plan (ESDP)(2011-2015): Review and update. Vientiane.

Ministry of Education and Sports (MoES). (2015). Education law of Laos: Revised version. Vientiane.

Munier, N. (2011). Who makes education policy? The cases of the Central African Republic, Laos and Botswana. (Dissertation/Thesis). Department of Political Science, Western Illinois University, ProQuest, UMI Dissertations Publishing.

Noonan, R., Phommalangsy, P \& Petsiriseng, I. (2013). Lao PDR: The great transformation. In L. Symaco (Ed.), Education in South-East Asia (pp. 115136). London: Bloomsbury.

OECD. (2005). The Paris Declaration on aid effectiveness, Paris: France.

OECD. (2011). Busan Partnership for effective development co-operation, Busan: Korea.

Pain, R. (2009). Commentary: Working across distant spaces: Connecting participatory action research and teaching. Journal of Geography in Higher Education, 33(1), 81-87.

Pearce, J., \& Eade, D. (2000). Development, NGOS, and civil society: Selected essays from development in practice introduced by Jenny Pearce; series editor: Deborah Eade. (Development in practice reader). Oxford: Oxfam.

Penrod, J., Preston, D. B., Cain, R. E., \& Starks, M. T. (2003). A discussion of chain referral as a method of sampling hard-to-reach populations. Journal of Transcultural Nursing, 14(2), 100-107.

Peters, Susan J. (2007). "Education for all?" A historical analysis of international inclusive education policy and individuals with disabilities.(UNESCO's global movement)(Report). Journal of Disability Policy Studies, 18(2), 98-107

Pettit, J. (2012). Empowerment and participation: Bridging the gap between understanding and practice. Institute of Development Studies, Sussex, UK

Phetsiriseng, I. (2009). Education reform context in Laos. In Y. Hirosato \& Y. Kitamura (Eds.), The political economy of educational reforms and capacity 
development in Southeast Asia, (pp.283-301). Springer Sciences + Business Media.

Phommalangsy, P. (2013). An analysis of the influence of foreign aid on education policy in Laos. (Unpublished PhD's thesis). School of Education, the University of Queenstown, Australia.

Phraxayavong, V. (2009). History of aid to Laos: Motivations and impacts. Chiang Mai: Mekong Press.

Pollard, A. (2009). Field of screams: Difficulty and ethnographic fieldwork. Anthropology Matters, 11(2), 1-24.

Prime Minister's Office (PM0). (2010). Decree No. 013/PM on International NonGovernmental Organisations (INGO). Vientiane.

Riska, G. (1999). NGOs in the GMS-Involvement Related to Poverty Alleviation and Watershed Management. http://www.mekonginfo.org/mrc en/doclib.nsf/0/2F696151FEAAF038C7256 834001 35B7E/\$ FILE/FULLTEXT. html\# part1.

Roberts, W. T. (2004). Nongovernmental organizations and the state in the developing world. (Dissertation/Thesis). The Graduate College, the University of Arizona, ProQuest, UMI Dissertations Publishing.

Robertson, S., Novelli, M., Dale, R., Tikly, L., Dachi, H \& Alphonse, N. (2007). Globalisation, education and development: Ideas, actors and dynamics. London: DFID.

Sachs, J. (2012). From millennium development goals to sustainable development goals. The Lancet, 379(9832), 2206-2211.

Save the Children. (2009). School Quality Improvement Programme (SQIP). Vientiane.

Save the Children \& UNICEF. (2012). UNICEF - Save the Children letter on collaboration. London.

Sida. (2004). Country strategy for development cooperation in Laos, 2004-2008. Stockholm: Swedish International Development Agency.

Silaphet, S. (2008). Effective Aid Coordination: A Case Study of Lao People's Democratic Republic (Unpublished master's thesis). Victoria University of Wellington, Wellington, New Zealand.

Simpkins, D. L. (2003). Third hand or third sector? The political potential of nongovernmental organizations in Thailand. (Dissertation/Thesis). Department of Political Science, the University of Michigan, ProQuest, UMI Dissertations Publishing. 
Soulineyadeth, S. (2014). Impact of Unexploded Ordnance (UXO) on Rural Communities' Livelihoods in Xiengkhouang Province, Lao PDR (Unpublished master's thesis). Victoria University of Wellington, Wellington, New Zealand.

Steer, L \& Wathne, C. (2010). Donor financing of basic education: Opportunities and constraints. International Journal of Educational Development, 30(5), $472-480$

Strand, A. (2005). Aid coordination: Easy to agree on, difficult to organise. In Barakat, S. (Ed). (2005). After the Conflict: Reconstruction and Development in the Aftermath of War. London \& New York: I.B.Tauris.

Sultana, F. (2007). Reflexivity, positionality and participatory ethics: Negotiating fieldwork dilemmas in international research. ACME: An International EJournal for Critical Geographies, 6(3), 374-385.

Takala, T \& Piattoeva, N. (2012). Changing conceptions of development assistance to education in the international discourse on post-Soviet countries. International Journal of Educational Development, 32(1), 3-10.

Tedlock, B. (2005). The observation of participation and the emergence of public ethnography. in Denzin, N and Lincoln, Y. (Eds). (2005). The Sage handbook of qualitative research. Thousand Oaks, London \& New Delhi: Sage.

Tvedt, T. (2002). Development NGOs: Actors in a global civil society or in a new international social system? Voluntas: International Journal of Voluntary and Nonprofit Organizations, 13(4), 363-375.

United Nations. (2015). Millennium development goals: The United Nations millennium summit. The United Nations, New York. Retrieved 10 June, 2015, from: http://www.un.org/en/events/pastevents/millennium summit.shtml

UNDP. (2013). Human development report 2013-"The Rise of the South: Human progress in a diverse world". New York: UNDP.

UNDP. (2014). Human development report 2014-"Sustaining human progress: Reducing vulnerabilities and building resilience". New York: UNDP.

UNESCO. (2000). The Dakar framework for action: Education for all: Meeting our collective commitments: Including six regional frameworks for action. Paris: UNESCO.

UNESCO. (2015). National EFA 2015 review report: Country report of Lao PDR. Vientiane: UNESCO.

UNICEF. (2010). Country annual report for Laos, 2010: Basic education and gender equality. Unpublished report. 
Urban, A.M., \& Quinlan, E. (2014). Not for the faint of heart: Insider and outsider shadowing experiences within Canadian health care organizations. Qualitative Research in Organizations and Management: An International Journal, 9(1), 47-65.

Vogt, W. P. (2005). Dictionary of statistics and methodology: A nontechnical guide for the social sciences. London: Sage.

Waby, T. (2006). South-East Asia on a shoestring. Lonely Planet.

Wall, C., \& Overton, J. (2006). Unethical ethics? Applying research ethics in Uzbekistan. Development in Practice, 16(1), 62-67.

Wallace, T., Bornstein, L., \& Chapman, J., 1963. (2006). The aid chain: Coercion and commitment in development NGOs. Rugby: Practical Action Pub.

Wiles, R., Crow, G., Heath, S., \& Charles, V. (2008). The management of confidentiality and anonymity in social research. International Journal of Social Research Methodology, 11(5), 417-428.

Willetts, P. (2001). "What are Non-Governmental Organizations.", UNESCO Encyclopaedia of Life Support Systems, Section 1 Institutional and Infrastructure Resource Issues, Article 1.44.3.7.

Willis, K. (2011). Theories and practices of development. Abingdon, Oxon; New York: Routledge.

World Bank. (2007). Increase effectiveness of aid for better results. Vientiane: World Bank.

World Bank. (2009). World development indicators 2009. Development Data Group, Washington. D.C: World Bank Publications.

World Bank. (2012). World development indicators 2012. Development Data Group, Washington. D.C: World Bank Publications.

World Bank. (2015). World Development Indicators 2012. Development Data Group, Washington. D.C: World Bank Publications.

World Health Organisation (WHO). (2014). Lao People's Democratic Republic Statistics.

Retrieved 20 June, 2015, from http://www.who.int/countries/lao/en/

Zeiser, P. A. (1998). Influencing international processes: The role of NGOs in global social welfare policy making. (Dissertation/Thesis). Graduate Faculty of Politics and Policy, Claremont Graduate University, ProQuest, UMI Dissertations Publishing. 


\section{Appendix I: Ethics Approval}

MEMORANDUM

\begin{tabular}{|c|c|}
\hline To & Oulah Lah Saeng Outhay \\
\hline COPH To & Joh Overton \\
\hline FROM & Dr Allson Kriman, Convener, Human Ethis Committee \\
\hline DATE & 6 Aptl 2015 \\
\hline PAGES & 1 \\
\hline SUEUECT & $\begin{array}{l}\text { Ethilca Approval: } 21604 \\
\text { The influence of Non-Govemimental Oganlatons on primay } \\
\text { education polloy in Laos }\end{array}$ \\
\hline
\end{tabular}

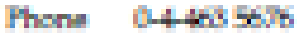

Far $\quad$ ththentin

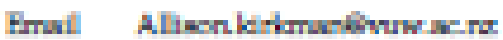

Thank you for your applcation tor ettical approval, which has now been consldered by the standing Commltee of the Human Etics Commitee.

Your applatilon has been approved from the above date and this approval continues untll 26 February 2016 . If your data collection is not completed by tris date you should apply to the Human Ethiss committee for an eatenslon to thls approval.

Best wshes wht the reseanch.

Allson Kilkman

Human Etrics Committee

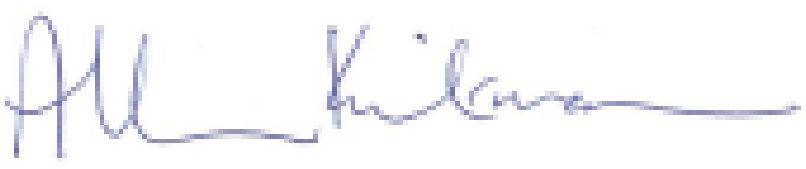


ฮิแมอ: Allison.kirkman@vuw.ac.nz

\section{บิถบับขึาภาบงะมุมัด}

\begin{tabular}{|c|c|}
\hline เทิ9 & ข่าบ จูลัด แสงจุไข \\
\hline สำเบิๆสิ่วใข้ & ข่าบ สจ. จจบ โจเอิตับ \\
\hline จๆภ & 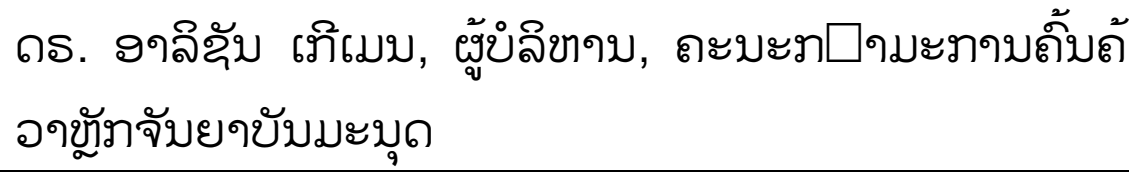 \\
\hline อับขึ & 06 เมสา 2015 \\
\hline ขังเจ้ย & 1 (ขึ่ง) \\
\hline ขิอฉั้ & 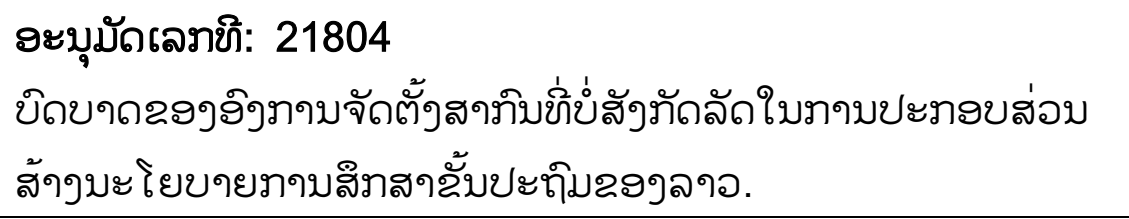 \\
\hline
\end{tabular}

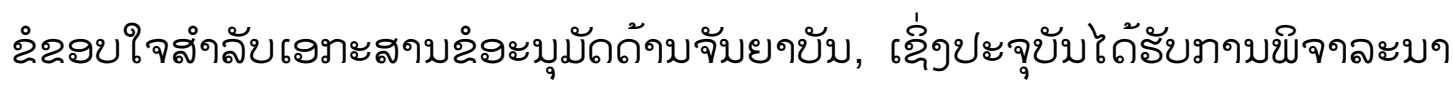
โดยภำมะภาบ 2ง9ถะบะรำมะภาบถิ้บถ้อๆจับยาบับมะมุด.

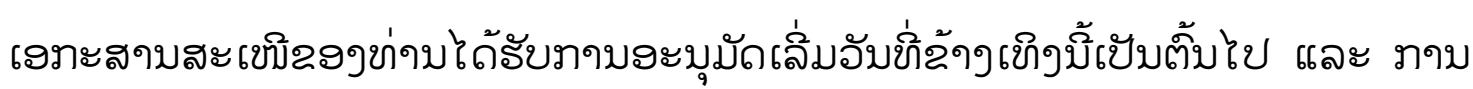

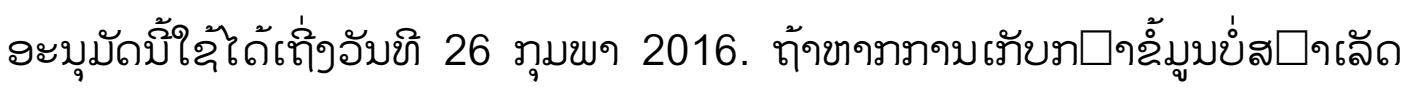

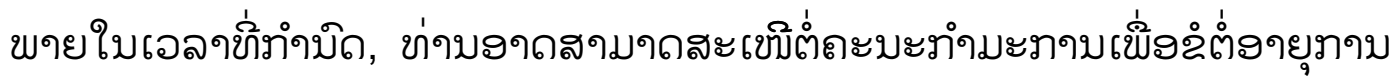
งะบุมัดบิ้.

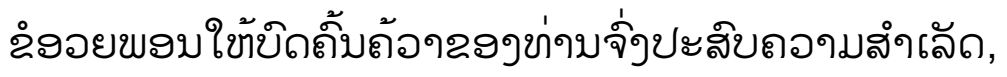
เฉับโดย: ๑ธ. จาลิฉับ เทิเมบ ถะบะภำมะภาบถิ้บถ้อๆขังจับยาบับมะมุถ 


\section{Appendix II: Supervisor's Support Letter}

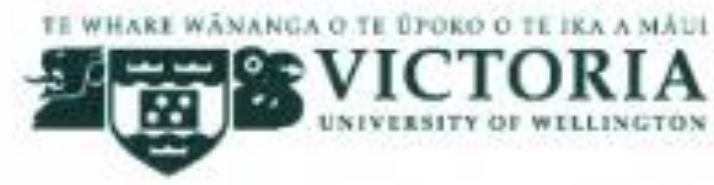

Prot. John Overtie

School of Geography. Envircoment and Earth Sciences

Teleptone $+64-4.4635281$

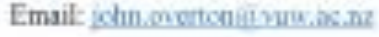

8 April 2015

To Whom It May Concern

\section{Re: Oulath Saengouthay}

This letter is to confirm that Mr. Oulath Saengouthay is fully registered as a Masters student in the Developenent Studies programme at the School of Geography, Evvironment and Earth Sciences (SGEES) at Victoria University of Wellington. As a part of this degree, Oulath is currently undertaking a research project lesding to s thesis. The working title of his thesis is: "The Influence of Non-Governmental Organisations on Primary Education Policy in Laos". This research project received approval from the Victoria University Human Ethics Committee on April 6, 2015 and has also been accepted by the Research Committee of SGEES.

1 am one of Oulath's supervisors and also Director of the Postgraduate Programme in Develogment Studies. I fully support Oulath's proposal and we feel that this research is both important and interesting. It has much potential not only as an acsdernic exercise but also it promises to he able to inform development policy and practice, particularly in the area of eutucation which is crucial for Laos and elsewhere.

If you have any further questions or would like to receive further information about the research project, you can contact me as Oulath's primary supervisor [Prof. John Overton at $+64-4$ 4635281 and john,overtongevuw ac.ne. Oulath's contact details are: $\$ 8562054424204$ or +64 0221589076 and saengovulafirmyvuw acine

We would be most gratefial if you could offer any assistance you can to Oulath and his research.

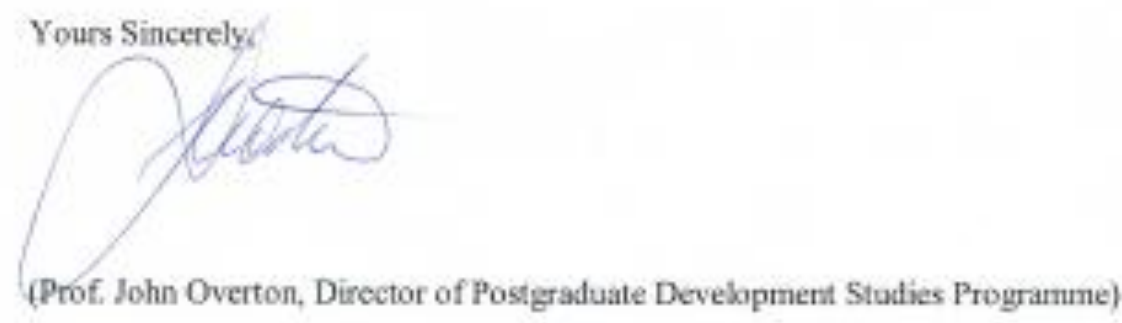


สจ. จงบ โอเอ๊ตับ

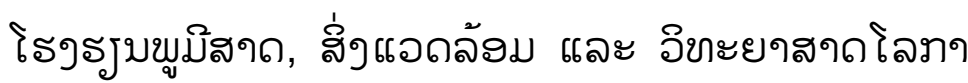

โขละสับ + 64-4-4635281

ฮิแdอ: john.overton@vuw.ac.nz

8 เมสๆ 2015

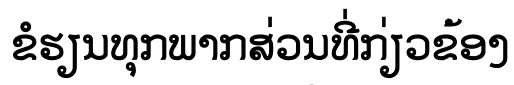

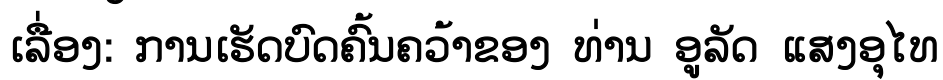

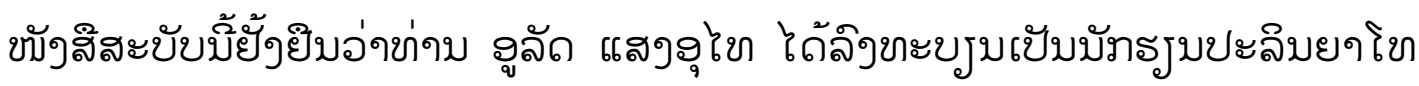

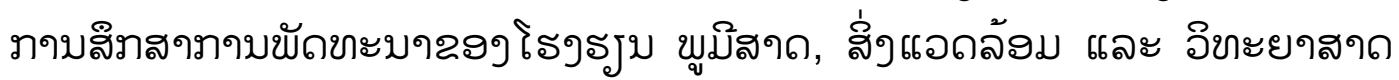
โลาๆ, อ๊าขเธยแข่วแออลิๆตับ.

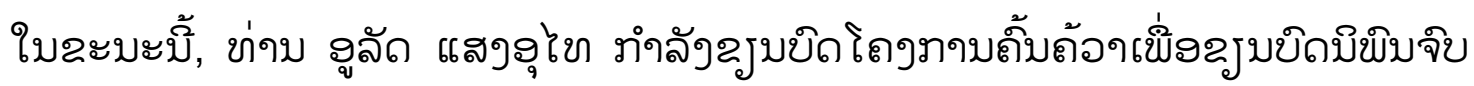

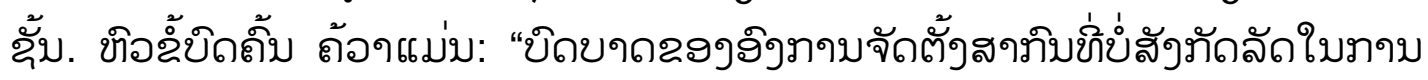

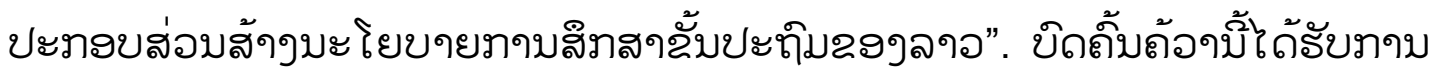

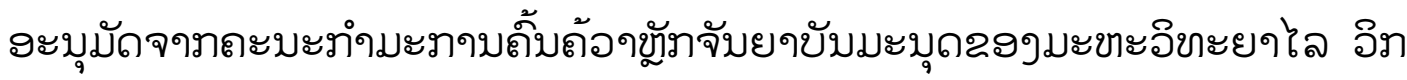

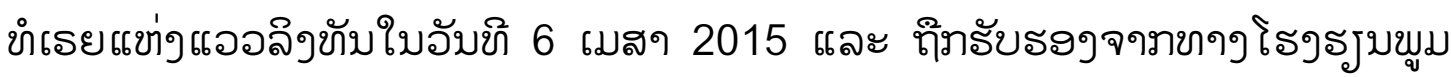
สาด, สิ่งแอด ล้งม และ อิขะยๆสาถโลภาเปับขึ่ธృบธังย.

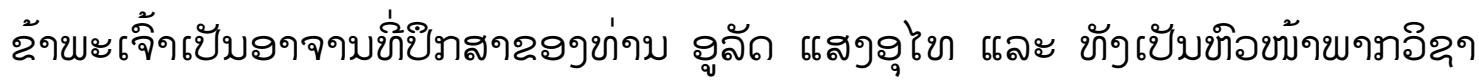

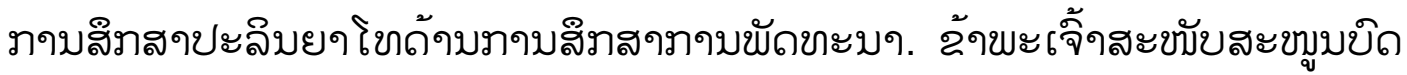

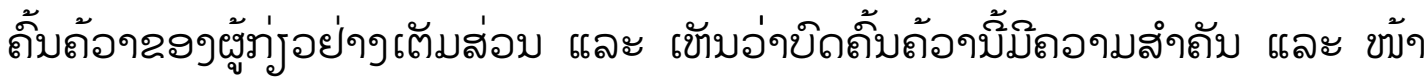

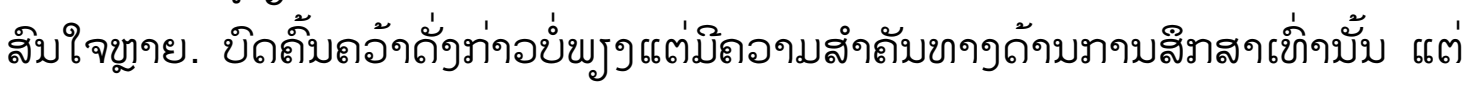

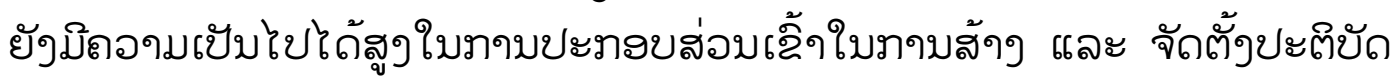

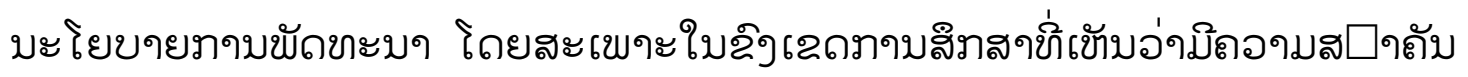
ขาลายสำลับปะเขลลาอ. 


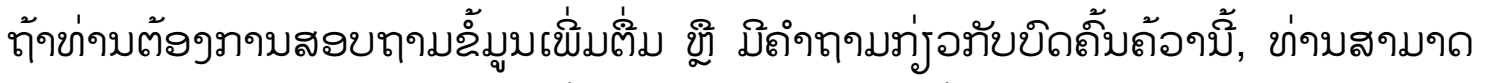

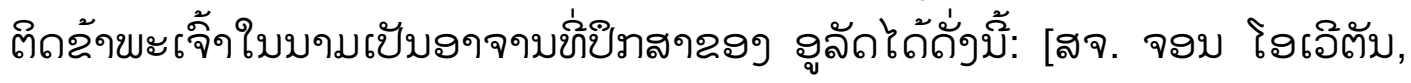
โข:+64-4-463 5281 john.overton@vuw.ac.nz; ขกล๊ติถต่ำ จูลัดโดยภ์9: 020 54424204,oulathmail@yahoo.com; saengooula@myvuw.ac.nz] .

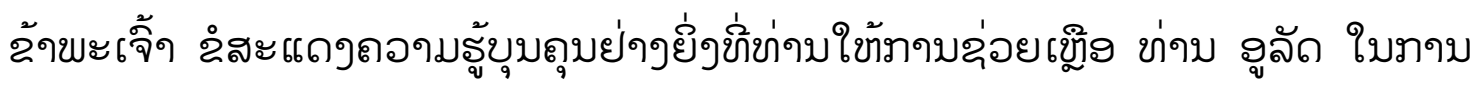
เรักบิลถิ้มถ้อาถั้งบิ้ถ้อย.

รృบมจล้อยถองมบัขถึย่างสูง,

สจ. จงบ โอเอิตับ

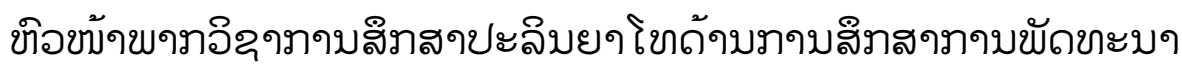




\section{Appendix III: Participant Information Sheet}

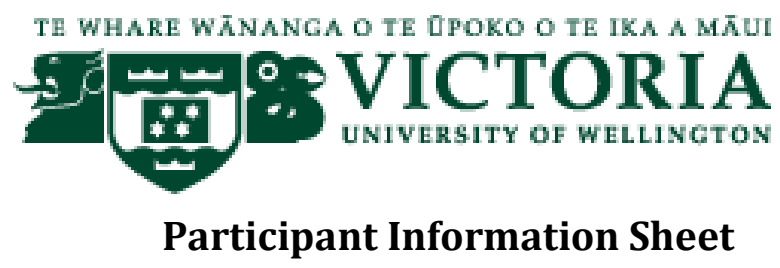

Research Title: The Influence of Non-Governmental Organisations on Primary Education Policy in Laos

Hello! My name is Oulath Saengouthay. I am a Development Studies student, under New Zealand Aid Programme, at Victoria University of Wellington, New Zealand. As part of my Master degree, I am writing a thesis on the Influence of Non-Governmental Organisations on primary education policy in Laos. The main objective of this research is to create a more inclusive arena for the Lao government and other stakeholders working in education by revealing the actual roles of NGOs and how these roles are played. The research findings will be used to inform the Lao government, NGOs and donors regarding the actual roles of NGOs for better partnerships and more holistic policy development.

I would like to invite you, as a representative of your organisation to participate in an interview in which you will be able to share your experiences and stories of how your organisation has participated in education policy development in Laos in order to improve development partnership and cooperation in primary education in Laos. Our conversation will be conducted using semi-structured questions that I have prepared in relation to this topic. It will take around 40 minutes.

Victoria University requires all students conducting research with people to undergo ethics assessment and approval. As part of this process there are several things that you need to be aware of before you consent to participate in this research:

If you give me your permission, the interview will be recorded to support the researcher's notes in case any ideas have been missed. Following our discussion, you have the right to check the interview notes. Written and electronically recorded material made during the interview will be safely stored and will only be seen by my supervisor and myself. The researcher will take all necessary steps to keep interview information safe during time in the field. All interview materials will be destroyed upon completion of the thesis.

It will be your decision as to whether you and your organisation will be identified or will remain confidential in the published thesis. As a participant, you do not have to answer all questions. If you agree to take part in the interview you are free to withdraw at any stage without having to give a reason. You are free to withdraw any information you have provided before data collection and analysis of the research is complete on $1^{\text {st }}$ October 2015.

Upon completion of my thesis, a copy of this thesis will be lodged in the Victoria University of Wellington. The summary findings will be made available to you, if you are interested. The final research may also be published in academic or professional journals and/or disseminated at academic or professional conferences as the opportunity arises.

I hope you will agree to participate in this research and I look forward to speaking with you soon. 


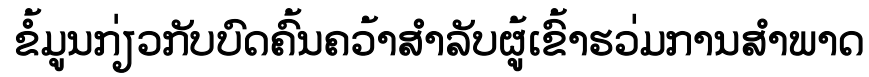

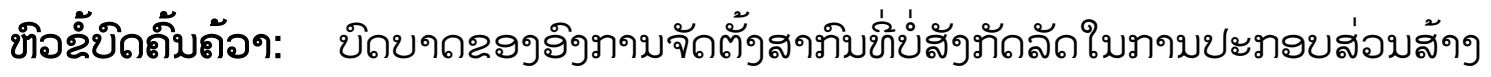
บะโยบขยางบสึาสาฉั้บปะฤิมฉองลาอ.

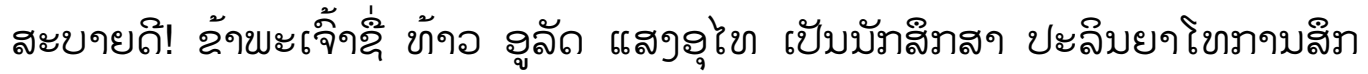

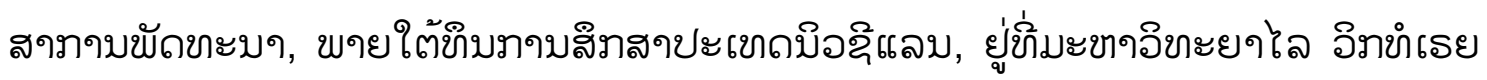

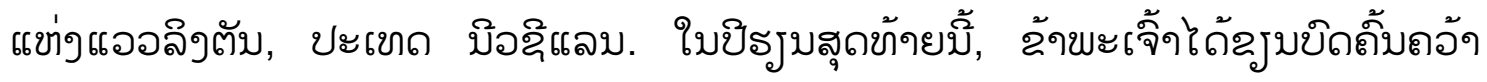

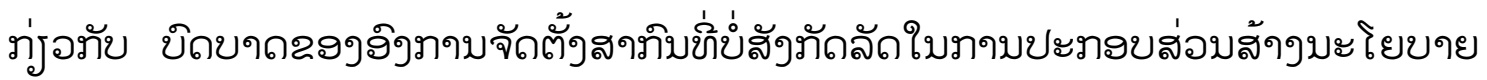

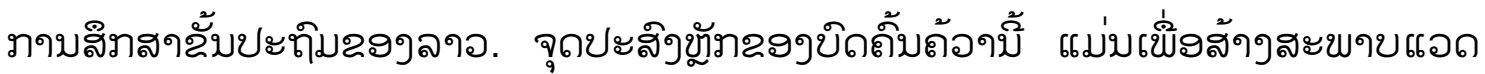

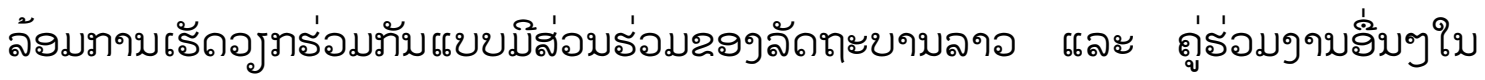

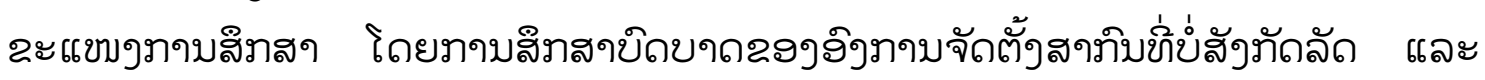

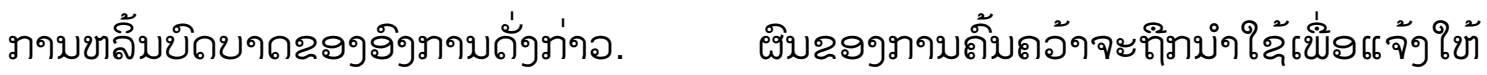

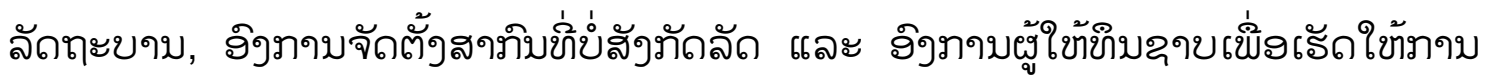

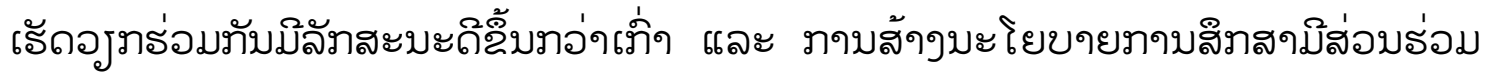
จาทขางส่อบขิ่ท่อว้องขลจยนั้บ.

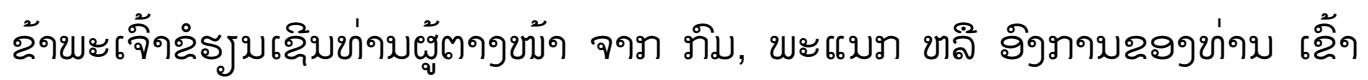

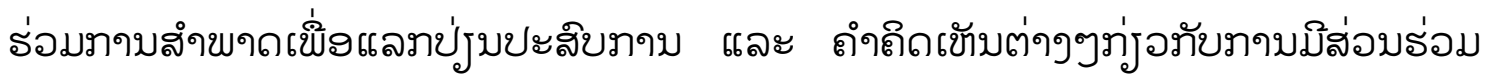

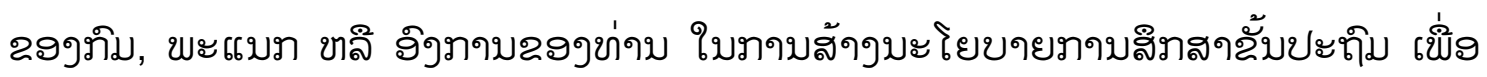

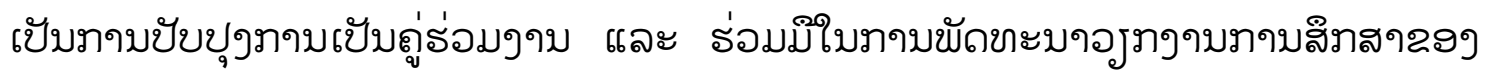

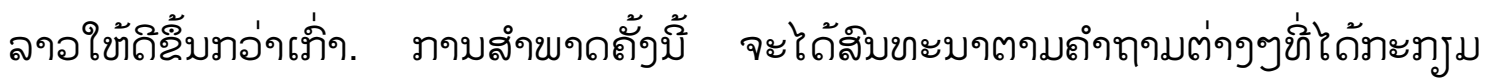

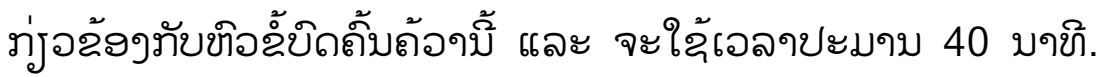

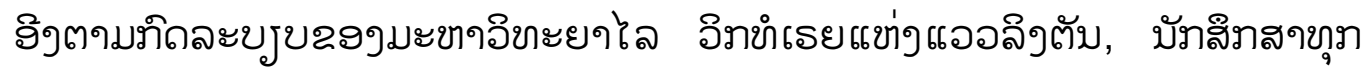

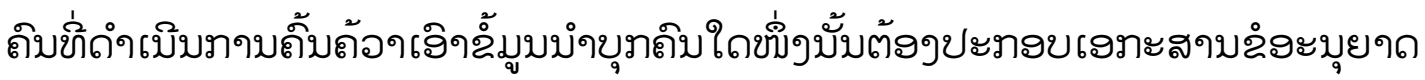

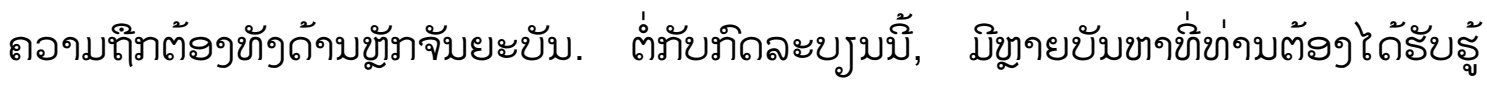
ท่งบขั่ข่าบจะเขับถึเฉิ้าธ่อมทาบถิ้บถ้อๆบิ้: 


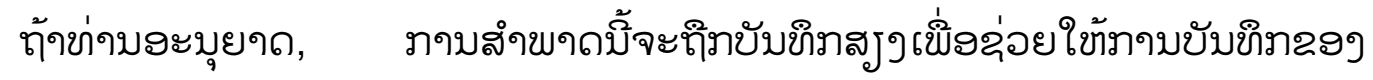

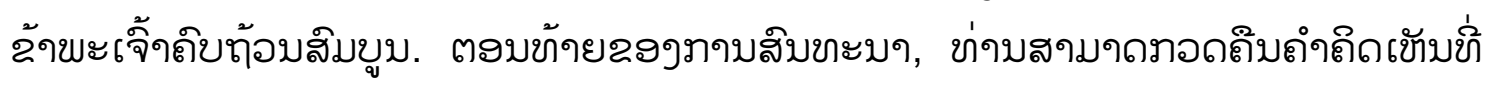

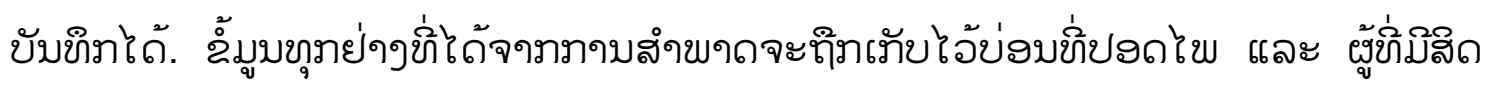

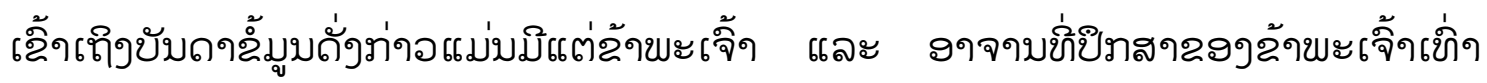

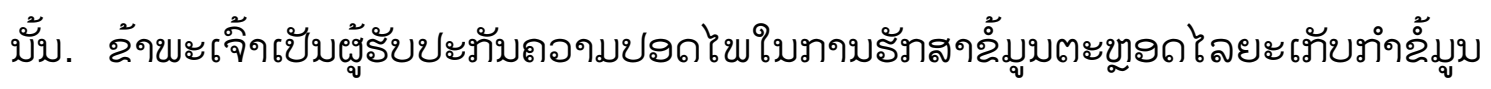

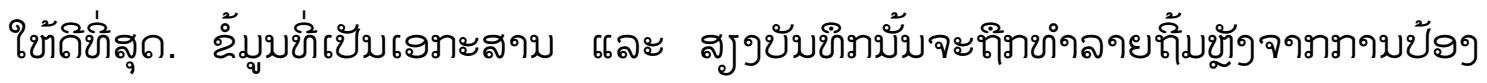
กับขิลจิบนั้บจำเลัดลิๆ.

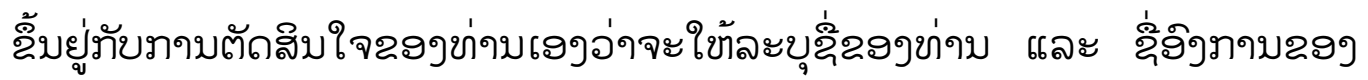

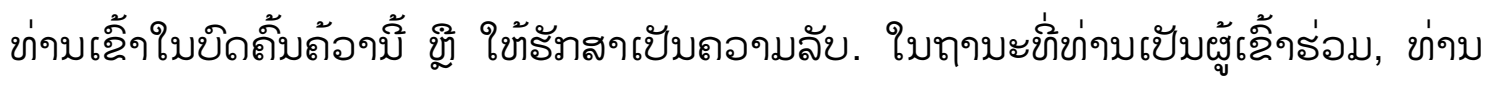

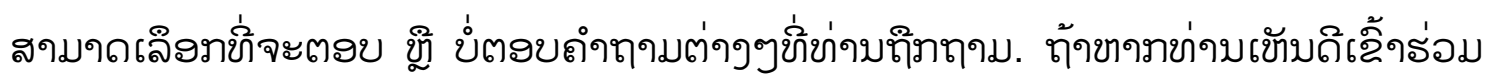

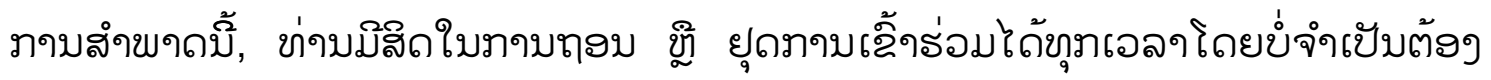

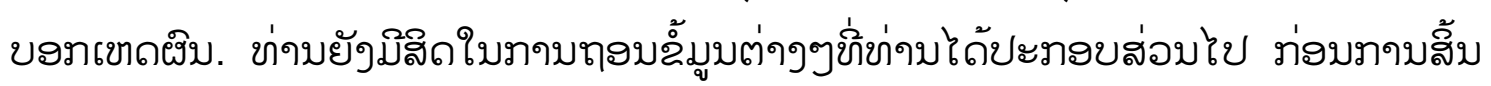

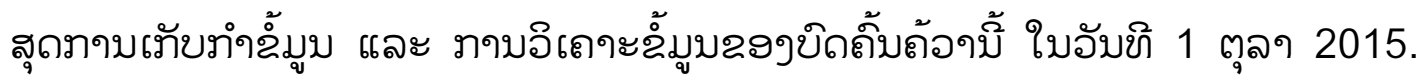

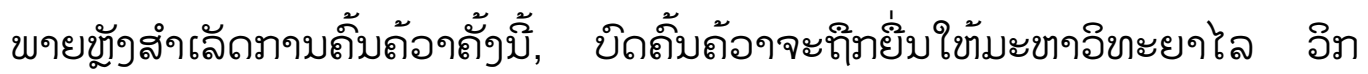

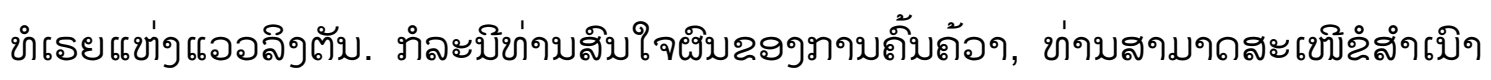

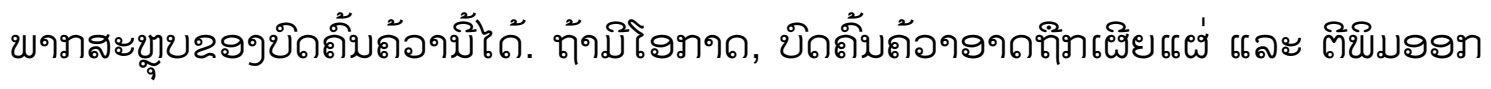
เขับองละสาบทาบลึกสา ฆู ภาบสำมะบาต่งๆๆ.

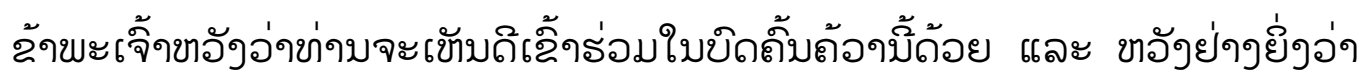
จะได้สิบขะบาภับข่าบใบไอขอิ้.

ถ้อยถอามบับถึย่างสูง,

จูลัด แสงจุไย (บัภลึกสง)

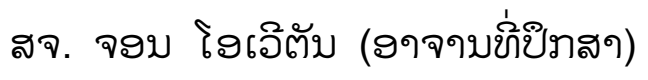




\section{Appendix IV: Research Consent Form}

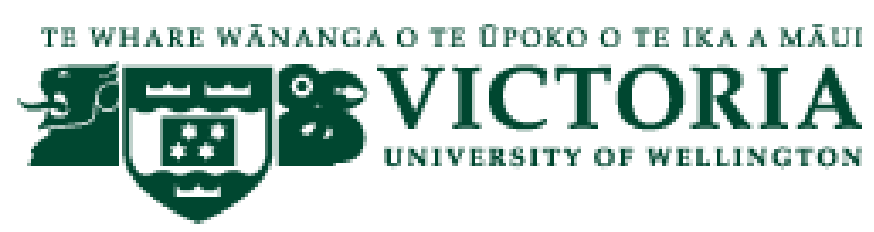

\section{Research Consent Form}

Title of project: The Influence of Non-Governmental Organisations on Primary Education Policy in Laos

Researcher: Oulath Saengouthay, School of Geography, Environment and Earth Sciences, Victoria University of Wellington

I have read the Participant Information Sheet and understand the purpose of this research project.

I understand the interview will be electronically recorded and any notes or recorded material from interviews will be destroyed at the end of the research process.

I understand that all information I provide will be safely stored accessed only by the researcher and research supervisor.

I understand I will have an opportunity to see a summary of the interview.

I understand I may withdraw myself, and any information I have provided, from this research project without explanation at any time before $1^{\text {st }}$ October 2015.

I understand the results of this research will be included in a thesis and may be used for publication in academic or professional journals, and for dissemination at academic or professional conferences.

I agree to take part in this research.

\section{Confidentiality:}

Confidentiality of participants is extremely important and fully taken into account in this research. Responses will form the basis of my research project and will be put into a written report on anonymous basis. It will not be possible for you to be identified personally. Only grouped responses will be presented in this research. All material collected will be kept confidential. No other person besides me and my supervisor John Overton will see diaries, reports and other relevant documents. 


\section{Please tick as appropriate:}

I would like to receive a summary of the results of this research when it is completed.

I consent to my name being used when my comments or opinions are used in this research.

I request that my name be omitted and a pseudonym assigned by the researcher be used if my comments or opinions are included in this research.

I consent to the name of the organisation I work for being used in this research.

I request the name of the organisation I work for to be omitted from this research.

Name:

Date:

Organisation:

Phone:

Email:

Signed: 


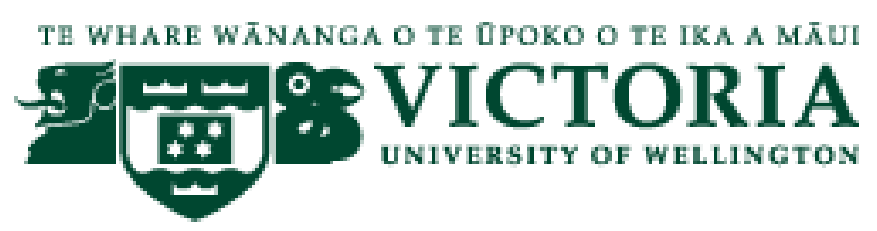

\section{แขบขอมทาบเขับถ๊เฉิ๊าร่อมทาบถิ๊มถอัง}

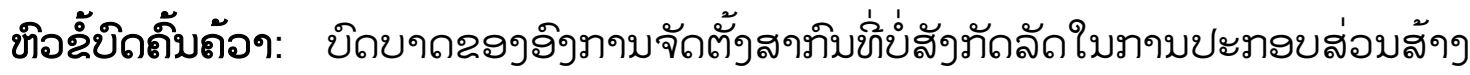
บะโยบายภาบลึาสาฉั้บปะฤิมลจงลาอ.

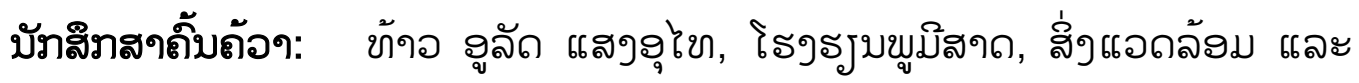
อิขะยาสาถโลภา, มะขาๆอิขะยๆไล อิภขเธยแข่าแออลิดตับ.

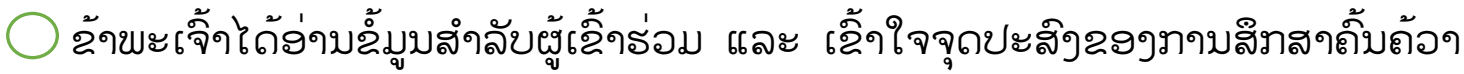
บิ้.

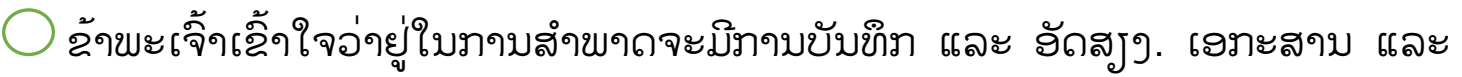

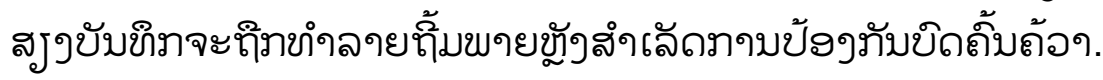

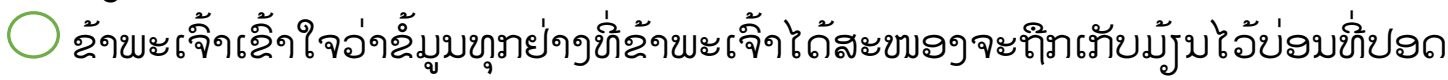

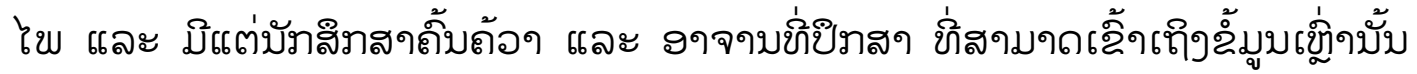
ไถ้.

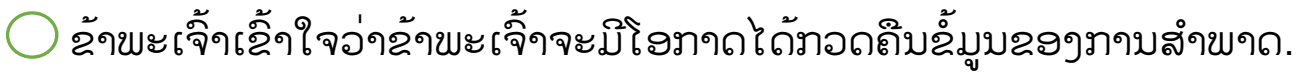

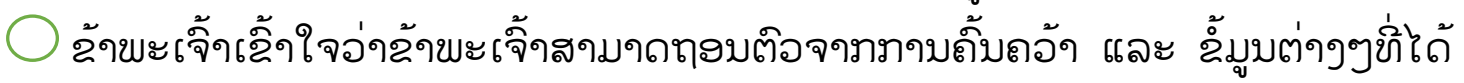

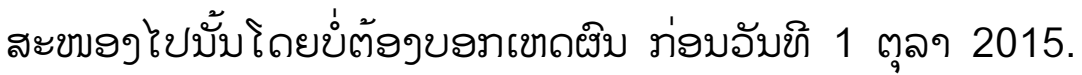

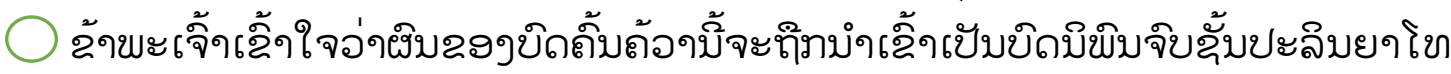
ภาบสึาสาราบขัลขะบา และ จาลจะท๊าเศิยแผ่ และ ติขึมเฉิ้าใบอาละสาบภาบ

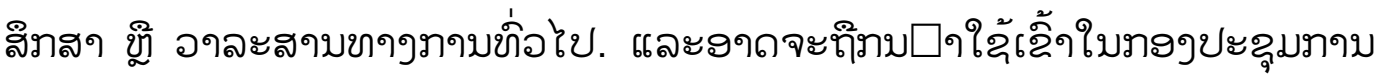
สึภสา ขู๊ ขางภาบอั่บๆอักล้อย.

ฉ้าขะเจิ้าเขับถึเฉิ้าธ่อมใบขิลถิ้บถ้อาบิ้.

\section{ทาบธัทสาถอามลับท่อกับผู้เฉ้าใข้สำขๆถ}

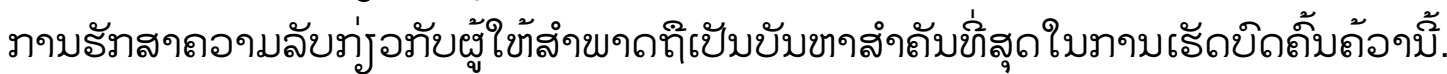

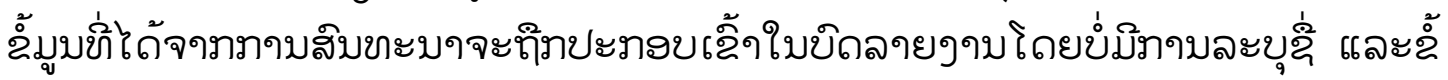

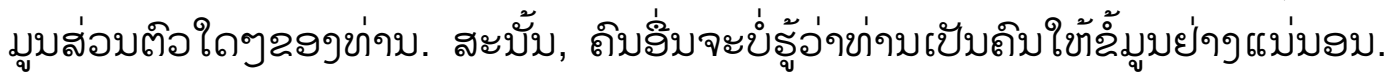

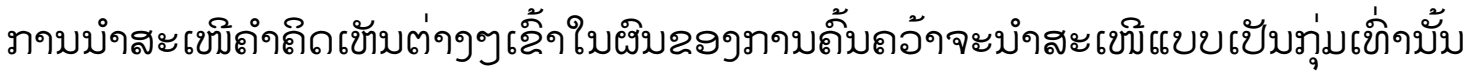

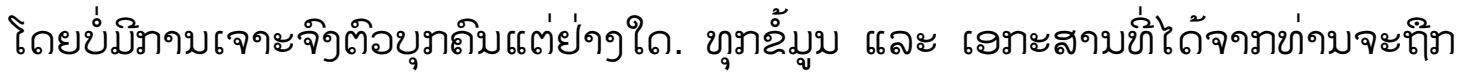

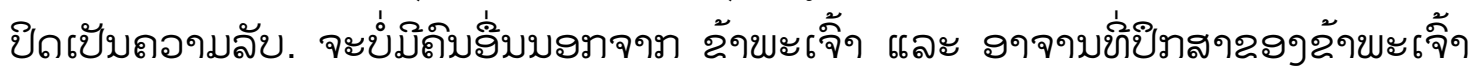




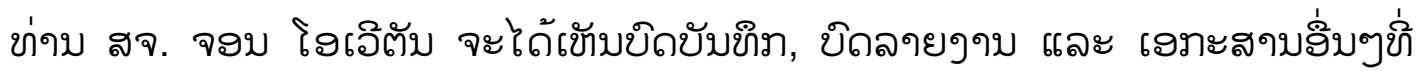
ท่อวฉ้อง.

\section{ภะลุบขขมาย $(\sqrt{ })$ ลิๆใส่ปะโขยาถำเอิ๊ขทิ่ข่าบเขับลิบำ:}

ฉ้าขะเจิ้ายๆาฉำอถถิบบิลบับขึาท่งบสิ้บสุดภาบสำขาค.

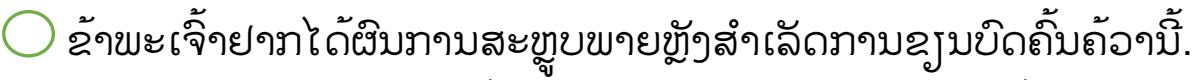

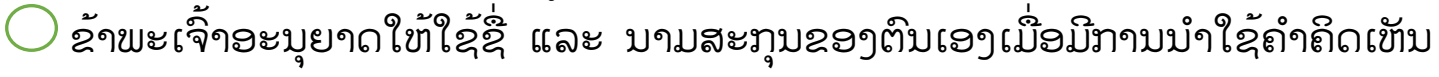
29งติบเจงเฉิ้าใบบิดถิ้บถ้อาบิ้.

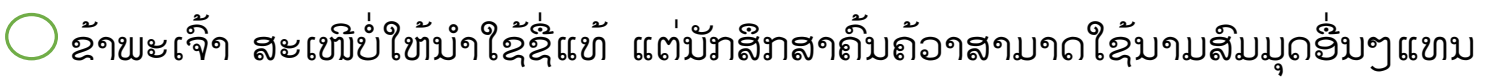

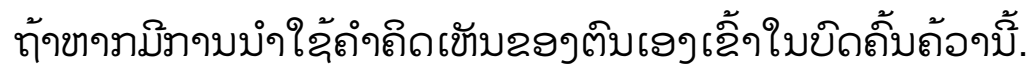

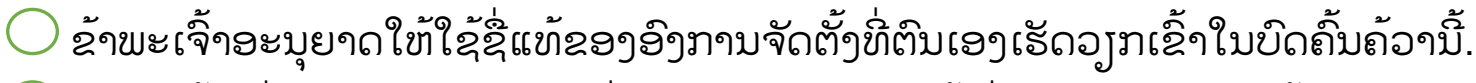

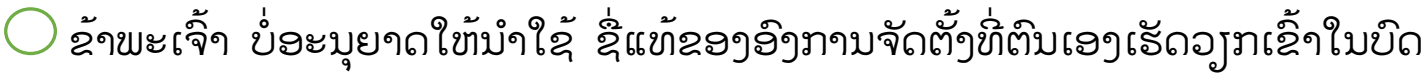
ถิ้บถ้อๆบิ้.

ขी:

ฉั่อิ่างมจัดตั้ๆ:

เขิโข:

ฮิเมอ:

จายเฉับ: 


\section{Appendix V: Interview Questions}

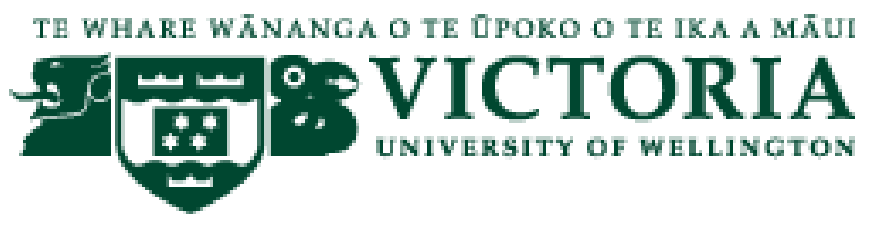

\section{Interview Questions for NGO Participants (30 - 40 mins)}

Research Title: The Influence of Non-Governmental Organisations on Primary Education Policy in Laos.

1) What is your position in this organisation and how long have you been in this position? How long how you been involved in Lao primary education policy development?

2) What is your view on the Lao primary education regarding qualitative and quantitative development?

3) How long has your organisation supported the development of Lao education?

4) What are key policy agendas that your organisation pushed and continue to push for change in Lao primary education?

5) How has your organisation been involved in education policy dialogues or participated in policy decision-making process?

6) Has there been any change since the adoption of Vientiane Declaration in 2006?

7) What are some strategies that you use to ensure that your inputs are incorporated in Lao primary education policy? How and where have your inputs been reflected in the existing primary education policy?

8) What is the relationship of your organisation with other NGOs and donor with regard to supporting Lao primary education?

9) Has your organisation been funded by any donor agency for primary education programme? Why does such donor fund your organisation?

10) What do you think are the basic differences between major donors and NGOs? How does the policy influence of the former differ from that of the latter?

11) How does such donor assist your organisation to influence government policy?

12) Is your organisation a co-chair of any education sector working group with MoES and or major donors/NGOs? Please explain how your position in such working group is important to your organisation in relation to policy influence.

13) What determines your seat in that working group? Budget? Expertise?

Personal relationships or what?

14) Do you think by co-chairing education sector working group, your organisation has increased negotiation power to influence policy change with the Lao government and donors? 


\section{Interview Questions for Government Participants (30 - 40 mins)}

Research Title: The Influence of Non-Governmental Organisations on Primary Education Policy in Laos.

1) What is your position in this department and how long have you been in this position? How long how you been involved in Lao primary education policy development?

2) What is your view on the Lao primary education regarding qualitative and quantitative development?

3) How has the government committed to the improvement of primary education?

4) Who are some key NGOs active in the primary education in Laos? How are those NGOs important to primary education?

5) How has the government engaged NGOs in the development process of Lao primary education policy?

6) What are some policy agenda that NGOs advocated and have been advocating for change in Lao primary education? Why are they pressing for such change?

7) How has the government incorporated NGOs' inputs in the existing primary education policy?

8) What are some other supports that NGOs give to the Lao government in addition to financial support?

9) Based on your experience, what are some conditionalities that NGOs discussed with the Lao government before agreeing to provide aid? Where are they formally reflected in policy documents?

10) Has there been any change since the adoption of Vientiane Declaration in 2006

11) How can you tell the differences between NGOs and other major donors such as DFAT, World Bank, JICA, EU, etc.?

12) Who are some NGOs and donors that are co-chairs in ESWG? Please explain how their positions in the ESWG are important to the Ministry in relation to Lao primary education policy? What determines their seats in that working group?

13) What are other mechanisms and platforms has the government provided to NGOs for education policy dialogues? 


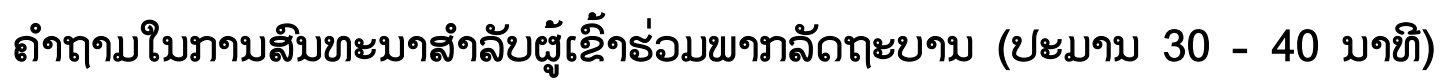

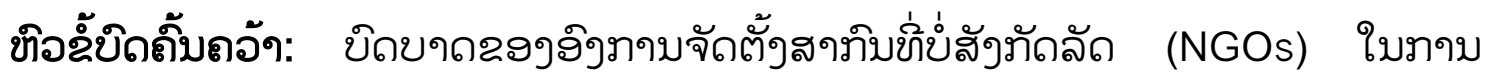
ปะทงขส่อบสังๆบะโยขายภางบลึาสาลั้บปะฤิมฉจงลาอ

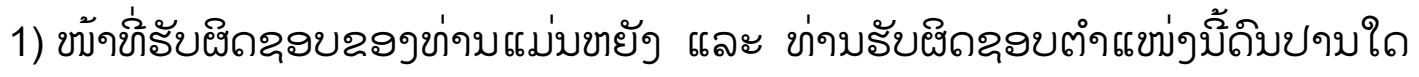
แล้อ? ข่าบไถ้เลิ้าร่อมภาบขัลขะบาบะโยขายภาบลึาสาฉั้บปะทิมถิบปจบใด แล้อ?

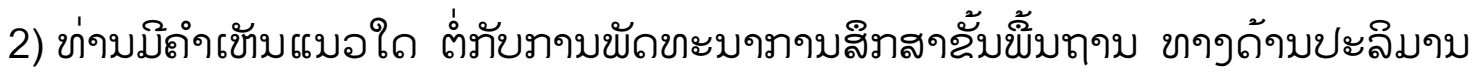
และ ถุบบะขขข? มีลั้สะถอก และ ขยุ้งยงภาแบอใด?

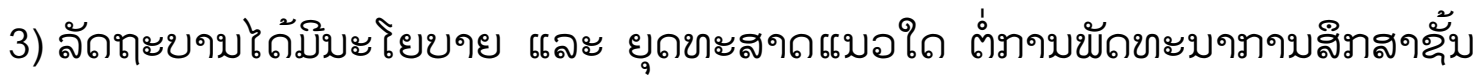
ปะฤิบ?

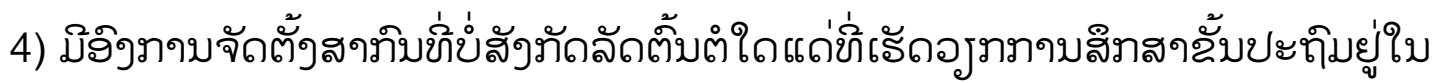
ลขอ? จิรภาบเขลิ่งบั้มมิถอามสำถับถึแบบใด?

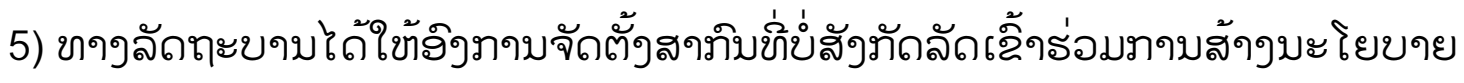
ภาบลึกสาลั้บปะทิบถิแบอใด?

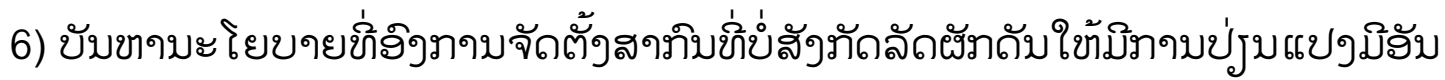
ใดแล่?

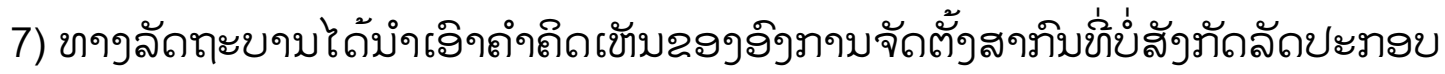
เฉิ้าใบบะโยขายภาบลึกสานั้บปะฤิบสะขับปะจุขับถึแบอใด?

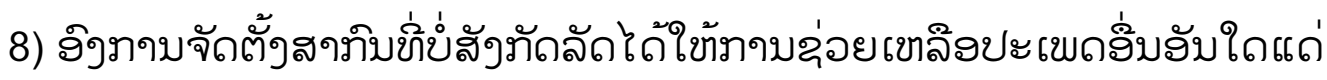

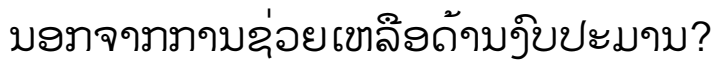

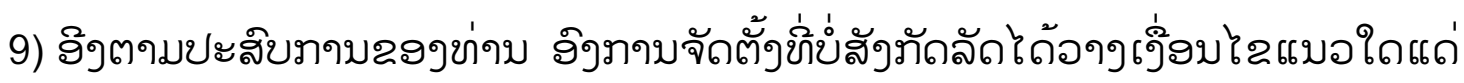

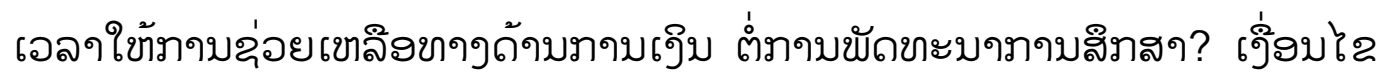
เขลิ่งบั้บสะแถาองายู่ใส?

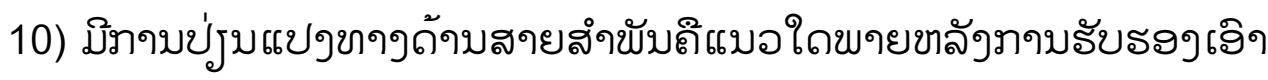
ฤะแขลลงภาบอรดจับใบขึ 2006? 


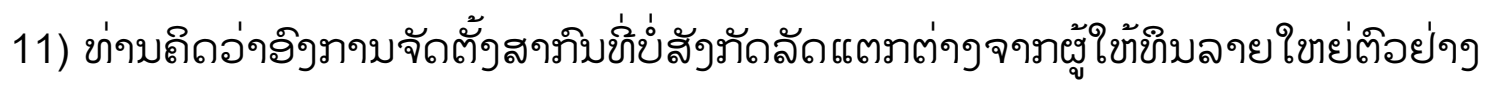
ฮิรภาบถิขัด, ขะบาถาบโลภ, ไจงๆ, ฮิยู และ งे่บๆ ถ๊แบอใด?

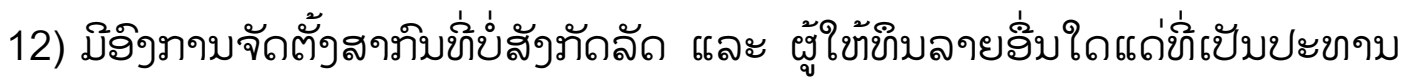

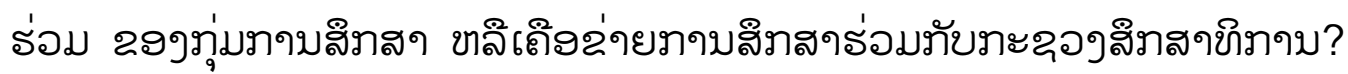

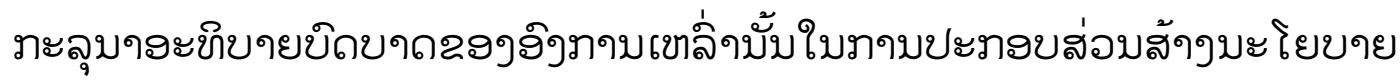

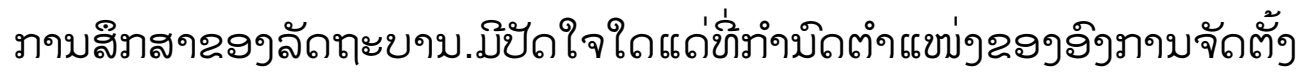

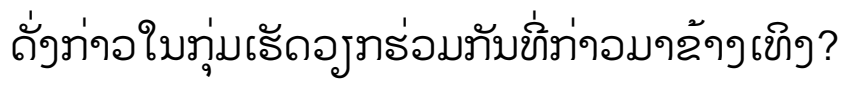

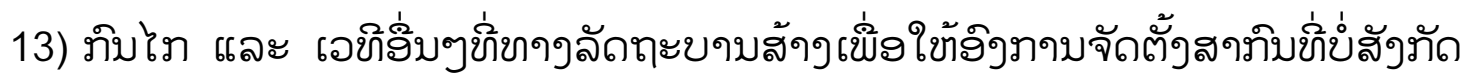

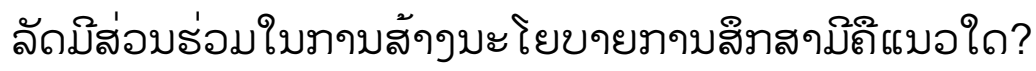




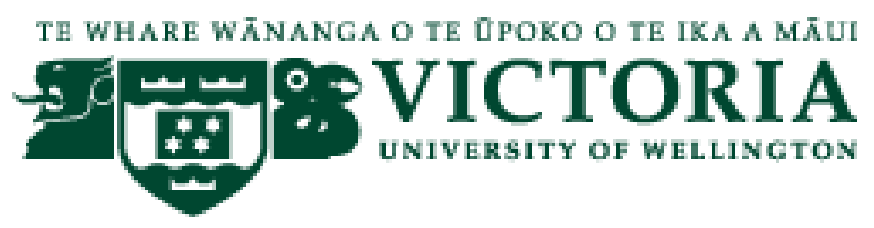

\section{Interview Questions for Donors and UN Participants (30 - 40 mins)}

Research Title: The Influence of Non-Governmental Organisations on Primary Education Policy in Laos.

1) What is your position in this organisation and how long have you been in this position? How long how you been involved in Lao primary education policy development?

2) What is your view on the Lao primary education regarding qualitative and quantitative development?

3) How long has your organisation supported the development of Lao education?

4) What are some strategies that your organisation uses to ensure its inputs are incorporated in government policy?

5) What is the relationship of your organisation with NGOs with regard to supporting Lao primary education?

6) What do you think are the basic differences between major donors and NGOs? How does the policy influence of the former differ from that of the latter?

7) Has your organisation funded any NGOs for their primary education programme? Why does your organisation fund such NGOs? Why doesn't your organisation implement such programme itself or just give money to the government to implement?

8) In your opinion, how is the relationship between NGOs and the Lao government, particularly at policy level? Has there been any change since the adoption of Vientiane Declaration in 2006

9) Do you think NGOs have any influence on government's primary education policy? To what extent and in what way?

10) How does your organisation work with NGOs to influence policy changes?

11) How do you see the role of NGOs in Education Sector Working Group (ESWG)? To what extent has NGOs' profile and policy influence increased through their membership and co-chairship in ESWG and focal groups, in your view?

12) Have you worked with NGO consortium for any particular education programme? How does that affect the role of NGOs in terms of policy influence?

13) How much has your organisation been involved in BEQUAL? How do you see the roles of NGOs in this large programme? Any significant policy influence from NGOs? 


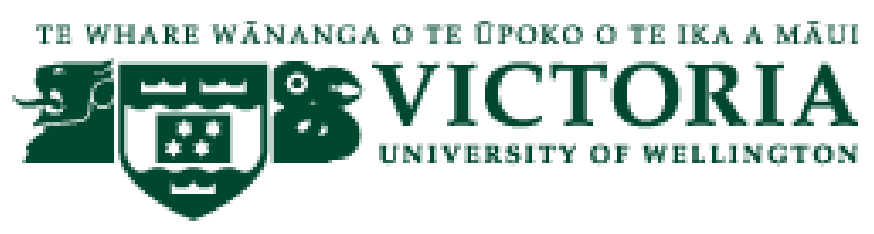

\section{Interview Questions for Education Specialists (30 - 40 mins)}

Research Title: The Influence of Non-Governmental Organisations on Primary Education Policy in Laos.

1) What is your view on the Lao primary education regarding qualitative and quantitative development? What do you see as the main gaps in Lao primary education policy?

2) How long how you been involved in Lao primary education policy development?

3) How do you see the role of NGOs in education development in Laos? What is their role at policy level?

4) How have you observed any change in their relationships since the adoption of Vientiane Declaration in 2006?

5) What do you see as the main challenges in relationships between NGOs and Lao government?

6) In your opinion, do you think NGOs have any influence on government's primary education policy? To what extent and in what way?

7) What are some strategies and mechanisms that NGOs use to ensure their inputs are incorporated in Lao primary education policy?

8) How effective do you think those mechanisms and strategies are?

9) How do you see the role of NGOs in ESWG? To what extent has NGOs' profile and policy influence increased through their membership and co-chairship in ESWG and focal groups, in your view?

10) What else do you think could be the main drivers for Lao primary education policy?

11) What do you think are the basic differences between major donors and NGOs? How does the policy influence of the former differ from that of the latter?

12) Why do you think donors keep funding NGOs and not giving all the money to the government to implement the projects itself? 


\title{
Appendix VI: Request Letter for Interview Appointment (for Government Offices)
}

\author{
สาขะละบะลัด ปะฉจนิปะไต ปะฉาฉิบลาอ \\ สับติขๆข เงมะลๆด ปะฉๆขึปะไ๓ เงาะขๆบ อัลขะมๆฤๆองบ \\ $-000$ \\ บะถงบขาลองอยๆจับ, ส.ป.ป ลๆอ \\ 7 ขึดสะขๆ 2015
}

\section{ใขสะเข็}

รృม:

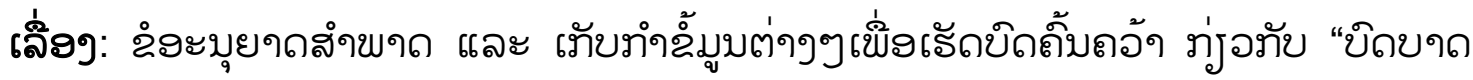

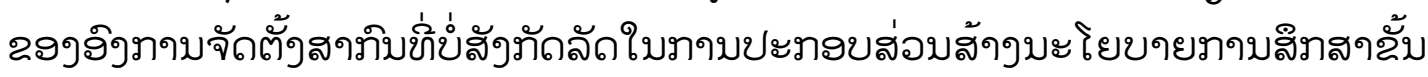
ปะฤิมลองลาอ".

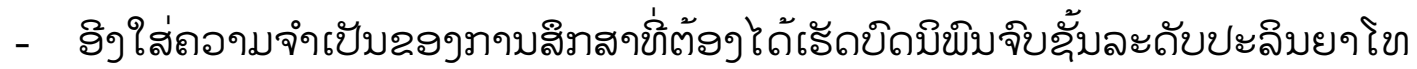

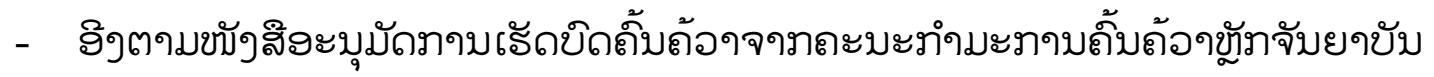
มะมุถลองมะขะอึขะยๆไล อึาขำเยแข่งแออลึดตับ สะบับอับขึ 6 เมสา 2015

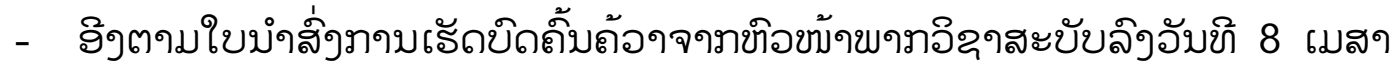
2015

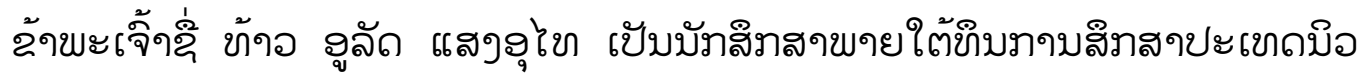
そิแลบ (New Zealand Aid Programme Scholarship) สิารృบปี 2014 - 2016

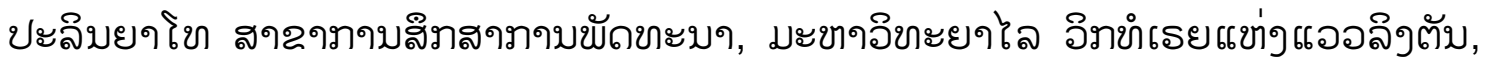

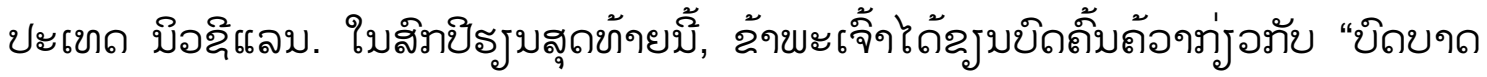

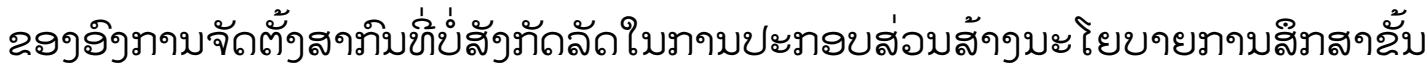
ปะทิมฉองลาอ" เข้่อปะภงขเปับบิลบิขิบจิบฉั้ม. 


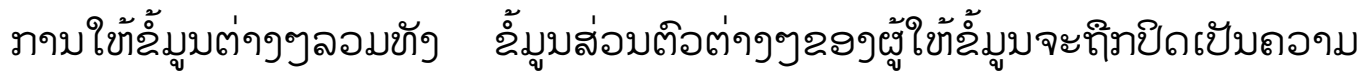

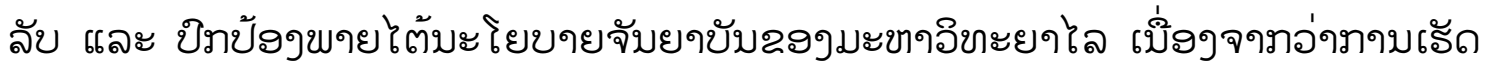

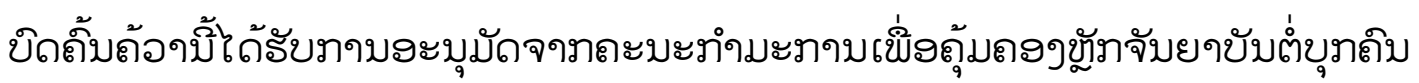

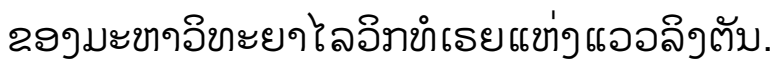

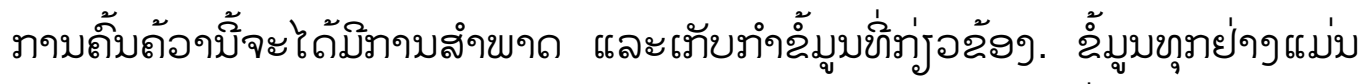

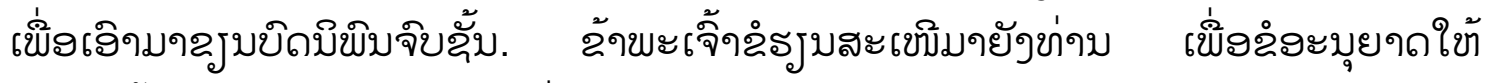

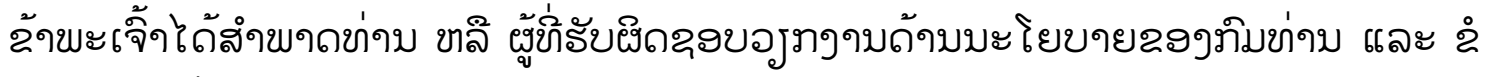

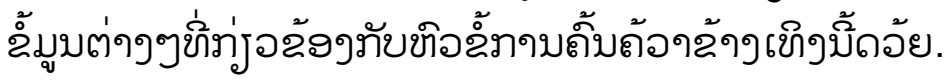

สงบฤามฉั้มูบเขิ่มติ่มไถ้ขี่ โขละสับ 02054424204 , อิเมอ:

oulathmail@yahoo.com; saengooula@myvuw.ac.nz

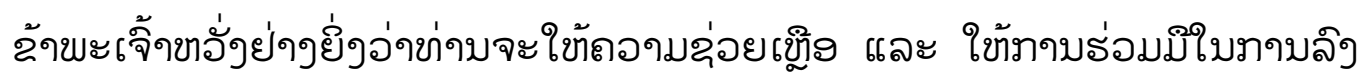
เทับทำฉั้มูบถั้วบิ้ถ้อย.

รృบมาถ้อยถองมเถิาลิบบับถึย่างสูอ.

ลายเฉับอะมุมัล:

ลายเฉับผูัธัรงอั:

เขภะสามถัลติล:

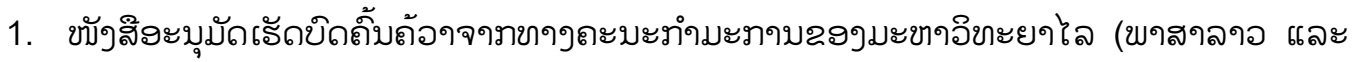
ฮังภึด)

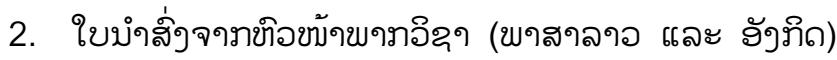

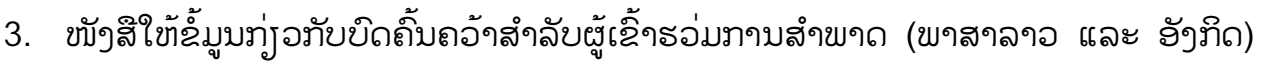

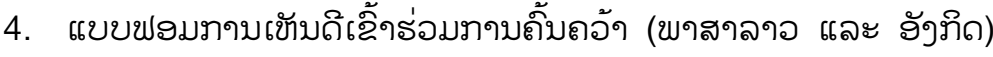

5. ธ่างถำฤๆมสำขๆถ (ขาสาลจอ) 